
Journal of Human Security | 2015 | Volume 11 | Issue 1

Journal of Human Security (ISSN: 1835-3800)

is an international, open access, academic, interdisciplinary journal, published by Librello.

\section{Cover image}

Pisky, Donetsk region, Ukraine, November 2015.

Pisky was a prosperous village on the outskirts of Donetsk near the Donetsk Airport. Today, there is not a single building without damage and the streets are desolated with only a few locals refusing to leave (author: Vasyl Koliada). 


\section{About Journal of Human Security}

\section{Aims \& Scope}

We are committed to a multidisciplinary approach to security analysis. Our associates contribute expertise from such diverse areas as political anthropology, international relations, environmental science, ethics, health care, psychology, economics, and engineering.

The goal of the Journal of Human Security is to disseminate applied research into a secure and sustainable future for humanity. It continues from the Australasian Journal of Human Security.

The Journal of Human Security endeavours to:

- $\quad$ Provide a forum for researchers to foster interdisciplinary inquiry in broad human security issues such as track two diplomacy, ethnic conflict, terrorism, religious extremism, human rights, demographic change, population health, human ecology, sustainable economics and related areas;

- Inform readers about upcoming events, ongoing and new research projects, trends and discussions, newly published monographs, and available scholarships;

- $\quad$ Encourage a multidisciplinary approach to issues that have traditionally been viewed as mostly unidisciplinary;

- Maintain an appeal to a wide readership with both high academic standards and close relevance to practice;

- Meet international standards of excellence.

Indexing, abstracting and archiving

BASE, Cengage (GALE), CLOCKSS, DOAJ, EBSCO, Google Scholar, J-Gate, NewJour, ProQuest, RePEc, ResearchBib, ROAD, SafetyLit, Scopus, SSOAR, CiteSeerX,

Sherpa/Romeo, UlrichsWeb, OCLC WorldCat

Journal of

Human Security 


\section{Editorial Team}

Editor-in-Chief

Sabina Lautensach, University of Northern British Columbia, Canada

Managing Editor

José Alberto Fernandez Monteiro, Librello, Switzerland

Assistant Editor

Luana Occhilupo, Librello, Switzerland

\section{Editorial Board}

Kamarulnizam Abdullah, Universiti Utara Malaysia, Malaysia

Angel Angelov, Sofia University, Bulgaria

Paul Bellamy, New Zealand Parliamentary, New Zealand

Michel Bouchard, University of Northern British Columbia, Canada

Malcolm David Brown, University of Southern Queensland, Australia

Stephen Burgess, US Air War College, AL, USA

Anthony David Burke, University of New South Wales, Australia

Gerald Chan, University of Auckland, New Zealand

Kevin Clements, University of Otago, New Zealand

Thomas Ditzler, Tripler Army Medical Center, HI, USA

Sean Peter Giovanello, Elon University, NC, USA

John Janzekovic, University of the Sunshine Coast, Australia

Christopher LaMonica, US Coast Guard Academy, CT, USA

Alexander Lautensach, University of Northern British Columbia, Canada

Deane Edward Neubauer, University of Hawaii, HI, USA

Math Noortmann, Coventry University, UK

John Michael Quinn V, Charles University of Medicine Prague, Czech Republic

Kirsti Stuvøy, Lillehammer University College, Norway

C. Vinodan, Mahatma Gandhi University, India

Jian Yang , University of Auckland, New Zealand

Yong Wang, Peking University School of International Studies, China 


\section{Table of Contents}

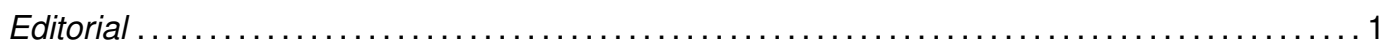

Editorial for Journal of Human Security Volume 11

Sabina Lautensach

Human Security Institute, Canada

University of Northern British Columbia, Terrace Campus, Canada

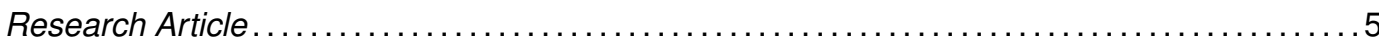

Sustainable Health for All? The Tension Between Human Security and the Right to Health Care

Alexander K. Lautensach

School of Education, University of Northern British Columbia, Canada

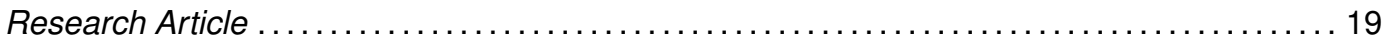

Human Security Workers Deployed in Austere Environments: A Brief Guide to SelfCare, Sustainment, and Productivity

Thomas F. Ditzler ${ }^{1, *}$, Abigail D. Hoeh ${ }^{1}$ and Patricia R. Hastings ${ }^{2}{ }^{1}$ Department of Psychiatry, Tripler Army Medical Center, HI, USA

${ }^{2}$ United States Department of Defense (DOD), Washington, DC, USA

${ }^{*}$ Corresponding author

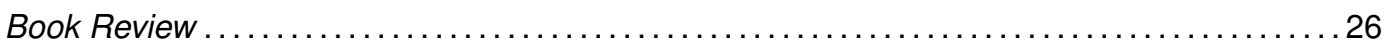

A Review of 'Humanitarian Intervention and Legitimacy Wars: Seeking Peace and Justice in the 21st Century'

Leah Merchant

Department of Political Sciences, University of Cincinnati, Cincinnati, $\mathrm{OH}, \mathrm{USA}$

Editorial

Notes from the Field: The Humanitarian Crisis in Ukraine

John M. Quinn

Prague Center for Global Health, First Faculty of Medicine, Charles University of Medicine Prague, Czech Republic

Research Article 34

Educational Pathways to Remote Employment in Isolated Communities

David Denkenberger ${ }^{1,2}$, Julia Way ${ }^{1,3}$ and Joshua M. Pearce ${ }^{1,4,5 *}$

${ }^{1}$ Michigan Tech Open Sustainability Technology (MOST) Lab, Michigan Technological University, MI, USA

2 Civil and Architectural Engineering, Tennessee State University, TN, USA

${ }^{3}$ Career Development Education, Michigan Tech Career Services, Michigan Technological University, MI, USA

${ }^{4}$ Department of Materials Science \& Engineering, Michigan Technological University, MI, USA

${ }^{5}$ Department of Electrical \& Computer Engineering, Michigan Technological University, MI, USA

* Corresponding author

Research Article 45

Educational Pathways to Remote Employment in Isolated Communities Jiyoung Song

School of Social Sciences, Singapore Management University, 90 Stamford Road, Singapore 


\title{
Editorial for Journal of Human Security Volume 11
}

\author{
Sabina W. Lautensach ${ }^{1,2,3}$ \\ ${ }^{1}$ Editor-in-Chief of the Journal of Human Security, Librello, Basel, Switzerland \\ ${ }^{2}$ Human Security Institute, Canada \\ ${ }^{3}$ University of Northern British Columbia, Terrace, BC, V8G 4A2, Canada; E-Mail: salaut@gmail.com
}

Submitted: 2 February 2015 | Published: 24 February 2015

\section{Dear Reader,}

This editorial marks the beginning of the journal's eleventh year since its inception as the Australasian Journal of Human Security. As a sample from an extremely tumultuous era in human history, this time span has consistently provided an abundance of human security issues for me to comment on. Yet, for the first time since that fateful day in September of 2001, I feel that the world has arrived at another historical turning point. I am referring to the attack on the Paris office of the satirical journal Charlie Hebdo on January 7 and the events immediately following it.

As with the attack on the World Trade Center, the immediate retrospective reaction of "well of course, it was inevitable" bounces around the internet commentaries. Truly, European immigration policies and migration trends have long moved along a collision course with the widespread xenophobia and cultural intolerance that seem firmly entrenched even in 'progressive' European countries, fuelling the growth of various protest movements on the political far right. Even to the casual tourist, the masses of African street dealers in public squares and railway stations seemed to increase with every year. In 2010 German chancellor Angela Merkel pronounced the failure of German multiculturalism as a public ideal [1].

Besides the unabated mass influx of migrants and domestic xenophobia, several additional factors contributed to this sense of inevitability. To summarise them very briefly:
- The office of the United Nations High Commissioner on Refugees (UNHCR) has since its inception insisted on a definition of refugees that excludes people displaced for environmental reasons. This has resulted in consistent underestimates of the problems arising from population displacement in West Africa and other regions most afflicted with environmental deterioration. Those migrants contribute the bulk of the influx into Europe through Italy, Spain and France, and most of them are Muslims. Recognised or not, the numbers of environmental refugees are bound to increase further.

- Around the world, governments are increasingly falling short of recognising and addressing the most pressing challenges to the human security of their citizens [2]. This includes ignoring anthropogenic climate change and overpopulation, collusion with and support of sinister corporate agenda, failing to demilitarise politics, and supporting a global economic system that, in the inimitable words of ecological economist Bill Rees, "wrecks its planetary home, exacerbates inequity, undermines social cohesion, generates greater net costs than benefits and ultimately threatens to lead to systemic collapse" [3]. - While the expansion of social media and global communications has led to unprecedented amounts of freely expressed opinion, not all of those voices extolled the virtues of tolerance and human rights. Ideologies of hate, violence and discrimination have gained exposure and adherents as result of the above developments. Backlash reactions, as in the 
- case of the 2014 film The Interview, involved multinational corporations and national governments and threats to cybersecurity.

- Despite all our 21st century interconnectedness, religious fundamentalism has also gained followers. This is by no means confined to Islam; radical Christians committed their share of torture, persecution and mass killings for many centuries, and the succession of radical Zionist regimes in Israel is made possible only by fundamentalist support. On the ideologically opposite side, radical secular modernists preach the utter commodification of nature and unending economic growth with equal disregard for human security and with similarly disastrous consequences.

- In spite of the equitable historical culpability of organised religions worldwide, Islam now has a severe image problem. The problem arises out of mistaken or self-serving interpretations of its scriptures by influential clerics, corruption in the ranks of some of its national leaders [4], stark contrasts between widely advertised Western and Muslim gender stereotypes and penal codes, and the stream of media accounts reporting publicly condoned violence against women and girls in some Muslim countries, regions or communities. I refer to this as an image problem because I feel unqualified to assess the extent of actual wrongdoing versus its representation in the media. Nevertheless, image is important-not least because it can elicit further wrongdoing on all sides.

The latter point requires some elaboration. Islam is by no means the only religion that features a somewhat spotty history of responsible leadership. There is something particularly unholy about using spiritual teachings to transform a congregation of kind-natured and generally well-intentioned people into a raging mob. This has been accomplished many times in history by a particular kind of religious leader in various creeds, the kind that in Noah Gordon's words [5] is "capable of praying and hating at the same time". Violence in the name of a religion is surely among that religion's most abominable sins, and yet it happens with astounding historical regularity. With every new incident, I lose a little more of what respect I have left for organised religions and their hierarchies of power.

Much religiously inspired violence arises from the perception of one's deeply held values and beliefs having been offended. In an age where mobility and displacement has caused an unprecedented extent of contact between people of diverse cultures, the chances of inadvertently offending one's neighbour are greatly increased. In fact, the occurrence of such offences is a statistical certainty. We have suggested elsewhere that the only effective measure to prevent violent reactions is for individuals and groups to "prepare to be offended", primarily through educational means [6].
So why do I feel that the recent attacks and their ramifications mark a historical turning point? One reason is the unprecedented amount of public debate about causes, contributing factors, mitigative policies and the framing of responses to such attacks. Most commentaries imply that recurrences are certain. For the sake of their human security, the countries of Schengen Europe need to facilitate and stimulate such a debate in order to come to grips with the problems arising from immigration. I shall come back to that issue later. Another reason is the rallying of public support, equally unprecedented, for the right to free self-expression-a fundamental human right enshrined in the Universal Declaration [7]. An essential foundation for guaranteeing the freedom of the press, this right lies at the heart of the perceived offences in the Charlie Hebdo instance. Many feel very strongly that the right to express free satirical commentary on anything and anybody is a hallmark of a democratic society. It is not by accident that among the first people to be arrested by newly formed autocratic regimes, 1933 Germany or post-WWII Warsaw Pact countries, for example, have always been writers of political satire.

To uphold the right to free self-expression in principle is as important as to delimit it appropriately. The re-invigorated debate should focus on where those limits should be placed and how they could be democratically determined and enforced. Holocaust deniers and neo-fascist hate propagandists have found out where European societies place the limits to public deception and tolerating intolerance, respectively. Those particular interpretations of free expression obviously crossed the line.

Of course, a widespread consensus on limits does not guarantee that the consensus is morally defensible. Many European societies show strong traditions of anti-Semitism and prejudice against other ethnocultural minorities such as the Roma. Oral traditions include the memories of Turkish invaders, domestic crusaders against Islam, and numerous wars against one's neighbours. Yet surprisingly seldom has it happened that someone actually took serious offence over a public statement such as a satirical cartoon. The arrival of Europe's Muslim populations changed that.

One might wonder why religion and humour seem so at odds. The more ardent and fundamental a person's religious beliefs, the less he or she seems to tolerate humorous innuendos about it. The only religious leader I see laughing a lot in public is His Holiness the Dalai Lama. What is wrong with the rest of them? This historical turning point might well be taken as an opportunity to examine one's own feelings and reactions and to make a serious effort to prepare to see one's religious values offended. The more difficult that seems to a person, the more urgently he or she probably needs to try.

Of course, the anticipatory effort to prepare to be offended also comes with some obvious limitations. It is unlikely to work in situations where confrontation 
between two well-defined cultural groups has persisted in the form of protracted violent conflict for generations. A striking example is the Israel-Palestine conflict with its complex historical background; in this case preparing for offence seems pointless as both sides already live in a state of persistent and multifaceted injury, aggravated by a cultural legitimation of revenge. Confrontations marked by longstanding historical grievances, habitual abuse of entrenched power differentials, widely advocated contrary ideologies and racism, and the poisonous influence of fundamentalist religion on both sides might well be immune to any individual effort to prepare for offence. Against such a background the individual experience of offence pales to insignificance, to a matter-of-fact confirmation of the perceived status quo. In a way the opposing parties are already prepared to be offended, and it offers little help. While Europe is fortunate not to be encumbered by such tragic circumstances, it will require serious efforts not to let the situation deteriorate to that extent. As in 1947 Palestine, the opportunities are still there.

Another obvious limit manifests in situations where the offence is too overwhelming, as in the case of over 2,000 annual cases of female genital mutilation in the UK [8] and in other Western societies. The fact that the practice violates local law seems less offensive to the host culture than does the gross violation of universally recognised human rights, committed on cultural grounds that appear immaterial to the host but all-important to the newcomer. This kind of moral transgression is clearly in a different category than a kosher restaurant serving pork, on account of the human suffering and injustice involved and the violation of moral norms that are globally subscribed to. Asking the host culture to 'just get used to it' would merely aggravate the offence and damage the status of universal human rights. A mutually acceptable compromise seems impossible in such situations.

This latter example shows how the situation of displaced ethnocultural minorities changes the moral ground on which the anticipatory effort to prepare for offence takes place. Displaced people, whether they arrived in their host country voluntarily or by force of circumstance, are insecure guests. What I mean by that is that they lack human security and particularly cultural safety, relative to their hosts; they deserve to be treated as one treats a guest in one's home (expected or not); and they are obliged to behave as polite guests. Now where did we all go wrong in relation to those norms?

What went wrong is, firstly, that neither side had much of an idea of the other's vulnerable spots and value priorities (and still hasn't, I reckon). Both sides have very different cultural senses of humour, honour, rights and obligations-not to speak of the language barrier. But most importantly, the house is now full.

For about half a century, European countries have operated under conditions of particularly strong ecological overshoot, meaning that the impacts and de- mands they made on their environmental support structures (ecosystems) vastly exceeded the capacity of those structures to sustainably support them. In other words, Europe's carrying capacity has long since been exceeded. The only reason this has worked so far is because Europeans could afford to trade, steal or otherwise appropriate resources and capacities from other parts of the world. European colonial empires were not just the passing fancies of monarchs! Even with monarchs having receded into the background, the neo-colonial means of perpetuating regional ecological overshoot have survived and flourished-until recently.

The most significant aspect of this historical turning point is that we are approaching the end of the Age of Waste. Resources are dwindling, populations and their consumption are still growing, pollution and its resultant effects on climate and health are changing the planet and the rules that dictate a species' survival. Many species are falling off the boat, never to be seen again. Ecosystems are collapsing into simpler states, less hospitable to humans and non-humans alike. Every 'developed' national economy will have to adjust to the new contingencies, either by force or by design; people will have to lead less luxurious, less wasteful lives. Such a transition is possible, especially in European societies that already have a low fertility and at least a vague collective memory of historic shortages and economic constraints. But the last thing they need for that effort is more people at this time.

In the short term, Europeans and their guests will do well to prepare to be offended by each other. Where those offences are grave, compromises will need to be negotiated. Furthermore, as an essential requirement for lasting human security, Europeans will need to embark on serious efforts towards their Great Transition [9] towards a sustainable future of acceptable quality. That will require economic degrowth, knuckling down to some hard work, and creating efficient, resilient communities that depend only minimally on external resources. Japan is leading this process by example. But in the less developed, poorer countries the collapse of agro-ecosystems will keep generating refugees by the millions, and they will keep trying to reach for the rich countries, primarily Europe and the US, as their only perceived chance of survival. In the longer term, and under the new conditions of a changed planet, if Europe is to have a reliable chance at attaining a sustainable future with acceptable human security for all its citizens it cannot accept additional millions of new citizens within its borders. Once the Transition is achieved, this policy should be reviewed.

I don't imply that siding with the neo-fascist fringe on their uncompromising 'Fortress Europe' fantasy would carry much promise of achieving that goal. Rather more promising alternatives require a differential approach directed at reducing the 'pull factors'. Immigrant quota should be limited to the demo- 
graphic replacement level [10], directing newcomers after appropriate training towards small and midsize communities without contributing to their ghettoization. About a third of all immigrants, amounting to about 575,000 individuals in 2012, could be accommodated by such an internal settlement regime. The remaining two thirds would need to be re-directed towards alternative settlement solutions, preferably in their home countries [10]. This reduction of the 'push

\section{References}

[1] Connolly K. Angela Merkel declares death of German multiculturalism. London, UK: The Guardian; 17 October 2010.

[2] Lautensach A, Lautensach S. Education for Sustainability: How Can Educators Address the Failure of Government? The 4th World Sustainability Forum, 1-30 November 2014. Available from: http://sciforum. net/conference/wsf-4/paper/2450.

[3] Rees WR. Avoiding Collapse: An Agenda for Sustainable Degrowth and Relocalizing the Economy. Vancouver, Canada: Canadian Centre for Policy Alternatives; 2014. p. 15.

[4] Weisman A. Countdown: Our last, best hope for a future on earth? New York, NY, USA: Back Bay Books; 2013.

[5] Gordon N. The Physician. New York, NY, USA: Simon \& Schuster; 1986.

[6] Lautensach A, Lautensach S. Prepare to be Offended Everywhere: Cultural Safety In Public Places. Second International Conference on Human Security: Twenty Years of Human Security. Human Security Research Center-Faculty of Security Studies, University of Belgrade, 7-8 November 2014. Proceedings forthcoming.

[7] United Nations. The universal declaration of factors' is where Europe requires the support of the UN and the international community. Without that support, the increasing dangers of uncontrolled immigration would render all sustainable goals elusive, jeopardising Europe's human security for generations to come.

Best wishes,

Sabina W. Lautensach

human rights. New York, NY, USA: United Nations; 1948. Available from: http://www.un.org/en/docu ments/udhr/index.shtml.

[8] McVeigh T. British girls undergo horror of genital mutilation despite tough laws. London, UK: The Guardian; 25 July 2010. Available from: http://www. theguardian.com/society/2010/jul/25/female-circum cision-children-british-law.

[9] Raskin P, Banuri T, Gallopín G, Gutman P, Hammond A, Kates R, Swart R. Great Transition: The Promise and Lure of the Times Ahead. Stockholm Environment Institute Polestar Report no. 10. Boston, MA, USA: SEI; 2002. Available from: http://www.seiinternational.org/publications?pid=1547. The point that no lasting human security can be achieved without environmental sustainability has been convincingly presented many times; I am taking it for granted here.

[10] At a total (2014) fertility rate of 1.60 children per woman, Europe's population would shrink in the absence of immigration. Of an estimated 1.7 million immigrants in 2012, 575,000 (or almost 34\%) could be absorbed without resulting in a population increase. Sources: Eurostat http://ec.europa.eu/ eurostat/statistics-explained/index.php/Migration_and_ migrant_population_statistics, CIA Factbook https:// www.cia.gov/library/publications/the-world-factbook/ geos/ee.html. 


\title{
Sustainable Health for All? The Tension Between Human Security and the Right to Health Care
}

\author{
Alexander K. Lautensach \\ School of Education, University of Northern British Columbia, 4837 Keith Ave. Terrace, B.C. V8G 1K7, Canada; \\ E-Mail: alexl@unbc.ca; Tel.: +1 2506153334; Fax: +1 2506155478
}

Submitted: 23 April 2014 | In revised form: 8 November 2014 | Accepted: 9 November 2014 |

Published: 24 February 2015

\begin{abstract}
In the current global environmental crisis medical aid and disaster relief is given by the UN and its branches, by governments and by NGOs, who regard it as their duty to address large-scale humanitarian catastrophes. The duty to give medical aid rests on traditional interpretations of health security and on the bioethical imperatives to relieve suffering and to save lives. However, those principles are not easily reconciled in the current situation of global environmental change and the threats it poses to human security. The global demand for health care has already outpaced resources in many regions, and those resources are likely to decline further. An ethic based on more comprehensive concepts of human security can lessen the contradictions between ethical priorities because it takes into account environmental security. However, that approach leads to clashes with common interpretations of human rights, including the so-called right to health care. The argument presented in this paper states that, under the imperative of ensuring the survival for humanity in acceptable and sustainable ways, the latest generation of human rights pertaining to health care and environmental quality have become ungrantable. While this does not render them negligible, it does necessitate a new approach to global development aid and health security, with severe consequences for individual autonomy.
\end{abstract}

Keywords: bioethics; global health care; health security; human rights; sustainability

\section{Introduction}

At the dawn of a new millennium, humanity finds itself on a crowded new planet with fewer resources and less hospitable climates-overall a tougher place to make a living. This change is the cumulative result of our species' ever-increasing demands on the biosphere and the global environmental changes that we set in motion decades ago [1]. The average number of people reportedly affected by 'natural' disasters (mainly earthquakes, droughts, floods, famines, storms, epidemics) quintupled from 1975 to 2010 [2]. Even as

(C) 2015 by the authors; licensee Librello, Switzerland. This open access article was published under a Creative Commons Attribution License (http://creativecommons.org/licenses/by/3.0/). 
percentages of the world population, the numbers of victims increased from $1.5 \%$ to $4.8 \%$.

This trend contrasts against a reported decline in victims of armed conflicts $[3,4]$ and against a decrease of the number of deaths from natural disasters, presumably caused by improvements in organisation and experience on the part of relief organisations [5]. The increase in the volume of humanitarian relief efforts ([5] p. 12) has kept the percentage of unmet demands at roughly 40 percent from 2000 to 2012, even though the total demand for humanitarian relief (measured as the UN's consolidated appeals for help) increased 4.7 fold over that time [5].

The question arises: how long can this increase in quality and quantity of humanitarian relief continue to keep up with the rising demands? The trend of rising demands is certain to persist as humanity's growing environmental impact and ongoing global environmental change exert further pressure on the biosphere. Even tectonic disasters reap ever higher tolls as population densities keep increasing. The global public has become jaded in the face of incessant reports of casualties and damage. Contributions to charities have stalled over recent years ([5] p. 11).

Besides the provision of food, potable water and shelter, the bulk of humanitarian assistance consists of public health measures in the pursuit of health security -protection from threats such as acute trauma and communicable disease. The WHO [6] summarises those threats as "emerging and rapidly spreading diseases, environmental change, the danger of bioterrorism, sudden and intense humanitarian emergencies caused by natural disasters, chemical spills or radioactive accidents, and the impact of HIV/AIDS." The current campaign against the Ebola epidemic in West Africa faces unprecedented numbers of people at risk. At the level of the individual, this protection extends to personal and family health care beyond the short-term focus of large-scale disasters. There, too, the demand has increased-from 2000 to 2008 global per capita health expenditures almost doubled ([7] p. 137). Burgeoning costs, increasing incidences of many environmentally caused diseases, and new pathogens have imparted further pressure on healthcare systems that are already strained by growing populations. In worldwide personal healthcare, too, assistance is struggling to keep pace with demand.

In humanitarian terms, extrapolating these dynamics into the longer term gives reason for concern. Yet the statements and projections made at the highest levels of national governments and the UN reveal little evidence that such prospective concern expressed at the ground level is shared among the leaders of humanity. Vague and optimistic statements about future 'economic growth' and technological development into unspecified directions take the place of evidence-based assessments of human insecurity. For example, The International Covenant on Economic, Social and Cultural Rights (ICESCR) [8], based on the Universal Declaration of Human Rights, commits its parties to cater to universal rights including an "adequate standard of living," clothing, housing, the "highest attainable standard of physical and mental health" and access to its underlying determinants (such as clean water, sanitation, food, nutrition and housing), and freedom from hunger. In its "principle of progressive realisation" the ICESCR obliges members to "take steps, individually and through international assistance and cooperation, especially economic and technical, to the maximum of its available resources, with a view to achieving progressively the full realization of the rights recognized in the present Covenant by all appropriate means." As another example, the US-based Global Health Council [9] aims to contribute the necessary "information and resources" to all efforts towards improvement and equity in health care. They name as the main challenges "insufficient financing, lack of inter-agency coordination, poorly-functioning information systems, health worker shortages and supply interruptions." Both mission documents imply that it is unconditionally possible to "improve the health of those living in the developing world" by "improving the effectiveness of programs and overall funding," [9] even in the face of abundant and convincing refutations of such cornucopian exuberance and techno-optimism $[10,11]$. The ICESCR [8] acknowledges that some of the rights (for example, the right to health) may be difficult in practice to achieve in a short period of time due to resource constraints, and it requires them to act as best they can within their means. However, it also implies an inevitable upward trend that, given enough time, all of humanity can enjoy the full realisation of their rights. That implication is where its fallacy lies. Sustainable health security for 'all', while absolutely worthwhile as an ideal, has become absolutely elusive for a population exceeding seven billion.

This paper aims to explain this widening gap between aspirations and projections about health security, to assess the underlying assumptions and values, and to suggest how our thinking and moral priorities need to change if health security is to be established for all of humanity. Based on those considerations, the paper offers three propositions. Firstly, I shall argue that the trend of increasing relief efforts coupled with increasing misery is profoundly unsustainable, which renders morally questionable any policies that do not take that lack of sustainability into account. Relief efforts depend on economic power, and the world's economic power is no longer growing as rapidly; in fact, abundant evidence suggests that it is bound to decline soon $[12,13]$.

Rather than just to accept an even greater increase in human misery once relief efforts inevitably taper off, it would help if alternative options could be considered proactively. My second proposition focuses on those options, especially on changes to the ethics that inform both humanitarian assistance and healthcare- 
the ethics of health security. Assuming that the first proposition is true, that the increase in misery is bound to outpace our efforts to mitigate it, humanitarian principles demand that we re-examine policies and underlying ethics proactively instead of continuing a losing battle against what many interpret as natural population control mechanisms that have begun to dominate the ecology of our species [14-16]. The development of new and more sustainable policy alternatives depends on revised ethics.

A re-examination and revision of health care ethics will attract much controversy. As a salient feature of the new ethics, my third proposition will state that the so-called 3rd generation human rights (including the 'right' to health care) are becoming increasingly ungrantable and should therefore be neither claimed nor promised. My argument will be based on the fact that, unlike other human rights, the 3rd generation depend largely on the availability of environmental resources, many of which are becoming ever scarcer. We will explore the implications for policy and practice in healthcare and humanitarian assistance.

\section{Present Forms of Humanitarian Assistance and Public Health Policies are Unsustainable}

Disasters such as earthquakes, famines, epidemics, and severe weather events are generally referred to as 'natural' or even as 'acts of God', although at this stage those attributes fully apply only to tectonic events. The rest can usually be traced to anthropogenic environmental change-various combinations of climate change, declines in ecosystem health and in resource availability, or the effects of violent conflict. Those changes are in turn caused by our increased industrial and economic activity, our increased consumption, global inequities in power and wealth, and the sheer increase in our numbers [17]. Those effects combine to a collective environmental impact on the biosphere's support structures that has been causing global environmental crises on many fronts. The anthropogenic 'natural' disasters mentioned above are one manifestation of those crises.

Other manifestations of the global environmental crises include pollution, resource scarcity, and the rapid loss of biodiversity. For the first time in human history those manifestations have reached global proportions, and their unprecedented magnitude suggests a quantum leap in the way in which humanity impacts on the biosphere. That quantum leap has been expressed in the word overshoot [18].

Collective ecological overshoot amounts to 'living beyond our means.' [19] Some scientific definitions rely on the comparison of humanity's ecological footprint with the Earth's bioproductive capacity [20]. A population whose footprint exceeds the amount of accessible productive land is clearly in regional overshoot [21]. Other definitions focus on the transgression of specific ecological boundaries that describe a safe operating space for sustainable living [22].

Overshoot has severe consequences. Human populations, like all other animal populations, obtain their sustenance from ecosystems which provide so-called 'ecosystem services.' [23] Human populations are special in that they employ technology to maximise the benefits of those ecosystem services. But regardless of this technological windfall, the capacities of local ecosystems remain limited. Generally, the environmental impact $I$ of a human population on local ecosystems is described by the $I=P A T$ formula, where $P$ means population size, $A$ stands for the affluence or economic means per capita, and $T$ represents the technological impact per capita $[24,25]$. The maximum sustainable impact, also referred to as carrying capacity ([26] p. 126) is thus described as the product of the three variables. It can be reached by small populations with a high-impact lifestyle or by larger populations where each individual demands less in terms of support services. Overshoot occurs when a population exceeds the maximum sustainable impact, where the services of the local ecosystems are being overtaxed. As a result, depending on the fragility of those ecosystems, they may undergo irreversible structural changes [18,27-29]. Inevitably the consequence for the population is such that various biological regulatory mechanisms lead to a decrease in population health, an increase in mortality, and eventually a drop in population size, below the system's carrying capacity. Numerous precedents from animal populations have allowed ecologists to characterize and predict those dynamics with impressive accuracy.

Despite their eventual severity, the consequences of overshoot for a human population may not always ensue right away [30]. A population may avoid immediate negative consequences as it may obtain the shortfall from other regions that are either underpopulated, defenceless, or otherwise disempowered. The practice is, however, often unjust and supports unsustainable patterns of consumption. Globally, of course, the shortfall is appropriated from future generations. Sooner or later (the timing is difficult to predict) the cumulative effects of resource scarcity, environmental deterioration, and poor public health will lead to the shrinkage of economies, with further decreases in per capita resource availability and in overall human security, and a rapid population decline.

Against that backdrop, the prospects for further intensifying humanitarian relief efforts (for large populations) and healthcare (for individuals and their families) seem unrealistic, at least in the long term. The increase in their economic costs is bound to clash with the decrease in budgets. Economies cannot remain stable, let alone grow, in the absence of an adequate supply of natural resources, renewable and nonrenewable. Moreover, addressing this vast problem only at the symptomatic level is morally objectionable. It is difficult to come up with a moral justification for a strategy that focuses predominantly on short-term hu- 
manitarian assistance and healthcare and fails to address the underlying chronic causes of large-scale human misery [31]. With the major economies shrinking, countries will increasingly focus on their own national welfare and the interests of their elites, while the world's poorest will be left to their own devices. Costintensive healthcare options will be increasingly restricted to those who can afford to pay for them. A recent study indicated that many of the programs and policies that pass for 'sustainable development' are probably neither sustainable, nor do they qualify as genuine development [32]. This bias towards short term solutions cannot be justified merely by pointing out the political difficulties and cultural taboos associated with addressing the underlying systemic problems. Yet, the question deserves serious consideration whether those moral objections to the current approach really warrant a change in practices that are almost universally regarded as not only 'good' but as the best possible course of action in the pursuit of health security. The answer depends on the extent to which the ethics that underlies those practices is itself sustainable.

\section{Health Security is Part of Human Security}

In order to come up with sustainable solutions, the ethics of humanitarian assistance and healthcare must be regarded within the more comprehensive ethical context of human security $[26,33]$, which has much in common with Potter's [34] 'bioethics'. From its first formulation in the UNDP's 1994 Development Report [35], human security has been conceived primarily as a moral imperative, namely the realisation that the security of human beings requires more than a secure state, that it also depends on the absence of structural and cultural violence [36] at the individual level. And since human individuals, unlike states, are capable of sensations and emotions, human security was recognised as partly contingent on those particular states of mind that we tend to associate with well-being and good health.

In the context of public health and humanitarian crises, efforts to improve human security include a relative safety from acute infectious disease, minimum complements of safe fresh water and adequate nutrition, and a formal guarantee for basic human dignity. Concern for human security also became extended further into the future. It has become acceptable to express concern with the future well-being of one's children and their generation, and their posterity. This long-term humanitarian concern has gradually come to inform the agenda of human security, as indicated by some common definitions of sustainable development $[37,38]$. Health care plays a prominent role in those agenda as illustrated by three of the eight Millennium Development Goals [39,40].

Along with health, the range of factors determining the state of an individual's human security is de- scribed by the seven dimensions of economic, food, health, environmental, personal, community and political security ([35] pp. 24-33), or the four pillars of military/strategic security, economic security, healthrelated security, and environmental security [41]. Environmental security focuses on the complex interactions between human populations and their ecological support structures, namely the source and sink functions of their host ecosystems. The dependence of many security determinants on a healthy environmental support system that imposes limits on growth has led to the notion of environmental security as the 'ultimate security' $[42,43]$. Such comprehensive models of human security have attracted some criticism (e.g. [44]); however, those critics offer little help with security concerns expressed at the grassroots, nor do they pay much attention to the primacy of ecological dependency.

The major contribution of those comprehensive models of human security in the context of this paper is that they place healthcare and humanitarian assistance into a larger, more comprehensive set of requirements that can "protect the vital core of all human lives in ways that enhance human freedoms and human fulfilment" ([45] p. 8). Based on those comprehensive models of human security, development agencies operating under national, super-national or non-governmental umbrellas have extended their security concept into ethical dimensions. This extension is evident in several key policy documents of the United Nations. In the Secretary-General's Millennium Report the UN's security agenda are defined as 'freedom from fear,' and their development agenda as 'freedom from want.' $[46,47]$ The UN's guiding principles on security are thus paraphrased in negative terms as freedom from a condition that is evidently undesirable [17]. Similarly, Alkire ([48] p. 2) defined the objective of human security as 'to safeguard the vital core of all human lives from critical pervasive threats, and to do so without impeding long-term human flourishing.' As a further step, some regard such freedoms as a new generation of human rights, as was mentioned on the example of the ICESCR [8] - a point to which we will return later.

While the formulation and widespread advocacy of a human security ethic seems a move in the right direction, the definition in terms of freedoms seems unsatisfactory for its lack of logical rigour, its paternalistic subjectivity and relativity of the criteria involved, and its neglect of systemic limits [41]. Positive definitions of human security (e.g. [49]) avoid some of those objections, but further progress is only possible by prioritising ecological integrity as an essential requirement for human security [50] and by addressing specific sources of insecurity. To name two examples relating to healthcare, the WHO's 2006 World Health Report points to the health-related dimension of insecurity, caused in part by a severe shortage of health care personnel, especially in poor countries $[51,52]$. The UN's Millennium Ecosystem Assessment [53] identified severe detriments to population health 
arising from global environmental deterioration [54]. It is important to note that recognising the ethical primacy of environmental security neither depends on, nor necessarily demands, a turn towards ecocentrism. In fact, the practice of the mainstream media labelling as 'environmentalist' anybody and everybody who expresses concern about environmental security is misleading and entirely unjustified [43].

The dependence of health security, along with all other aspects of human security, on environmental security becomes most evident when we examine its prospects over the long term, i.e. its sustainability. Sustainability is described by the balance between supporting the quality of life for a human population and the continued functioning of its environmental support structures, namely ecosystems ([55] p. 198). Ecosystems consist of local communities of species and their physical environment. They serve as sources of food, fresh water, raw materials and energy, and they recycle the population's wastes. At the most elementary level, then, sustainability just means continued survival. However, human populations can survive in different modes. Recognising that the survival of societies is contingent on collective choices, Potter [34] distinguished five distinct modes of human survivalmere, miserable, unjust, idealistic, and acceptable. Together they describe the total range of possible survival modes; currently a combination of unjust and miserable survival dominates globally. Each mode is characterised by a corresponding state of public health. Given the central importance of human well-being and of principles of justice in human security I suggest that sustainable human security on a global scale is identical with the acceptable survival of humanity, meaning an acceptable quality of health for the population at large according to new metrics such as the Genuine Progress Indicator [56].

With respect to health care, acceptable survival of the population will mean minimising human suffering through the equitable distribution of scarce resources of care. That includes doing without costly symptomatic interventions while maximizing the benefit of low-cost preventive care and of lifestyle adjustments. This follows from the extent to which cost intensive health care systems such as those in North America and Europe currently depend on wealthy economies which are in turn unsustainable $[57,58]$ as well as globally unjust.

To summarise the sequence of causation, unsustainable practices sooner or later lead a population into overshoot, which in turn erodes environmental support structures and decreases their capacity to deliver resources and to accept wastes in the future. This loss of ecological integrity and capacity means that the environmental security of the population is compromised, which can manifest itself in shortages of food, energy, or of other commodities, or in elevated levels of pollution, and sometimes in the emergence of new pathogens. Such changes invariably di- minish population health and lead to economic decline, civil disorder, and vulnerability to external enemies [59], all of which compromise health further. Evidence is provided by the historical precedents of cultures that disappeared as a result of this sequence of effects [60], and by the correlation of pathogen emergence with ecosystem destruction [52]. The upshot is that whatever safeguards may be in place to protect the economic security of a population, its public health, its national security, and the rule of law -they seem of little help in the long term unless sustainability and environmental security are guaranteed. This resonates with Barnett's [61] finding of a mutual dependence between environmental security and peace and with Myers' [42] thesis of environmental security as the 'ultimate security.' As for population health, its dependence on ecological integrity has been extensively documented [62-65]. We can establish causal connections not only between unsustainable practices, environmental insecurity and health crises but also between excessive population size and compromised population health. We also saw that intensified health care assistance for large populations is not a sustainable option, no matter how vociferously it is demanded. In other words, much of the ethics informing current practices of healthcare is not sustainable. This puts into question its underlying beliefs and priorities, particularly certain purported human rights, including the 'right to health care' with, as we shall see, some significant political ramifications.

\section{The Ethical Challenge to Make Health Security Sustainable}

The practice of humanitarian assistance and of health care in general is governed by the aims to relieve suffering and to save lives, under the four bioethics principles of beneficence, non-maleficence, autonomy and justice [66]. These moral principles, among other sources, have generally served the healthcare professions well as the ethical foundation of their professional conduct. Nevertheless, problematic aspects remain, among them the unjust allocation of scarce resources that has culminated in today's extreme global inequities in terms of health care quality [67]. In response to this problem, a discourse of rights has developed among advocates of justice in global health care, rights that are linked to the greater body of human rights.

As mentioned earlier, many popular conceptualisations of human security are founded on human rights. These rights developed historically in three stages, each based on a set of basic needs [68]. The first generation of human rights was civil and political in nature and was based on the cardinal value of freedom. The second generation are economic and social human rights, based on the cardinal value of human equality. At this stage a third generation of rights is being formulated, as illustrated by the UN 
and numerous major NGOs focusing on the right of every global citizen to enjoy freedom from fear and freedom from wants $[8,47]$. Many welcome those freedoms as overdue additions to the list of human rights specified in the UN's Universal Declaration of Human Rights [69]. They extend on the rights specified in Article 25 of the Declaration which refers to "the right to a standard of living adequate for the health and well-being of himself and of his family, including food, clothing, housing and medical care and necessary social services..." [69] In terms of environmental security those freedoms amount to certain quality attributes pertaining to environmental support systems, sometimes referred to as 'environmental rights.' The UN's Millennium Development Goals [39, 70] refer to them as the right to clean air, safe potable water, adequate nutrition, shelter, the safe processing of wastes, and adequate health care. The document reveals no awareness of the limited capacity of ecological support structures to supply those resources. Likewise, UNFPA's State of the World Population Report frames overpopulation as a problem of unrecognised rights to make free reproductive choices and 'unmet needs' [71]. Some have claimed that future generations also have a right to adequate health care $[8,72,73]$. Not surprisingly, people widely disagree over the extent to which citizens of affluent societies should recognize third generation rights for global humanity and for future generations.

In our examination of environmental security we established that the purification of air and water, the provision of foods and shelter, and the processing of wastes are directly carried out by ecosystems, many of them local, involving varying extents of 'management'. It follows that the sustainable provision of those services depends on the biological integrity of those ecosystems $[50,74]$. Likewise, the health of a population is evidently affected by the state of its ecosystems $[27,65]$. Accordingly, it would make sense for human communities to claim the right that 'their' ecosystems not be harmed or diminished in their capacities. The fact that such a claim is not usually made, and that instead the demands pertain exclusively to the human recipients of those services represents both a grave logical fallacy and a strategic error in judgment by human rights advocates. Failing to recognise and emphasise the indispensable role of those support structures amounts to an opportunity wasted. The integrity of an ecosystem can, given sufficient care, experience and motivation, be maintained sustainably, barring any major external threats such as climate change. Among the conditions of such a policy would be that the total environmental impact of the community does not exceed the sustainable maximum, i.e. the ecosystem's carrying capacity.

In contrast, claiming that the individual community member has a right to a certain minimum quality of service regardless of environmental conditions makes no sense because no-one has the power to grant such a demand, not even the most absolute dictator, once the population's impact has exceeded that threshold. The reason is that satisfying this demand depends ultimately on physical resources, which are of course limited-as opposed to conducive human attitudes or legislation. Overshoot effectively prevents any government from converting the so-called 'right' into an opportunity for all. Thus, those third generation 'environmental rights,' including the 'right' to adequate health care, belong in a different category from the other human rights, the category of ungrantable 'rights.' Being grantable, however, is an essential property of any right [75]. Therefore, a right that cannot be granted is no right at all (hence our use of inverted commas), and it makes no sense to promise or to claim it.

Our suggestion that claiming ungrantable 'rights' also represents a strategic error in judgment is also based on the effect that such a claim diminishes the status of other rights to which realistic and legitimate claims could be made. For example, if the UN's Human Rights Council added to the list of human rights the right to own a circus, clearly ungrantable, the entire list would as a result acquire a less serious, less binding, and more conditional appearance [76]. This would be regarded as a disservice by humanists who harbour genuine concern for human rights and their enforcement. Including ungrantable 'rights' among the list is likely to diminish the sense of urgency with which all human rights ought to be respected worldwide. On the health care side, people become habituated to media images of sick individuals from poor countries and they take it for granted that whatever 'right' to health care those people or their advocates might proclaim is quite immaterial to their own privileged situation. This tacit assumption can all too easily be extended to inequities in political representation, in self expression and sexual preference, and to other presumably 'self-evident' rights, all entirely grantable, which would compromise civil society worldwide.

The problem of ungrantable 'rights' does of course not diminish the policy makers' duty to promote the environmental security and public health of communities, especially when it comes to the world's disempowered. The fundamental conceptual link between rights and duties remains unaffected by the absence of grantability on the side of the right. As I suggested above, the concept of ecosystem integrity can be instrumental in formulating policy guidelines that would go a long way towards guaranteeing that rights can be fulfilled. However, under conditions of overshoot, a gap appears between the discourse of rights, which is in part rendered wishful thinking, and the discourse of duties, which remains unaffected. Consequently, moral reasoning, in order to convince, can no longer rely on rights-based arguments but needs to make greater use of arguments invoking duty, utility and virtue. This would also help with a more concise formulation of codes of behaviour and their translation into effective policies and legislation. 
Of course this shift in the argument only applies to third generation 'rights' whose grantability depends heavily on environmental resources. In contrast, the fulfilment of grantable rights depends primarily on human behaviour and preferences. In the light of this distinction, the question arises whether ungrantable 'rights' are of any use at all. Specifically we might ask, is there any benefit in insisting on the individual global citizen's entitlement to adequate health care, considering that such adequate healthcare is seldom forthcoming and is bound to diminish further?

\section{From Health Care 'Rights' to Health Care Demands}

The preceding discussion emphasised the need to use rights-based arguments sparingly and prudently when debating health security and human security in general, and to invoke grantable rights in different ways and on different occasions compared to those kinds of demands that are based on ungrantable 'rights.' Heretofore I will refer to the latter as 'environmental demands,' and specifically to 'health care demands.' I do not mean to insinuate that such demands have no place in debates about humanitarian assistance and basic health care-on the contrary: The qualities of air and water, of nutrition, of shelter, of the ways of recycling wastes, and the status of public health are still among the best indicators to assess the health security of a community. And they can help bolster some legitimate rights-based arguments, namely in connection with the right to distributive justice. I perceive at least three distinct benefits of health care demands, and for environmental demands in general.

First, in the case of a community or region that has not yet reached the maximum sustainable environmental impact, health care demands can highlight situations of injustice and inequity. Based on claims for distributive justice they would help promote initiatives to elevate the quality of health care for society's poorest and their standard of living in the community. For example, elevated local incidences of cancer in society's poorest are often used to bolster demands on the authorities to explore possible causes and to implement equitable policies to improve prevention, screening and treatment.

Secondly, in situations where the maximum sustainable impact has already been exceeded health care demands serve to highlight that very circumstance. No other physical observation illustrates the fact of ecological overshoot more clearly than the widespread squalor caused by polluted air and water, famine, and the resulting abundance of ill health [27]. Vociferous demands for mitigation can make a significant difference politically. Also, comparisons of national footprints with available bioproductive areas $[77,78]$ have made it abundantly clear that overshoot has now been the norm for many regions and historical reality for the globe since the mid-1980s [53,
$58,79]$. Yet the worldwide efforts by powerful groups to ensure that information about overshoot is delayed, distorted, ignored or denied require concerted efforts to disseminate such information and to educate the public $[11,80]$. The language of health care demands and environmental demands is one that everyone understands, even if those demands are bound to remain largely unmet. The causal connections between overshoot and poor health have not yet widely entered the public's awareness. Calls for fairness and equity can help to direct public attention to regions where overshoot is worst.

Thirdly, health care demands are the mainstay of the discourse on justice in bioethics. An effective way to illustrate the widening gap between global rich and poor is to compare the health indicators that reflect the qualities of their respective lives, in addition to the often invoked data on per capita consumption or income. Regardless of the extent of overshoot, such comparisons highlight the injustice inherent in the global economic order, its trading schemes, and its underlying maldistribution of political power [81]. While insisting on one's right to a certain quality of health care may not lead to improvements, demands for equitable health care are more justifiable and authorities are often more inclined to listen to them; after all, they can invoke a right that is grantable.

Insisting on health care demands in those contexts represents of course only the first step in an argument that necessarily leads to a discussion of Potter's [34] five modes of survival, and of measures that might lead us from the current prevailing global mixture of miserable and unjust modes towards more acceptable alternatives. However, that "Great Transition" [82] confronts us with another problem where many of the grantable human rights - the ones that refer mostly to human behaviour and social capital in a civil society-conflict with health security and environmental security in general.

\section{Reconciling Health Security with Human Rights and Civil Liberties}

Our assessment boils down to this: Worldwide efforts by humanitarian organisations and healthcare systems accomplish a great deal of good in terms of at least a modicum of health security for much of humanity. But their efforts indirectly cause an inordinate amount of harm, especially to future generations, through their contribution to further growth of populations and economies. Moreover, they do not address the sources of the problems. This harm will continue until our global population, through a massive population reduction, reaches either a few million who enjoy all the trappings of modern diagnostic and therapeutic medicine, or a billion or two who receive the equivalent of adequate health care of a mid-rank country such as Cuba, or some solution in between $[82,83]$. The challenge lies in getting there with a minimum of suffering. 
History abounds with well-intentioned efforts by powerful rulers to enforce measures for the 'common good,' which arguably required that the individual rights and liberties of some or all of their subjects be curtailed. Article 29 of the Universal Declaration of Human Rights [69] serves that purpose, albeit not in a dictatorial way. Even in retrospect it is often difficult to assess whether such a specific curtailment in fact led to preferable outcomes. Certainly human rights were often violated in the course of such measures. In principle, every law that is passed represents a compromise between benefits to society and sacrifices to individual autonomy. This basic dilemma is amplified many times in scenarios depicting the transition towards sustainability [82].

The demand to attain sustainability can be entirely justified on the basis of intergenerational justice. Such moral extensionism towards future generations is evident in mainstream definitions of sustainability as in the Brundtland document [37]. However, the argument of intergenerational justice requires that the welfare of future generations be weighed against the rights and liberties of existing humans, and that is where many of those definitions falter [34]. The requisite drastic changes in lifestyle choices towards greater efficiency, reduced consumption, adaptation to global changes, and organisational restructuring, most likely accompanied by a reduction in the global population, would necessitate either an unprecedented amount of consensus on sacrificing our current privileges or a draconian repression of individual autonomy [84-86]. Neither option sits well with the humanistically inclined advocates of intergenerational justice. Of course, denying the conflict is always an option: In 2005, then Secretary-General Kofi Annan ([47] p. 1) stated in his report 'In Larger Freedom' advocating development, security and human rights for all, "The world must advance the causes of security, development and human rights together, otherwise none will succeed. Humanity will not enjoy security without development, it will not enjoy development without security, and it will not enjoy either without respect for human rights." The problem lies with his naive use of the word 'all.'

Another way to justify the demand to attain sustainability is by the ecocentric appeal to spare the Earth further ecological devastation from the hands of humanity. In fact, there is good reason to assume that only an ecocentric ethic can ultimately provide the moral basis for sustainable behaviour $[26,87]$. The arguments, which for reasons of space cannot be repeated here, rely on the overarching importance of environmental security and avoiding errors in 'managing nature.' To ecocentrists, even of the light green persuasion, many human rights and liberties carry less moral weight than the survival of other species and the existence and integrity of entire ecosystems and the biosphere. This has given cause for occasional charges of 'ecofascism' from rights-oriented circles
([88] p. 362). For ecocentrists the dilemma between human rights and environmental preservation usually presents less of a challenge because they value the latter so much more. The particular moral priorities of ecocentrism were also the reason why traditionally ecocentric ethics were considered incompatible with the ethics of health care, where the moral priorities lie squarely on the side of 'doing no harm' to humans. Yet the dependence of sustainable public health on environmental integrity suggests that at this juncture ecocentric ethics resembling Potter's [34] 'bioethics' are likely to lead to better health care for more future people than traditional humanitarian ethics could.

How could such an ecocentric ethics of health care help us reconcile health security with human rights? Avoiding overshoot would ensure that adequate resources will support the health of future generations and that the emergence of new pathogens from compromised ecosystems will be minimised [52]. The sacrifice comes in the form of severe curtailment to individual rights of the citizenry. The cohort of health care recipients is also likely to change. If current trends were allowed to continue, the gap between rich and poor would be even wider and the percentage of affluent citizens would be smaller because of shrinking economies. A more equitable redistribution would most likely come at the cost of individual rights ([17] p. 161). Also, the immigration of millions of ecological refugees from inundated coastlines and inhospitable local climates into countries that are willing to accept them will have altered demographic profiles. In the face of those changes, the following suggested measures would help render health care environmentally safe and sustainable.

- The shrinking of economies and the growing numbers of disenfranchised masses will render it even more urgent that drastic steps towards more equitable distribution of health care expenditures will finally be implemented. This would mean the end of public funding for elective treatments, for costly diagnostic equipment and for intensive hightech therapies. The ethics of triage would assume a prominent role in medical decision-making. Still, more equitable health care would lower average mortality.

- The constriction at the therapeutic side of health care will be compensated, at least in part, by an expansion of the preventive side [89]. Appropriate changes to lifestyle and nutrition would no longer be left to the autonomous decision of the citizen or unpredictable market forces but be imposed across society by legislation. For example, manufacturers of 'junk food' will be forced to switch to healthier products and consumers will have only relatively healthy foods to choose from, locally produced by sustainable methods, and lower on the food chain [54].

- The worldwide trends towards the commercialisation of disease and the commodification of treatment would have to be reversed. Just as state 
security should not be left to private contractors, so should the other aspects of human security be exempted from privatization, particularly at this juncture where the well-being of more and more people depends on decreasing funds. If health security is accepted as the overarching goal then its provision must not be restricted to those who can pay for it. Moreover, private enterprise is less accessible to enforcement and verification. This change of course will raise many ethical challenges about the reorientation of medical research, about the extent to which pharmaceutical companies will be allowed to participate, about development aid, and about our policies towards epidemics-which, after all, have evolved as just another biological mechanism of population control and are therefore bound to increase for as long as populations do; the current Ebola epidemic will not be the last instance.

- Above all, no health care resources could be used to support and promote human reproduction -on the contrary, all health care decisions would be informed by the overarching need to aid population attrition. In animal ecology, widespread infertility is recognised as a biological control mechanism that allows a population to curtail its exponential growth. Infertility is among the few such mechanisms that cause relatively little human suffering. The discourse of rights and needs [71] needs to change to a discourse of limits and obligations.

With respect to the four principles of bioethics, the curtailments described above indicate that patient autonomy would be severely reduced under ecocentric ethics of health care [57]. Similar restrictions will be placed on many of the democratic freedoms that citizens of many rich countries have become accustomed to, either as a function of population density in concentrated urban communities [90] or in tightly regulated rural socio-ecological communities $[31,91]$. On the other hand, ecosystems would receive a degree of autonomy of their own [92]. With regards to justice, it should be noted that ecocentric ethics does not necessarily call for greater equity in health care, although it is likely that the withdrawal of many elective services from the general population will lead to political demands to also curtail the health care privileges of the elites. Under ecocentrism the justice principle is merely expanded to include and prioritise the health of ecosystems $[93,94]$. However, prioritising comprehensive health security mandates an equitable approach, because the extent of security in a society is primarily determined by its least secure segment.

As for beneficence and non-maleficence, their importance remains unchanged but under ecocentrism what constitutes good and bad in health care is redefined in a more holistic way that conceives of humans as parts of larger ecological entities (socioecological communities) [91] that have moral standing and interests of their own. While we may continue to benefit from their functioning, we have no right to compromise them for our short-term interests or our pursuit of ungrantable individual 'rights.' The current overarching moral imperative of health care, to save lives, will be given less priority and the relief of suffering, the minimising of utilitarian cost-benefit ratios and the avoidance of ecocide will be emphasized more.

Notwithstanding those encouraging prospects for sustainable health care under ecocentric principles, it remains a fact that most practitioners and policy makers in health care are not ecocentrists. Their decisions seem to be primarily informed by an ethic that Mary Midgley referred to as "relentless humanism". This is illustrated, for example, by the language and the ideals underlying the health care targets of the UN's Millennium Development Goals $[39,70]$, the ICESCR [8] and the Global Health Council [9]. To the determined anthropocentrist the only recourse in the dilemma between rights and security is to weigh the extent to which human rights and liberties will have to be curtailed if the transition is to be accomplished, against the extent that rights and liberties will be lost amidst anarchy, chaos, famine, disease, and incessant warfare over diminishing resources, if sustainability is not achieved [59]. To most people who value the future welfare of their children and grandchildren, this utilitarian comparison of benefits and harms will lead them towards the side of sustainability [95]. Those who place more emphasis on traditional principles and virtues might find this dilemma rather more paralysing. A mere emphasis on distributive justice would dictate again a course change away from elective and preferential treatment and lead to more equitable health care, even though in the face of continued overshoot it may only turn out equitably miserable.

My suggestions apply in principle to all national systems of health care but not to equal extents. Crisp [96] suggested ways in which Third World and developed countries are capable of complementing their respective capacities and needs in a global 'co-development' whereby a more acceptable level of health care can be attained at a global scale. Much of the extra capacity that would be freed up by the elimination of elitist services in rich countries will be sorely needed in poor countries. Thus the reforms towards the new health care need to be implemented in a coordinated fashion around the world, tailored to the specific needs and strengths of regional communities.

The opposition to those reforms, too, will vary among countries but will be massive in many. Where health care has been privatized to a large degree a formidable opposition can be expected from the corporate providers and their privileged clients. It seems unlikely that such private health care providers could be integrated into the new schema. To the extent that countries will be swelled by masses of impoverished refugees, the principle of health care as a business will be less and less useful for their sustainable health 
security. This will constitute a greater problem in North America than in European countries. Another obstacle will be the inertia of education systems, of the media, and of the food, beverage, and agricultural industries that will not easily be persuaded to promptly support and promote the transition to healthier food and life styles. A third direction from where opposition can be expected are staunch advocates of democratic rights and civil liberties who will have difficulties with the removal of unhealthy and unhelpful choices from the grocery shelves as well as from the clinics ([17] $\mathrm{p}$. 162). On top of all that will come vociferous objections on religious and cultural grounds.

The all-important first step towards sustainable global health care will have to be a frank and open discussion of the issues at hand. Global limits, needs and capacities, rights and duties, means and ends must be made explicit and placed on the table in panel discussions, parliamentary debates, academic conferences, classrooms at all levels, governmental organ-

\section{References}

[1] McKibben B. Eaarth: Making a life on a tough new planet. New York, NY, USA: Times Books; 2010.

[2] CRED (Centre for Research on the Epidemiology of Disasters). EM-DAT: The International Disaster Database. Brussels, Belgium: CRED; 2013. Available from: http://www.emdat.be/natural-disasterstrends.

[3] HSRP (Human Security Report Project). Human security report 2012: Sexual violence, education, and war-beyond the mainstream narrative. Vancouver, Canada: Human Security Press. Available from: http://www.hsrgroup.org/human-security-reports/ 2012/overview.aspx.

[4] Pinker S. The better angels of our nature: Why violence has declined. New York, NY, USA: Viking Penguin; 2011.

[5] Buston O, Smith K. Global humanitarian assistance report 2013. UK: Development Initiatives, 2013. Available from: http://www.globalhumanitarian assistance.org/.

[6] WHO (World Health Organisation). World Health Day 2007: High Level Debate Tackled Need for Improved International Health Security. Geneva, Switzerland: WHO; 2013. Available from: http:// www.who.int/world-health-day/previous/2007/activ ities/global_event/en/index.html.

[7] WHO (World Health Organisation). World Health Statistics 2011. Geneva, Switzerland: WHO; 2011. Available from: http://www.who.int/whosis/ whostat/EN_WHS2011_Part2.pdf.

[8] United Nations Office of the High Commissioner for Human Rights. International covenant on economic, social and cultural rights. New York, NY, USA: OHCHR; 1966. Available from: http://www. ohchr.org/en/professionalinterest/pages/cescr.aspx.

[9] Global Health Workforce Alliance. Global isations, election meetings, public hearings, council meetings and any other public forum that promises leverage with the wider public. Precaution needs to trump scientific uncertainty. Population issues must no longer be regarded as taboo [97]. The longer those issues remain below the public horizon the greater the possibility that events will overtake deliberations. What might help is the uncomfortable realisation that, whichever choices are taken and whichever ethics gain the upper hand, the kind of health care as we have come to rely on in affluent countries will not last.

\section{Acknowledgment}

The work for this essay was supported by a grant from the University of Northern British Columbia. Part of the essay appeared in [32]. The author thanks the anonymous reviewers for their constructive and helpful comments. No conflict of interest arises for the author from this publication.

health council: member profile. Geneva, Switzerland: WHO; 2014. Available from: http://www.who.int/work forcealliance/members_partners/member_list/ghc/en/.

[10] Wright R. A short history of progress. Toronto, Canada: House of Anansi Press; 2004.

[11] Rees W. What's blocking sustainability: Human nature, cognition and denial. Sustainability: Science, Practice and Policy. 2010;6(2):13-25. Retrieved on 20 January 2011. Available from: http://sspp.pro quest.com/archives/vol6iss2/1001-012.rees.html.

[12] Heinberg R. Peak everything: Waking up to the century of declines. Gabriola Island, Canada: New Society Publishers; 2007.

[13] Costanza R, Kubiszewski I, Giovannini E, Lovins $\mathrm{H}$, McGlade J, Pickett KE, Ragnarsdottir KV, Roberts D, De Vogli R, Wilkinson R. Development: time to leave GDP behind. Nature. 2014;505(7483): 283-285.

[14] Pimentel D. Overpopulation and sustainability. Frontiers in Ecology and the Environment. 2006;4(3): 155-161.

[15] Grossman R. The importance of human population to sustainability. Environment, Development, and Sustainability. 2012;14(3):973-977.

[16] Macbeth $\mathrm{H}$, Collinson $\mathrm{P}$, editors. Human population dynamics: cross-disciplinary perspectives. Cambridge, UK: Cambridge University Press; 2002.

[17] Hempel LC. Environmental governance: the global challenge. Washington, DC, USA: Island Press; 1996.

[18] Catton WR Jr. Overshoot: The ecological basis of revolutionary change. Urbana, IL, USA: University of Illinois Press; 1980.

[19] UNEP-MAB (Millennium Assessment Board). Living beyond our means: Natural assets and human well-being. London, UK: UNEP-WCMC; 2005. Available from: http://www.maweb.org/en/Reports.aspx.

[20] Wackernagel M, Rees W. Our ecological foot- 
print: Reducing human impact on the earth. Oxford, UK: John Carpenter; 1996.

[21] Chambers N, Simmons C, Wackernagel $M$. Sharing natures interest: ecological footprints as an indicator of sustainability. London, UK: Earthscan Publications; 2000.

[22] Rockström J, Steffen W, Noone K, Persson A, Chapin III FS, Lambin E, Lenton TM, Scheffer M, Folke C, Schellnhuber HJ, Nykvist B, de Wit CA, Hughes T, van der Leeuw S, Rodhe H, Sörlin S, Snyder PK, Costanza R, Svedin U, Falkenmark M, Karlberg L, Corell RW, Fabry VJ, Hansen J, Walker B, Liverman D, Richardson K, Crutzen P, Foley J. A safe operating space for humanity. Nature. 2009;461(24September):472-475.

[23] Vitousek PM, Mooney HA, Lubchenko J, Melillo JM. Human domination of earth's ecosystems. Science. 1997;277(25 July):494-499.

[24] Ehrlich PR, Holdren J. The impact of population growth. Science. 1971;171(3977):1212-1217.

[25] York R, Rosa EA, Dietz T. STIRPAT, IPAT and ImPACT: analytic tools for unpacking the driving forces of environmental impacts. Ecological Economics. 2003;46(3):351-365.

[26] Curry P. Ecological ethics: An introduction. 2nd edition. Cambridge, UK: Polity Press; 2011.

[27] McMichael AJ. Human frontiers, environments and disease: past patterns, uncertain futures. Cambridge, UK: Cambridge University Press; 2001.

[28] Wackernagel $M$, Schulz NB, Deumling $D$, Linares AC, Jenkins $M$, Kapos V, Monfreda C, Loh J, Myers N, Norgaards R, Randers J. Tracking the ecological overshoot of the human economy. Proceedings of the National Academy of Sciences (USA). 2002; 99(14):9266-9271.

[29] Meadows D, Randers J, Meadows D. Limits to growth: The 30-year update. White River Junction, VT, USA: Chelsea Green Publishing Co.; 2004.

[30] Raudsepp-Hearne C, Peterson G, Tengo M, Bennett EM, Holland T, Benessaiah K, MacDonald GK, Pfeifer L. Untangling the environmentalist's paradox: Why is human well-being increasing as ecosystem services degrade? BioScience. 2010;60(8):576-589.

[31] Rees WR. Avoiding collapse: an agenda for sustainable degrowth and relocalizing the economy. Vancouver, Canada: Canadian Centre for Policy Alternatives; 2014.

[32] 'Genuine' development is based on long-term considerations of human welfare within systemic limits, as proposed in Lautensach AS, Lautensach SW. Why 'sustainable development' is often neither: a constructive critique. Challenges in Sustainability. 2013;1(1):3-15. See also [56].

[33] O'Brien K, St.Clair AL, Kristofferson B, editors. Climate change, ethics and human security. Cambridge, UK: Cambridge University Press; 2010.

[34] Potter VR. Global bioethics: Building on the Leopold legacy. East Lansing, MI, USA: Michigan State University Press; 1988.

[35] UNDP (United Nations Development Pro- gramme). Human development report: New dimensions of human security. New York, NY, USA: Oxford University Press; 1994.

[36] Galtung J. Violence, peace, and peace research. Journal of Peace Research. 1969;6(3):167-191.

[37] WCED (World Commission on Environment and Development). Our common future: The Brundtland Report. Oxford, UK: Oxford University Press; 1987.

[38] UN Millennium Project. Investing in development: A practical plan to achieve the Millennium Development Goals. New York, NY, USA: United Nations; 2005.

[39] United Nations. End poverty 2015: Millennium development goals. New York, NY, USA: United Nations; 2009. Available from: http://www.un.org/ millenniumgoals/.

[40] Chen LC, Leaning J, Narasimhan V, editors. Global health challenges for human security. Cambridge, MA, USA: Harvard University Press; 2004.

[41] Lautensach AK. Expanding human security. Australasian Journal of Human Security. 2006;2(3):5-14.

[42] Myers N. Ultimate security: The environmental basis of political stability. New York, NY, USA: W.W. Norton \& Co.; 1993.

[43] Lautensach SW, Lautensach AK. Environmental security: international, national and human. In: Harris PG, editor. Routledge Handbook of Global Environmental Politics. New York, NY, USA: Routledge; 2013. pp. 246-258.

[44] Buzan B, Waever O, De Wilde J. Security: A framework for analysis. Boulder, CO, USA: Lynne Rienner; 1998.

[45] Commission on Human Security. Human security now. New York, NY, USA: United Nations; 2003.

[46] United Nations. We the peoples: The role of the United Nations in the 21st century. New York, NY, USA: United Nations; 2000. Available from: http:// www.un.org/en/events/pastevents/pdfs/We_The_Peo ples.pdf.

[47] Annan K. In larger freedom: Towards development, security, and human rights for all. Executive Summary. New York, NY, USA: United Nations; 2005. Available from: http://www.un.org/ga/search/view_ doc. asp?symbol=A/59/2005.

[48] Alkire S. A conceptual framework for the Commission on Human Security. Center for Research on Equality, Human Security, and Ethnicity (CRISE). Working Paper 2, Oxford, UK: University of Oxford; 2003. Available from: http://www.crise.ox.ac.uk/ pubs/workingpaper2.pdf.

[49] Hastings D. The human security index: An update and a new release. Document Report Version 1.0. 2011. Available from: http://www.humansecurity index.org/wordpress/wp-content/uploads/2012/02/ hsiv2-documentation-report1_1.pdf.

[50] Westra L. Ecological integrity. In: Mitcham C, editor. Encyclopedia of Science, Technology and Ethics. Vol. 2. D-K. Detroit, MI, USA: McMillan Reference USA; 2005. pp. 574-578. 
[51] WHO (World Health Organisation). World health report. Geneva, Switzerland: WHO; 2006. Available from: http://www.who.int/whr/2006/en/.

[52] Garrett L. Betrayal of trust: The collapse of global public health. New York, NY, USA: Hyperion; 2000.

[53] MAB (Millennium Assessment Board). Millennium ecosystems and human wellbeing. Washington, DC, USA: Island Press; 2005. Available from: http:// www.millenniumassessment.org//en/Products.Synthes is.aspx.

[54] Hales S, Butler C, Woodward A, Corvalan C. Health aspects of the Millennium Ecosystem Assessment. EcoHealth. 2004;1(2):124-128.

[55] Lemons J. Afterword: University education in sustainable development and environmental protection. In: Callicott JB, da Rocha FJR, editors. Earth summit ethics: Toward a reconstructive postmodern philosophy of environmental education. Albany, NY, USA: State University of New York Press; 1996. pp. 193-217.

[56] Donella Meadows Institute. A genuine talk on progress and the genuine progress indicator. Mother Pelican. 2014;10(4):1-4. See also Costanza et al [13].

[57] Jameton A, Pierce J. The ethics of environmentally responsible health care. Oxford, UK: Oxford University Press; 2004.

[58] World Wildlife Fund (WWF). Living planet report: species and spaces, people and places. Gland, Switzerland: WWF International; 2014.

[59] Homer-Dixon T. Environment, scarcity, and violence. Princeton, NJ, USA: Princeton University Press; 1999.

[60] Diamond J. Collapse: How societies choose to fail or succeed. London, UK: Viking Penguin; 2005.

[61] Barnett J. Environmental Security and Peace. Journal of Human Security. 2007;3(1):4-16.

[62] Rapport DJ. The dependency of human health on ecosystem health. Ecosystem Health. 1997;3(3):195-196.

[63] Karr JB. Bridging the gap between human and ecological health. Ecosystem Health. 1997;3(3):197199.

[64] Soskolne CL, Bertollini R. Global ecological integrity and "sustainable development"-cornerstones of public health. WHO European Centre for Environment and Health. Proceedings 1999. Rome, Italy, 3-4 December 1998. Bonn, Germany: World Health Organization.

[65] Chivian E. Environment and health: 7.Species loss and ecosystem disruption-the implications for human health. Canadian Medical Association Journal. 2001;164(1):66-69.

[66] Beauchamp TL, Childress JF. Principles of biomedical ethics. 6th edition. New York, NY, USA: Oxford University Press; 2009.

[67] Dasgupta PS, Ehrlich PR. Pervasive externalities at the population, consumption, and environment nexus. Science. 2013;340(19 April):324-328.

[68] Fien J. Education for the environment: Cur- riculum theorising and environmental education. Geelong, Victoria, Australia: Deakin University Press; 1993.

[69] United Nations. The universal declaration of human rights. New York, NY, USA: United Nations; 1948. Available from: http://www.un.org/en/doc uments/udhr/index.shtml. In thirty articles, the Charter specifies the human right to life, liberty, and security of person; to freedom from discrimination by race, creed, gender, and equality before the law and due process; to a fair and public hearing in case of criminal accusations; to be presumed innocent until proven guilty; to free association and nationality, to freedom of movement; to own property; to freedom of expression and of religion; to democratic choice of representation; to respect for human dignity; to work and to equal pay as well as to leisure; and to a basic humanistic education. Negative rights include freedom from inhuman or degrading treatment or punishment; from arbitrary arrest, detention, or exile. Article 29 recognises appropriate duties and limitations of the rights of the individual for the common good but does not mention ecological limits.

[70] Sachs JD, McArthur JW. The Millennium Project: A plan for meeting the Millennium Development Goals. The Lancet. 2005;365(22January):347-353.

[71] UNFPA (United Nations Population Fund). By choice, not by chance: Family planning, human rights and development. State of the World Population 2012 Report. New York, NY, USA: UNFPA; 2012. Available from: http://www.unfpa.org/public/home/publications/pid/ 12511.

[72] Deckers J. Negative GHIs, the right to health protection, and future generations. Journal of Bioethical Inquiry. 2011;8(2):165-176.

[73] Jameton A, Pierce J. Environment and health: 8. Sustainable health care and emerging ethical responsibilities. Canadian Medical Association Journal. 2001;164(3):365-369.

[74] Karr JB. Measuring biological condition, protecting biological integrity. In: Groom MJ, Meffe GK, Carroll CR, editors. Companion to Principles of Conservation Biology. Sunderland, MA, USA: Sinauer Associates; 2006. Available from: http://www. sinauer.com/groom/article.php?id=23.

[75] Rawls J. A theory of justice. Cambridge, MA, USA: Harvard University Press; 1971. Ungrantable does not necessarily mean unjustifiable. Rawls showed that a right becomes unjustifiable when a person exercising that right impinges on the opportunities of other people exercising the same right. In the case of 'environmental rights,' their impact depends on the total number of people claiming them. Thus they violate Rawls' postulate only if their collective exercise results in the carrying capacity being exceeded. But their property of being ungrantable remains true under all conditions, in the sense that they cannot be guaranteed even by a ruler with the greatest political power and the best intentions. 
[76] This devaluing effect is also evident with legal norms: In Canada there still exists a federal law prohibiting the transport of any alcoholic beverage across a provincial boundary. Needless to say, most citizens are neither aware of this law, nor would they pay it any heed if they were. As an adjunct effect, however, this anachronism renders liquor legislation in general slightly more ridiculous and 'worth ignoring' in the public eye.

[77] Wackernagel M, Onisto L, Callejas Linares $A$, López Falfán IS, Méndez García J, Suárez Guerrero AI, Guadalupe Suárez Guerrero MA. Ecological footprints of nations: How much nature do they use?-How much nature do they have? Xalapa, Mexico: Centre for Sustainability Studies and San Jose, Costa Rica: Earth Council; 1997. Available from: http://www.ucl.ac.uk/ dpu-projects/drivers_urb_change/urb_environment/pdf_ Sustainability/CES_footprint_of_nations.pdf.

[78] GFN (Global Footprint Network). Ecological footprint atlas. 2009. Available from: http://www. footprintnetwork.org.

[79] Myers N, Norgaards R, Randers J. Tracking the ecological overshoot of the human economy. Proceedings of the National Academy of Sciences. 2002;99(14):9266-9271. Available from: http://www. pnas.org/cgi/reprint/99/14/9266.pdf.

[80] Lautensach AK. Environmental ethics for the future: rethinking education to achieve sustainability. Saarbruecken, Germany: Lambert Academic Publishing; 2010.

[81] A thought experiment can illustrate the fact that health care demands can, in the long run, only satisfy considerations of justice, not considerations of rights. In a highly inequitable society that has exceeded its maximum ecological impact only an elite minority can enjoy the full benefits of abundant health care services, because those in turn depend on ecosystem services. The majority survive (or not) in relative misery. A benign dictator set on reforming this society along environmental demands made by the masses could distribute health care benefits more equitably. This would improve the situation in terms of distributive justice but it cannot bring about acceptable health care for all, thus leaving many demands unmet. Furthermore, neither total utility nor average utility would increase, even if the population has stopped growing.

[82] Raskin P, Banuri T, Gallopín G, Gutman P, Hammond A, Kates R, Swart R. Great transition: the promise and lure of the times ahead. Stockholm Environment Institute Polestar Report no. 10. Boston, MA, USA: SEI; 2002. Available from: http://www.seiinternational.org/publications?pid $=1547$.

[83] The example of Cuba seems apt because this country is one of the few who has made genuine efforts, albeit not entirely voluntarily, to operate sustainably with only a minimum of petroleum products. In time, 'peak oil' will force the rest of the world to develop similar approaches to healthcare; Parker $\mathrm{CL}$, Schwartz BS. Human health and well-being in an era of energy scarcity. In: Heinberg R, Lerch $D$, editors. The Post-Carbon Reader. Heraldsburg, CA, USA: Watershed Media. 2010. pp. 385-405.

[84] Bowers CA. Education, cultural myths, and the ecological crisis: Toward deep changes. Albany, NY, USA: State University of New York Press; 1993.

[85] Daly $\mathrm{HE}$, Cobb JB. For the common good: Redirecting the economy toward community, the environment, and a sustainable future. 2nd ed. Boston, MA, USA: Beacon Press; 1994.

[86] Lautensach AK, Lautensach SW. Summary and conclusions. In: Lautensach AK, Lautensach SW, editors. Human Security in World Affairs: Problems and Opportunities. Chapter 20. Vienna, Austria: Caesarpress; 2013. pp. 411-448.

[87] Lautensach AK. The ethical basis for sustainable human security: a place for anthropocentrism? Journal of Bioethical Inquiry. 2009;6(4):437-455.

[88] Regan T. The case for animal rights. Berkeley, CA, USA: University of California; 1983.

[89] Halstead SB, Walsh JA, Warren KS, editors. Good health at low cost. New York, NY; USA: Rockefeller Foundation; 1985.

[90] The extent to which individuals can exercise democratic rights depends on the size and density of the population, as anyone who has lived in a large apartment block will confirm. Under certain conditions, some democratic rights thus become ungrantable. Fifty billion humans living on earth, even if they could be fed, would probably be stacked up in tanks from birth, with very little individual autonomy or rights.

[91] It has been repeatedly proposed that all life forms and natural communities have interests (Singer P. Animal liberation. New York, NY, USA: New York Review Books; 1975). The fact that we may not know what exactly their interests are should not prevent us from imparting on them a certain moral standing (Sagoff M. Has nature a good of its own? In: Costanza R, Norton BG, Haskell BD, editors. Ecosystem health. Washington, DC, USA: Island Press; 1992. pp. 57-71.) and respect (Taylor $P$. Respect for nature: A theory of environmental ethics. Princeton, NJ, USA: Princeton University Press; 1986).

[92] Simonsen $\mathrm{SH}$, Biggs RO, Schlüter $\mathrm{M}$, Schoon M, Bohensky E, Cundil G, Dakos V, Daw T, Lotschy K, Leitch A, Quinlan A, Peterson G, Moberg F. Applying resilience thinking: seven principles for building resilience in social-ecological systems. Stockholm Resilience Centre; 2014. Available from: www. stockholmresilience.su.se.

[93] Costanza R. Toward an operational definition of ecosystem health. In: Costanza, R, Norton BG, Haskell BD, editors. Ecosystem health: New goals for environmental management. Washington, DC, USA: Island Press; 1992. pp. 239-257.

[94] Callicott JB. Animal liberation: A triangular affair. Environmental Ethics. 1980;2(Winter):311-338.

[95] Hardin G. Carrying capacity as an ethical 
concept. In: May L, Wong K, Delston J, editors. Applied ethics: a multicultural process. 5th edition. Toronto, Canada: Prentice Hall; 2011. pp. 186-194.

[96] Crisp N. Turning the world upside down: The search for global health in the 21st century. London,
UK: Royal Society of Medicine; 2010.

[97] Coole D. Too many bodies? The return and disavowal of the population question. Environmental Politics. 2013;22(2):195-215. 


\title{
Human Security Workers Deployed in Austere Environments: A Brief Guide to Self-Care, Sustainment, and Productivity
}

\author{
Thomas F. Ditzler ${ }^{1, *}$, Patricia R. Hastings ${ }^{2}$ and Abigail D. Hoeh ${ }^{1}$ \\ ${ }^{1}$ Department of Psychiatry, Tripler Army Medical Center, 1 Jarrett White Rd, Honolulu, HI, 96859, USA; \\ E-Mail: abigail.d.hoeh.ctr@mail.mil (ADH) \\ 2 Joint Chiefs of Staff (JCS) Surgeon's Office, United States Department of Defense (DOD), 1400 Defense \\ Pentagon, Washington, DC, USA; E-Mail: patricia.r.hastings2.mil@mail.mil \\ * Corresponding Author: E-Mail: thomas.f.ditzler.civ@mail.mil; Tel.: +1 8084331246 \\ Submitted: 15 September 2014 | In revised form: 24 December 2014 | Accepted: 15 January 2015 | \\ Published: 14 April 2015
}

\begin{abstract}
Since the early 1990s, the human security movement has sought to expand the concept of security beyond the traditional military defense of national borders to focus on the intra-state security needs of populations at the individual level. Specific initiatives frequently address problems of population health, ethnic conflict, religious extremism, human rights, environmental or natural disasters, and other critical issues. For expatriate human security workers in the field, the environment may present meaningful challenges to their wellbeing and productivity. This can be especially so for those who have relatively more experience in academic, business, or administrative settings, and less in the field. The authors' goal is to illuminate practices that have demonstrated their efficacy in enhancing wellness, sustainment, and productivity for human security and other humanitarian and development workers deployed to austere environments. The content represents a synoptic consensus of best general practices and guidance from a range of resources comprising United Nations agencies and activities, national and international non-governmental organizations (NGO's), private volunteer organizations (PVO's), national military services, and international business concerns.
\end{abstract}

Keywords: humanitarian; human security; non-governmental organizations; population health; private volunteer organizations

\section{Introduction}

From its beginnings in the early 1990's, the human security movement has engaged a stunningly broad constellation of challenges. Human security workers may represent disciplines of anthropology, interna

(C) 2015 by the authors; licensee Librello, Switzerland. This open access article was published under a Creative Commons Attribution License (http://creativecommons.org/licenses/by/3.0/). 
tional relations, environmental science, ethics, health, engineering, economics, law, or other professional fields. For those who engage in human security work in the field, environments are often austere. Workers may confront their mission in the context of civil strife, limited or depleted natural resources, endemic disease, meager or absent health care, unsafe transportation, inadequate public health assets including water and sanitation, and other critical infrastructure. Research on psychological distress among such workers indicates that chronic exposure to such environmental stressors, including the suffering of others, is associated with negative mental health outcomes, including depression, anxiety, and "burnout" characterized by long-term exhaustion and diminished interest. These outcomes are, in turn, associated with decreased work satisfaction and productivity [1]. To effectively meet the challenges of these environments, workers require strong support from their sponsoring organizations; the best preparation emerges from a transparent and interactive agency-worker partnership that embraces a shared responsibility for mission outcome. Specific agency-based support should include pre-employment screening of potential workers, provision of mission-specific education, training, and ongoing worksite support in the field. Whatever the specific activities of the agency, planning for success should include thorough worker preparation in self-care and sustainment. Specific skills typically include healthy practices of personal hygiene, diet, physical fitness, cultural adaptation, socialization, and development of effective stress management strategies. These skills are mission-essential for all deployed workers. The advantage of healthy, self-sustaining workers is reflected in greater mission success, improved job satisfaction and increased worker longevity [1].

\section{Pre-Deployment Issues}

If being engaged a new organization, workers are advised to contact current or former workers familiar with the organization to learn as much as possible about its leadership style and general culture, to get a clear understanding of screening, hiring, and field support procedures as well as vacation or leave policies and access to health care.

Many experienced workers make a "deployment book" to leave at home with an appropriate person. The content typically includes relevant personal information that someone else would need to contact the worker. At the very minimum this should include names and contact information of key deployment agency personnel at both the home office and in the area of operation $(A O)$, copies of the ID page of the worker's passport with several other recent pictures of him or her, and a letter of instruction on what to do if the worker is ill, detained, or missing. A more substantive document might include copies of required authorizations and permissions necessary to permit another to carry out legal, business, financial or other personal responsibilities on the worker's behalf, such as a power of attorney.

In addition, it is important for the worker to conduct a thorough background study of the AO. There is no single best way to organize the effort, but areas of focus often include the region's history, geography, social organization, political institutions, spiritual system(s), health care, transportation, important social customs and traditions, and language. Learning some of the local language is an obvious advantage in any environment. In situations with one principal language, workers can pursue pre-deployment study. There are many government, academic, and commercial sources available in a range of media.

Unfortunately, many of the languages of the field environments human security workers engage are not commonly spoken, or the number of languages or dialects commonly spoken precludes the acquisition of meaningful skills. This is especially so in settings in host communities with a large number of refugees or internally displaced persons. A properly vetted local translator is a necessity, and can also serve as a cultural informant to provide useful information on a range of issues related to important customs, traditions, and social conventions. For workers attached to organizations already in the $\mathrm{AO}$, translation and related language issues are usually managed by the sponsoring agency. In the absence of a translator, the pre-deployment language practice mentioned above can go a long way in facilitating productive social exchanges. It is a truism that workers' level of wellness, comfort, security and productivity can be largely predicted by their working knowledge of the culture around them.

\section{Health Preparation}

Health authorities recommend that basic preparation include a comprehensive pre-deployment medical exam, a review of routine personal medications, and consultation on medications indicated for potential medical threats in the $A O$ [2]. A dental exam is also considered good planning. It is worth noting that even in otherwise sophisticated military organizations, dental problems are a common cause of evacuation from the field. Hormonal changes may predispose females to gingivitis, making a dental exam more important than many may realize [3]. For routine maintenance medication, seasoned workers often take a supply that extends two months beyond the scheduled deployment. In preparation for work in arduous environments, the basics of nutrition would advise keeping a healthy weight with a BMI of 19-25, and eating a balanced diet including grains, fruits, vegetables, milks, and meats/proteins. Women need more iron, calcium and folic acid. If unable to secure these nutrients on a reliable basis, it is best to discuss possible supplements with a health care provider. 


\section{Equipment}

Proper fit and comfort of personal gear is an important, but easily neglected aspect of self-care. Most military and camping equipment items are sized for males and may need to be modified for females. Injuries to the lower back and legs of female soldiers are twice those of men [4]. Jumping from relatively low heights can cause knee and hip injuries. Women are more prone to stress fractures of the hip and leg. Females involved in extreme athletic endeavors can have similar problems due to low body fat, loss of menstruation, and hormonal changes which can weaken bones and predispose to stress fractures [5]. One of the factors contributing to these types of injuries may be equipment, which is not typically designed for females. [6]. A female may have difficulty carrying the same load in the same way as a male, often because she has a shorter back. The best backpack for females is often one that has adjustable shoulder straps, a chest strap, and a waist belt to place some of the bag's weight on the hips. Because a female's shoulders may not be as broad as a male's it is often beneficial for a greater amount of weight to be placed on the hips.

Ankle injuries are also more common in women than in men. If at all possible, women should select boots made for the female feet. Females have higher arched and semi-curved feet. In contrast, the male heel and ankle is typically wider due to the pull of the calf muscles and musculature [7]. Before deploying, women should ensure that foot-gear is well broken in. Also, a supportive sports bra can make long treks much more comfortable and decrease back and shoulder pains. Most females with field experience would advise a pull over the head sports bra to lengthen its use, as harsh washing can break or rip the eyelets used to fasten a regular bra.

\section{Safety and Security}

Among seasoned humanitarian workers there is a common saying: "if you don't have security, you don't have anything". This aphorism is especially true for emergency workers responding to large-scale natural or technologic humanitarian disasters, or those who are working in areas of armed conflict or other general social strife. Clearly, workers deployed to these areas are in exceptional circumstances, and security measures are unique to each environment. Typically, security practices involve responses reflecting the collaborative efforts of the supporting humanitarian agencies/organizations, the host government, and in some instances, military personnel or civilian police (see Appendix A for more information about physical security in high risk areas). In stable environments, unavoidable hazards, threats, and vulnerabilities require a clear and consistent risk management strategy. The most effective security plans start with detailed background knowledge of the $\mathrm{AO}$; there is no substitute for situational awareness of the environment and culture. Below are a number of principles, precepts, and practices that have demonstrated their utility in maximizing collective security and wellness for program leadership and workers.

- Safety and security is everyone's concern at both the organizational and personal level. A useful aphorism is: "have the plan, know the plan, carry out the plan".

- Safety plans and rules must be communicated to all; acceptable and unacceptable risks must be clearly defined along with procedures for exceptional circumstances (e.g.travel at night, traveling alone, etc.)

- Ensure that safety and security issues are an integrated part of administrative and supervisory meetings. This will reify the expectation of shared security vigilance among colleagues

- Have clear contingency plans for special threat situations including severe weather, important infrastructure failure, civil disruption, or other security conditions

- Communication practices are critical and should include standardized training for communication equipment, procedures and terminology.

- Know relevant local laws and customs, especially about what to do in cases of a vehicular collision, pedestrian accident, or inadvertent property damage. Especially in rural tribal settings or areas embracing transitional justice, the customary response may be harsh.

- Do not defer routine vehicle maintenance, and ensure that all vehicles have up-to-date maps on board along with serviceable mobile communications equipment.

- If possible, have secure vehicle parking and maintain an environmentally appropriate medical kit on board.

- Personal wellness is a large part of safety. In addition to physical fitness, adequate sleep and appropriate nutrition, workers can increase safety for themselves and others by abstaining from recreational drug use, and moderating alcohol.

- For those concerned about the need for emergent medical care or the possibility of rapidly deteriorating security conditions, consider rescue and evacuation insurance (see Appendix B for more information on several well-known firms).

\section{General Hygiene in the Field}

The routine conveniences of daily hygiene materials and practices may be much less available in the field. Important hygiene practices to maintain are: dental care, regular bathing, hydration maintenance, avoidance of simple sugars, and abstaining from alcohol and tobacco products. Fluoride toothpaste is advised in most cases. In the absence of toothpaste, table salt or baking soda may work well, or use a cloth and water to wipe over each tooth surface to help avoid debris build-up. 
Ideally, all workers should have access to a way to wash every day to avoid disease, parasites and skin infections. Showers are preferred to baths to avoid urinary tract infections (UTIs). Minimal requirements for bathing are: a secure environment, at least one quart of water, soap, and proper drainage. If no shower facilities are available and water use is restricted, commercially available wet-wipes can ensure a minimum level of hygiene until a shower is available. Wet-wipes may also be used as toilet paper if this comfort is not available.

A common hygiene problem for workers (and for women in particular) is difficulty urinating in environments with less than optimal privacy or in situations in which it could be dangerous to disrobe. In responding to this, workers may sometimes resort to strategies that are sub-optimal for peak performance and health. For example, some may decide to voluntarily minimize fluid intake to avoid urination, which could increase the likelihood of UTIs. If one will be away from any medical facilities it may be practical to have an antibiotic prescribed for use if needed. In addition to increasing the likelihood of a UTI, water restriction can cause dehydration. Voluntary water restriction may not be subjectively perceived as dangerous to the individual owing to the belief that the sensation of thirst will automatically cue them when it is time to hydrate. In reality, anyone with a clear sensation of thirst is already dehydrated. Controlled studies indicate that among women, even mild dehydration is associated with headache, lowering of mood, increased fatigue, increased perception of task difficulty, and impaired concentration [8-10]. More severe restriction can also lead to heat injury including heat exhaustion or heat stroke, which can be fatal. The risk of heat injury may be increased in very dry environments in which the sensation of perspiration may not provide a clue for fluid loss [11]. Urine retention also increases the likelihood of bladder injury in the instance of blunt impact or deceleration injury (e.g. fall, or vehicular mishap) as the pelvis or abdomen can more easily traumatize the distended bladder. Fluid intake is critical to peak performance and, though this may be considered in hot environments, it can be problematic in cold regions where women can face the danger of cold exposure because of the need to disrobe more fully to urinate.

It is not unusual to have some change in menstrual period length or flow in a physically or emotionally stressful environment. Women are encouraged to have enough sanitary supplies for at least 30 days if resupply is predictable and longer if resupply is not assured. Some external irritation may occur in hot environments, but cornstarch or a thin layer of petroleum jelly may improve comfort. Pads can also be used if stress incontinence may be an issue. For women who use tampons, cardboard applicators are usually a better choice than plastic because plastic applicators can cause micro-abrasions in the vaginal mucosa and are not bio- degradable. Both tampons and pads can do double duty when used as dressing or to occlude bleeding sites.

\section{Climate Issues}

It has long been known that a high level of physical fitness is a key element in worker safety and productivity. As a practical matter, physically fit workers are less likely to get sick or injured; and they recover more quickly when illness or injury occurs. In addition, active physical conditioning helps workers to acclimatize to the environment. This is especially important in environments of extreme heat or cold including desert environments, where daily cycles of extreme temperatures are common. Caution is advised when exercising in very hot or cold weather as chance of injury tends to increase with temperature extremes. In general, women do not tend to perspire as quickly or easily as males [12]. The way the female body adapts to heat relies on the principal of a smaller total body mass combined with the larger surface area to body mass ratio. This explains why women will often do better than men in hot topical (wet) environments, but not as well initially in hot desert (dry) locations where perspiring can make a difference in acclimatization (US Army Public Health Command, 2010). Also, women typically have lower finger temperatures and higher rates of peripheral vascular disorders that could make them more susceptible to peripheral cold injury.

\section{Social Acculturation and Gender Roles}

The process of adaptation to a new and sometimes jarringly different social environment has traditionally been referred to as "culture shock". Hopefully workers will have availed themselves of basic background information about the work environment and the process of cultural adjustment. In many areas, traditional gender role expectations may place meaningful constraints on working women, even if they are expats in a humanitarian role. Expat female and male colleagues in these areas are well advised to have a clear understanding of culturally acceptable interaction in a shared space.

Customary dress is often conservative for both men and women. This may involve covering the limbs, (i.e. long pants for males and long sleeves and long pants or long skirts for females), and often includes covering the hair for females. These modes of dress can make one's job more difficult physically and emotionally. For example, if acceptable clothing comprises a full-length, dark colored robe, heat may become a meaningful problem. Likewise, covering the ears can decrease the ability to hear the spoken word or localize other sounds. Full facial coverage can also impair peripheral vision and the ability to see what is near ones feet. In some areas, women wear tight fitting shorts under their skirts to ensure if there is an inadvertent move- 
ment of the skirt that their upper legs will not be seen.

Norms for behavior may not allow male or female workers to talk to the opposite gender. Females may not be allowed to be in the company of males who are not a relative; in some instances, a male aid worker may put a local female at risk by speaking with her or being in her company. Age can also be a difficulty with regard to the youth of a country adapting to foreign languages more quickly than adults and change the dynamics of a family or clan if the younger children or adolescents are acting as interpreters.

Body language can be a powerful force for good or ill. In many circumstances, there are subtleties that must be briefed to those going into an area. It is especially important to be aware of norms about physical touching, and in many cultures there a certain gestures that are best avoided. Other normative communication issues might concern gaze behavior. In many western cultures, looking another person in the eyes is often considered a sign of sincerity; in many other settings it may be considered rude or aggressive. Also, the social expectations of gaze behavior may be different depending on the gender of the speakers. Similarly, asking about another's spouse or family may be viewed as friendly or intrusive. It is worth noting that many cultures also have strong customs, traditions, and social rules governing the processes of gift giving; once again, a little cultural homework can go a long way. This is especially so if the host country is also accommodating refugees or internally displaced persons, where multiple standards may apply.

\section{Emotional Self Care}

This skill set has been variously referred to as stress management, resiliency, personal wellness, mental health, emotional well-being, psychological hardiness, and other terms. Research confirms that humanitarian workers, especially those responding to large scale disasters, have high rates of subsequent psychological distress. These frequently include a range of mood disorders, anxiety disorders, and in some instances spiritual or philosophical problems, sometimes involving loss of hope or purpose $[1,13,14]$.

Although the field work of human security workers may not routinely engage the magnitude and complexity of career disaster responders, the cumulative effects of their work can still be emotionally challenging. Whatever the specific mission, it is clear that evidence from a number of studies reveals the most common source of psychological distress is the persistent exposure to the suffering or deprivation of others (Antares Foundation, 2012; Brunette, 2011). An important but less striking source of strain may include separation from family and friends, physically demanding work, different language and working through translators, unusual foods, crowding and lack of privacy, different social customs (especially concerning gender roles), harsh climate, or a lack of accustomed comforts. Over time the otherwise fairly ordinary inconveniences can produce an emotionally corrosive effect sufficient to compromise general wellness and productivity.

Based on a review of the literature, Blanchetiere [14] proposed that causes of stress may be thought of under four general headings: 1) situational factors, including personal security, health risks, and demands of the population; 2) job related factors, comprising living conditions, cultural change; workload, colleague relations, and job security; 3 ) organizational climate, involving program roles and expectations, management style and worker support; 4) personal risk factors, incorporating poor self-care, psychological vulnerabilities, unrealistic expectations and motivation, and lack of experience. The sources of stress, therefore, are complex, interrelated, persistent, and idiosyncratic. The key to management lies in having in place an individualized self-care program focused on health maintenance and increased comfort. The plan embodies the worker's aggregate knowledge, skills, experience, beliefs, behaviors, plans, and attitudes that contribute to the maintenance of well-being. Effective plans begin in the pre-deployment phase, during which the worker reflects on the personal values, goals and expectations they attach to their efforts. These insights can help to identify the substance of their motivation and facilitate the earnest assessment of their particular strengths and limitations that shape specific self-care plans. Below are some self-care ideas that have proved useful for many.

- Monitor your mood, and establish mutual support relationships; share your thoughts and feelings with trusted coworkers at appropriate times.

- Make a point of planning an exercise schedule and stick to it. Because the operational tempo may be high, it is important to block out specific time to ensure you maximize the advantages of a regular physical care regimen.

- Real time electronic communication (social media, FaceTime, Skype, etc.) can facilitate a sense of connectedness with home.

- Keep a log (diary) of thoughts, feelings and activities; this often helps in processing your activities and may later provide an instructive source of reflection on your experiences.

- Sharing humor can provide welcome relief from the stress, but it is important to keep things positive. If the tone turns negative or angry, it can compromise trust and erode the collaborative spirit.

- Personalize your living quarters with photos, significant keepsakes, and other reminders of home; it helps maintain a sense of continuity and attachment - When possible, seek recreation away from the work area.

- Even if you will not be on site for an extended period, it is generally a good idea to unpack your bags to lend an element of order and predictability to your personal environment.

- Be careful about the use of alcohol; the pressures 
of field work can potentially lead to an unhealthy increase in consumption. Recreational drug use is clearly contraindicated.

\section{Coming Home}

As the mission winds down, workers are often invigorated by thoughts of returning home to their family, friends and customary lifestyle. They may reflect on their endeavors, and the relationships they have developed with colleagues and those they sought to help. Workers often look forward to having time to consider what they have learned and accomplished, and to sharing their experiences with others. Indeed, being part of a team with a shared goal in service to others can be a great source of healthy pride. However, there is often sadness about departing.

Sometimes the feelings can be surprisingly intense. Departing workers and those they served all benefit from making adequate time to get closure, and saying goodbye or making plans to stay connected. In some circumstances this may involve a communal activity or formal event; in others, it may be more personal. Whatever form it takes, the departure process reifies the value of what has been done and acknowledges the contributions of all.

On returning home, workers embrace the challenges of reconnecting with their previous world. Especially for those who have less experience in foreign placements, or who have been away for a longer time, the process can be surprisingly disquieting. Although formal research is scarce, comments of field workers from diverse missions reveal a number of common themes that may emerge for returnees. Below are some of the most frequent of these with some advice from humanitarian mission leaders [13].

- As a returnee, understand that the homecoming may be less eventful and rewarding than you had imagined.

\section{References}

[1] Cardozo BL, Crawford CG, Eriksson C, Zhu J, Sabin M, Ager A, Foy D, Snider L, Scholte W, Kaiser R, Olff $M$, Rijnen B, Simon W. Psychological distress, depression, anxiety, and burnout among international humanitarian aid workers: a longitudinal study. PloS one. 2012;7(9):e44948.

[2] Brunette GW. CDC Health Information for International Travel 2012: The Yellow Book. New York, NY, USA: Oxford University Press; 2011.

[3] WebMD. Hormones and Oral Health. Available from: http://www.webmd.com/oral-health/hormonesoral-health.

[4] US Army Public Health Command. A guide to female soldier readiness. USAPHC (Prov) technical guide 281. Available from: http://phc.amedd.army.mil/ Pages/default.aspx.
- Once home, get lots of rest. Jet lag only lasts a few days, but returning to the pace and activities of home may require some adaptation. Give yourself time to adjust; don't try to do too much too fast. This is especially important if you are returning to work.

- Family and friends can be problematic if their need for your attention inadvertently overburdens you. It may be necessary to diplomatically explain your need for some undisturbed time.

- You may want to talk a lot about your experience and find that others are simply disinterested, or that they don't seem to connect with the magnitude of what you have experienced. They may be much more interested in telling you what has happened for them during your absence.

- In other cases, you may find the questions of others to be intrusive. You may experience anger or frustration with those who seem insensitive or unsympathetic to what may have been a life changing experience for you.

- These contradictory feelings, while troublesome, are part of the readjustment process; as a general rule, try to be at least as understanding of yourself as you would be of someone else in your position.

\section{Conclusions}

A large and expanding body of research clearly validates the critical role of individual worker wellness in the success of human security field missions. From pre-deployment planning, through mission responsibilities in the AO, to the return home, both workers and agencies clearly benefit from a thoughtful plan for self-care. The rewards of worker self-sustainment can be measured in terms of both mission success on the ground and long term worker wellness. Hopefully the authors' efforts will provide some useful guidance on how to approach the process.

[5] AAOS. American Academy of Orthopaedic Surgeons. OrthoInfo. Stress Fractures. Available from: http://orthoinfo.aaos.org/topic.cfm?topic $=$ a00112.

[6] Simpson KM, Munro BJ, Steele JR. Backpack load affects lower limb muscle activity patterns of female hikers during prolonged load carriage. Journal of Electromyography and Kinesiology. 2011;21(5):782-788.

[7] Wilkerson RD, Mason MA. Differences in men's and women's mean ankle ligamentous laxity. The Iowa orthopaedic journal. 2000;20:46-48.

[8] Armstrong LE, Ganio MS, Casa DJ, Lee EC, McDermott BP, Klau JF, Jimenez L, Le Bellego L, Chevillotte $E$, Lieberman HR. Mild dehydration affects mood in healthy young women. The Journal of Nutrition. 2012;142(2):382-388.

[9] Ganio MS, Armstrong LE, Casa DJ, McDermott BP, Lee EC, Yamamoto LM, Marzano S, Lopez RM, Jimenez L, Le Bellego L, Chevillotte $E$, Lieberman HR. 
Mild dehydration impairs cognitive performance and mood of men. British Journal of Nutrition. 2011; 106(10):1535-1543.

[10] Masento NA, Golightly M, Field DT, Butler LT, van Reekum CM. Effects of hydration status on cognitive performance and mood. British Journal of Nutrition. 2014;111(10):1841-1852.

[11] US Army. FM 90-3/FMFM 7-27. Desert Operations. Headquarters Department of the Army US Marine Corps. Technical manual. 2003. Available from: http://armypubs.army.mil/doctrine/dr_pubs/dr_a/pdf/f

\section{Appendix A: Security Planning Resources}

Rogers, C., \& Sytsma, B. (1999). World Vision Security Manual.

Van Brabant, K. (2000). Operational security management in violent environments. Overseas Development Institute.

Adventist Development and Relief Agency. Guidelines for Developing a Security Plan. Retrieved from http://www.adrasouthpacific.org/site_data/109/assets /0038/2161/Guidelines_for_Develpoing_a_Security_ Plan.doc

\section{Appendix B: Rescue and Evacuation Resources}

Rescue and evacuation insurance through Global Rescue (globalrescue.com)

International Medical Group (imglobal.com)

Adventure Sports Insurance (adventuresportsinsurance.com) m90_3.pdf.

[12] Buono MJ, Sjoholm NT. Effect of physical training on peripheral sweat production. Journal of Applied Physiology. 1988;65(2):811-814. Available from: http://jap.physiology.org/cgi/reprint/65/2/811.

[13] Antares Foundation. Managing stress in humanitarian workers; Guidelines for good practice. Available from: https://www.antaresfoundation.org/.

[14] Blanchetiere P. Resilience of humanitarian workers. 2006. Available from: http://www.dochas.ie/ Shared/Files/4/resilience-of-aid-workers.pdf.

International SOS (internationalsos.com)

\section{Appendix C: Aid Worker Training Resources}

All resources accessed on 23 December 2014

http://www.jhsph.edu/research/centers-andinstitutes/center-for-refugee-and-disasterresponse/education_training/HELP/

http://www.goinginternational.com/ https://www.icrc.org/eng/resources/documents/misc/ help_course.htm

http://www.who.int/hac/techguidance/training/course s/en/

http://reliefweb.int/training

http://www.disasterready.org/about

http://www.sphereproject.org/blog/free-onlinehumanitarian-training-resources/ 


\title{
A Review of 'Humanitarian Intervention and Legitimacy Wars: Seeking Peace and Justice in the $21^{\text {st }}$ Century'
}

\author{
Published: 27 April 2015
}

Humanitarian Intervention and Legitimacy Wars: Seeking Peace and Justice in the $21^{\text {st }}$ Century Richard Falk

Routledge: New York, NY, USA. 2014

224 pp.; ISBN: 978-0-415-81553-6

In his book Humanitarian Intervention and Legitimacy Wars: Seeking Peace and Justice in the $21^{\text {st }}$ Century, Richard Falk argues that, with the growing prevalence of soft power, historical lessons of asymmetric warfare and legitimacy wars must be taken into account. Falk rejects the realist notion that the state is the only rational actor, offering a more constructivist approach that focuses on the norms, culture and morality of the international community. $\mathrm{He}$ asserts that humanitarian intervention is on the decline, and legitimacy wars are increasing. Much of this legitimacy is based on international law and its relevance in the international community.

Starting with the tribunals at the end of World War II, Falk seeks to demonstrate that geopolitics has created a double standard that prevents international law from being exercised evenly. After WWII, the only states that were subject to tribunals and punishments for war crimes were those states on the losing side. For example, the United States' use of nuclear weapons was overlooked, even though Falk sees this as a clear violation of international law. Falk finds this "top-down" approach to be ineffective because the norms of international law are not applied evenly.

In the future, Falk argues that legitimacy wars will make the push for humanitarian intervention. Soft power will overtake military prowess as the major player in international relations. Developed by Joseph Nye, soft power focuses on reaching desired outcomes without the use of coercion. One of the main differences of soft power is that it is not a trait exclusive to states; NGOs and international institutions can use soft power to influence other actors.

The use of soft power depends on people and civil societies to bring legitimacy to the struggle of a people against oppression of many kinds, putting international law and morality at the center of the struggle. He uses the issue of Palestine as an example. Many of the previous attempts at a solution have relied on the ineffective norms of international law, but the boycott, divestment and sanction (BDS) campaign of 2004 was far more successful. The BDS was created from the ground up by a coalition of NGOs. This has becomes a more successful, nonviolent way of pushing for Palestinian legitimacy and self-determination.

Falk's emphasis on issues of soft power is timely, given the current state of affairs. Ethnic groups like the Iraqi Kurds and the Palestinians are pushing for self-determination, basing many of their arguments on the human rights violations they have suffered and the basic need for their own state. All military action and violent activities are in pursuit of this one goal: to expand the rights of their people through any means necessary. He provides insight into this future direction of global conflict and provides a better understanding of where these conflicts will take place and how they will be won.

While Falk's theory is well developed, the early chapters do not provide sufficient definitions. The definition of "legitimacy war" seems lost. This makes the later examples of Palestine and Kosovo difficult to understand. What, exactly, makes these cases different from others like them? How does this relate to an understanding of soft power? The case studies in the later sections of the book are less impactful because the full definition of a "legitimacy war" is never fully given.

While there are some definitional pitfalls, Falk's book does provide a better map of what conflicts will look like in the future. He provides a better understanding of how soft power and civil society can have a role in conflicts. His case study of Palestine is particularly relevant, given the recent conflicts in the area. This book would be of interest to students of international law, human security, and international relations.

Leah Merchant

Department of Political Sciences, University of Cincinnati, Cincinnati, OH, USA; E-Mail: leahcmerchant@gmail.com 


\title{
Notes from the Field: The Humanitarian Crisis in Ukraine
}

\author{
John Quinn \\ Prague Center for Global Health, First Faculty of Medicine, Charles University of Medicine Prague, Czech Republic \\ Submitted: 4 May 2015 | Accepted: 16 May 2015 | Published: 9 July 2015
}

\begin{abstract}
Humanitarian crises are politically and socially charged, and as actors, donors and organizations move in to help, duplication of services can ensue. Despite the influx of humanitarian actors into the war zone of eastern Ukraine, more are still needed to address immediate threat to the health of more than 5 million at-risk people in the area. The humanitarian disaster in Ukraine requires fast support and stakeholder involvement to mitigate preventable death among at-risk populations. As the crisis unfolds and many more people are caught in the crossfire with no health security, WHO is leading the charge to organize healthcare and humanitarian action to relive human suffering and engender health security for all.
\end{abstract}

Keywords: complex emergency; conflict medicine; health security; humanitarian crisis; human security in war

\section{Introduction}

Former Ukrainian president Yanakovich's refusal to sign an agreement bringing Ukraine economically closer to the EU in November 2013 set off a political and social revolution. Perceived power vacuums prompted a pre-planned annexation of the Ukrainian Crimean Peninsula by Russia. Currently, Russia deploys lethal hybrid warfare with proxy Russian backed terrorists throughout two large regions, Donetsk and Luhansk, and is spreading and probing further west into the regions of Eastern Ukraine. Ongoing terror attacks in major cities throughout the country are spreading fear of a Russian campaign to take over all of Ukraine or spark further violence and obliterate human and health security for the region.

Millions of civilians have been caught in the middle, with only intermittent access to basic health and hygiene services and an overall deterioration in an already failed health security state in a European country. Ukraine is a fragile state and extractive practices over the past decade have given way to institutional decline and ministerial decay. The repercussions of this are a decrease in human and health security which is unable to weather any shocks in times of crisis and disaster. The humanitarian crisis that has erupted has proven how much human life can be lost in such a short period of inaction and non-intervention in global health.

\section{Institutions in Decay}

Extraction of wealth and institutional rot tore out any resilience mechanisms for territorial defense, as well as any capacity for offering basic services like primary or emergency health care that existed under post-Soviet rule. This is especially seen in the regions of Donetsk and Luhansk and has quickly spilled-over into the port city of Mariupol and, in the north, the regional capital and border city of Kharkiv. The recently lost city of Debaltseve, where civilian casualties piled up during a ceasefire that never began, highlights how Russian hybrid warfare grinds through the civilian population.

As the Ukrainian state reorients itself and is busy making monumental and frame-shift changes towards stable and transparent democratic institutions, the humanitarian sector has speedily risen to the challenge of filling many gaps to enable health security for those caught in the 
middle - if only fleetingly - starting from at the bottom of a deep hole and on the back foot. This short report from the field is to serve as a snapshot of the current health situation in Eastern Ukraine and map what players and actors are doing to encourage health and human security and mitigate morbidity and mortality for a country in a state of full-blown war.

\section{Health Security in Ukraine: A Snapshot of Spring}

The simple numbers put forward in many United Nations (UN) and World Health Organization (WHO) reports, and reiterated by multiple humanitarian and non-regulatory parties such as the Organization for Security Cooperation in Europe (OSCE), the International Committee for the Red Cross (ICRC) and many others, put just over 5.5-6 million people living in violence-affected areas in Ukraine. Extremely conservative estimates based surveys carried out in only selected areas due to security concerns designate roughly one million Internally Displaced People (IDPs), the majority of whom are found in the Kharkiv region which experienced daily city center explosions at governmental and civic locations, assassination attempts against military leaders and multiple improvised explosive devices (IEDs) targeting the courthouse and even the regional hospital during winter and spring. With this, there have been at least 7,300 reported killed and over 17,400 wounded in eastern Ukraine as of $15^{\text {th }}$ February [1]. Many unofficial estimates of the dead are far greater as the fog of war makes record- and data-keeping impossible.

No consistent number has been put forth for the amount of displaced peoples in Russia and other neighboring countries, whether forced or voluntarily, but some estimates assess that between 500,000 to 600,000 have crossed borders and are now in resettlement camps and some private homes.

As with all conflict and mass flows of displaced peoples, health risks increase as access to a paper-based primary healthcare system limits known medical histories, information about allergies, prescription medications' names or dosages. Poor patient knowledge of their own health conditions is rooted in the paternalistic medical system of Ukraine. Children's vaccine records have also been lost and there is no access to basic care while on the run from fighting.

Inconsistent access to prescription medications exacerbates an already growing non-communicable disease (NCD) crisis as many reports by medics and the author of this paper find civilians and medics working in the field are asked for any anti-hypertensive medication for those in chronic crisis, cholesterol lowering medications, injectable insulin and other diabetes type II medications, which have long been cleared off the shelves. And with limited food supplies exacerbating poor medical outcomes and contributing to morbidity and mortality in addition to direct Russian mortar and Grad rocket attacks; the prognosis for human security is very poor. Indeed, NCDs for an ageing population throughout Eastern Ukraine is a major public health risk and concern when not at war, let alone with a breakdown of public serves [2]. Access to pharmaceuticals for diabetes, hypertension and cardiovascular disease in many areas of Luhansk and Donetsk has been entirely disrupted and in most cases, are non-existent.

These and many other issues compound poorly addressed mental health risks for the civilian, military and volunteer defense populations exposed to combat-related stressors. Such stressors can include extended aerial bombardment, not knowing the status of family members, kidnappings, public assassinations, starvation or any number of other lethal acts of violence which occur hourly amid peace talks and ceasefire negotiations that few combatants consistently follow. These acute factors act as major stressors for an already deteriorated health security situation across Eastern Ukraine.

Beyond NCDs is the more acutely-needed emergency medical care in a healthcare system and infrastructure which is not prepared for battlefield trauma. The term "battlefield" relates to all things pre-hospital as hybrid warfare takes place in schools, metros, soccer fields or any other place where local populations and potential targets may gather. Ex-hospital and emergency medical services have depleted to the level that there are only volunteer-based bullet hole-ridden civilian unarmored trucks and scattered ambulances taking patients to hospitals without adequate supplies of medicines, doctors or nurses to staff the ambulances, as all have fled the violence and supplies have been long since exhausted.

As with a majority of human conflict, doctors are seen as pillars of the community offering not only health promotion but also hope and stability. However, in the midst of Russian hybrid warfare, health care professionals serve as soft wartime targets [3]. Violence against healthcare workers was reported during the main street protests in 2014 , including a case where police threw grenades into a makeshift field hospital where medical staff were treating people [4].

\section{Public Health}

Basic services like sewage, running water and heating in healthcare facilities are limited or entirely absent. Surgeons are having to learn on the spot how to treat wartime injuries and basic surgical supplies like c-arm $\mathrm{x}$ ray, portable ultrasound, central venous line access, disposable urinary bladder catheters, chest tubes and abdominal drains are no longer in supply. This significantly limits the capabilities of surgeons and trauma teams to treat all patients presenting signs of battlefield trauma. The Ministry of Health is completely inadequate at providing continuous medical supplies as well as capacity, resources and staffing. It also lacks the flexibility to make quick legislative changes to mitigate these shortcomings institutionally as volunteers and NGOs bang down doors trying to obtain aid and supplies to meet the acute need that is being felt. 
Ukrainian State institutions in and near to battleground activity can provide no health security for the chronically ill, the mentally ill, the disabled, women, the elderly or orphaned children. These highly vulnerable groups are in need of immediate protection, food and access to healthcare services. Many health partners are conducting field missions and assessments while the extreme winter temperatures are just beginning to make way for spring. As a means of mitigating this, a mobile hospital from the Regional Trauma Center based in Lviv, and a military hospital from Odessa have been deployed, with budding capabilities and resources. Most civilian mobile hospitals deployed are volunteer-based, and thus find it difficult to integrate into the governmental communications, procurement and staffing systems within the Ministry of Defence, let alone to get any protection when rocket attacks commence.

The Ukrainian government has requested a mobile hospital from United States State Department and the Californian Emergency Medical Services Authority (EMSA), which is run by US Federal Disaster Medical Assistance Teams (DMATs). Another promised NATO-based Role II medical facility is also in development, provided by the US Air Force to give medical care to all patients in need before shipping them to a safer location for further medical care. One of the main issues in sending such a major medical asset to support military operations and the civilian population is that the Ukrainian institutional capacity is lacking and may not be a viable partner to manage and run such a medical asset sustainably. Much work remains to be done to aid further non-lethal medical aid and mutual aid requested by Ukraine, Ukrainians and all those caught in the middle of fighting. In late April and early May 2015, NATO led an institutional- and policy-supporting conference for the Ministries of Defense and Health to support its Role II care of soldiers and civilians caught in the crossfire. Many NATO countries' military experts and policy advisors attended the conference. Unfortunately, fatally corrupt ministries and internal politics prevented any constructive moves at the conference to find workable solutions to the pre-hospital dearth of resources and public health crisis that plagues Eastern Ukraine.

\section{Humanitarian Financial Crisis}

Financial concerns at the Ministry of Health $(\mathrm{MoH})$ have become more pressing, and this holds true also for many other services providing health security to Ukrainians. The internal rot of corrupt procurement systems has led to institutional demise with criminal levels of incompetence. Reform of Ukraine's healthcare delivery system to change it from one based on Soviet-style secondary care to a primary care-based one able to tackle the mortality and morbidity crisis in the country is acutely necessary and still lacking to a point of enemy intent [5].

At the eleventh hour, the World Bank (WB) UnderDirector Paolo Belli, pushed forward many capacitybuilding programs to help bolster the healthcare systems on both the long and short term in late 2014. In early March 2015, the WB approved a US\$214.73 million loan for the Serving People, Improving Health Project to support the implementation of reforms and improve service delivery in Ukraine's health sector [6]. The new WB five-year project will seek to develop medical infrastructure and improve the quality of health services with the help of a new funding mechanism within hospitals, as well as enhanced primary and secondary prevention, early detection, and treatment of cardiovascular diseases and cancer. It is also expected to improve first aid and emergency services [6].

In mid February 2015, the International Monetary Fund (IMF) released plans for approximately US\$17.5 billion from itself and the international community to be allocated to stabilizing the Ukrainian economy. This financial injection will be a great boost for an economy where surgeons are instead taking jobs as taxi drivers because the state currency, the Hryvna (UAH), has fallen precipitously with no sign of wage increases to compensate. The IMF's Director commented, "Of course, resolution of the conflict, so critical for people, would also strengthen and speed up prospects for macroeconomic stabilization and growth" [7]. This needed growth will also bolster human and health security for those presently caught in the middle of fighting.

\section{Infectious Disease: Old Threats and New Risks}

Ukraine is not an endemic zone for infectious diseases. However, access to essential vaccines for flu, routine pediatric vaccinations like polio, tetanus and in some areas measles, are at very low levels or even entirely unavailable with local bureaucracy one barrier and the limited access of the primary healthcare setting another. With this, the Ukrainian health system was weak before the crisis and is now on the verge of collapse in areas affected by combat, areas with high IDP loads, and regions requiring surge capacity and resilience to disruption of service delivery from the human security crisis.

The average vaccination coverage in the country for some diseases is well under $40 \%$ [8]. In some regions and communities most children have not been vaccinated at all during the past months. Therefore, outbreaks of polio and measles are likely throughout the summer of 2015. About 30 to $70 \%$ of healthcare workers have fled the combat areas or died, so health care has broken down and no supplies are available to replenish stocks.

As access to Luhansk and parts of Donetsk is not verified. Due to the recent law that limits Ukraine's support to the Donbas region, many people living there are deprived of healthcare services. Reports about civilian casualties from Debaltseve are still pending, but since the beginning of the conflict in mid-April 2014 and until 19 February 2015, at least 5,793 people (including 63 children) were killed and 14,595 (including 169 children) were wounded in the east of Ukraine [9,10].

During the second half of 2014, given the large population displacement and the lowest immunization coverage 
in Europe, Ukraine is at high risk of communicable disease outbreaks, especially among children. As the result of a financial deficit, an ineffective procurement system and the crisis, the government tender process for procurement of vaccines for 2014 in Ukraine has not been fully implemented. Regional stocks of vaccines have already been exhausted.

With further delays in procurement, the gap in vaccine supply is expected to continue. For a long period, UNICEF and WHO have been working with the authorities to improve all pillars of the immunization management system. At the time of writing, the Ministry of Health, together with UNICEF and WHO, and supported by the Governments of Canada and the USA, are in the process of filling some of the gaps by procuring polio vaccines. Draft Laws 2150 and 2151 pertaining to this topic were registered at the Verkhovna Rada of Ukraine on 17 February. These laws will allow state procurement of medicines and vaccines to be delegated to UNICEF and WHO [9].

The HIV/AIDS epidemic in Ukraine is one of the fastest growing in the world.Moreover, according to WHO, Ukraine is among the 27 highest multidrug-resistant tuberculosis (MDR-TB) burden countries in the world. Despite the adoption of the Stop TB Strategy by the National TB Programme (NTP), its components have not been sufficiently implemented. Financing of TB control activities mainly depends on the commitment and capacity of each oblast health administration. Laboratory capacity is limited and case detection efforts mainly focus on mass screenings of the general population.

Priority is given to hospital-based treatment and appropriate treatment depends on the local capacity to purchase the drugs. Provision of directly observed therapy (DOT) is lacking and patient support is limited. MDR-TB control activities are inadequate, as are efforts to address TB/HIV co-infection. There is a lack of anti-TB drugs in the country because of inadequate drug supply management and problems with the procurement of quality-assured drugs. The recording and reporting system is suboptimal, and expansion of the application software for a nominal electronic database is slow.

\section{Health Systems Affected}

The ongoing crisis has had a direct effect on the health of the population, resulting in trauma, including injuries and burns. Adequate emergency medical services, including well equipped ambulances, trained first-aid personnel and health workforce, intensive care facilities, surgeries and burns units, as well as medications and consumables, are insufficient and making them immediately available is a top priority [11].

Needless to say, in late November an OCHA report commented that the humanitarian community remains deeply concerned by the Ukrainian Government's announcement that all governmental services and personnel will be withdrawn from areas controlled by armed groups by 1 December (Decree 875/2014). The fear that this edict will worsen the humanitarian disaster unfolding in hard-toreach conflict areas controlled by armed groups is apparent. The health security of civilians is at great risk, with circumstances compounding the problems of a public health system already bursting at the seams.

As the Russian Ruble spirals out of control, the Ukrainian Hryvna is not far behind. This means that funds needed to buy food, and pay for heating supplies and essential medicines are not guaranteed-and in many areas entirely blocked. Moreover, the National Bank of Ukraine has worsened the crisis by closing down many of its operations and services in the East, which has caused disruption of state-funded pensions and disability payments.

\section{Improving Coordination}

These issues, among many others, threaten health security throughout Ukraine. But they are not new and have been tackled with varying degrees of success by government ministries, the humanitarian sector, and the many new volunteer groups which have appeared since the onset of violence and the decay of social order in Ukraine. As has been seen in many humanitarian disasters and public health catastrophes, many actors have immediately made efforts to address some of the numerous health-related shortcomings in health security. Such actors include international non-governmental organizations (INGOs), government bodies and ministries, loosely affiliated stakeholders and independent actors, but such fragmented efforts have led to a situation where many organizations are doing much the same thing with minimal benefit.

Due to security concerns, access to Donetsk and Luhansk is extremely limited, which in turn limits access for donors and organizations and minimizes their effectiveness. Due to the political and financial nature of donorbased organizations which provide medical care, technical assistance and other forms of direct emergency aid, their efforts are hampered by the factions imposing violence in these regions. In order to access these regions, organisations are confronted with Ukrainian Government forces and volunteer battalions (as of spring 2015 almost all volunteer units have been absorbed into Ukraine MoD) loosely loyal to them (but answerable only to their benefactors), separatists and Russian or Russian-backed troops.

Of course, no war is clear-cut with easy distinctions between sides and combatants, or which acts of violence are acceptable and which are not. The war in Ukraine is no different. OSCE has done a fine job of observing this violence but its representatives may be compromised in many locations as the Russian Federation is a member of OSCE and as Russia is not an official actor in the violence and conflict in Ukraine many of the Russian-speaking representatives of the OSCE in Ukraine are in fact loyal to Moscow.

The precarious security situation has led to stove-piped programs and the presence of multiple actors who are unwilling to communicate and share information and data 
across organizational boundaries. This duplication of aid sees two or more organizations at addressing the region's immediate needs based on information that may be dated or one-sided and politically- or financially-motivated.

An example of such a problem was seen in late August 2013, when fighting was escalating daily and many combatant and civilian deaths were being reported across the regions (oblasts) of Eastern Ukraine. To provide support for emergency medical aid, ICRC, WHO, International Medical Corps (IMC), Doctors Without Borders, local oligarchs from both sides and various other INGOs started to send everything from boots to diapers to first-aid kits of varying quality, as well as offering medical support to perfectly well functioning medical care facilities (MCFs). The resource- and labor-intensive acts of acquiring medical equipment both inside and outside of Ukraine, sending it to high-conflict areas with security-approved convoys, and offering a greater or lesser degree of training or inservice on newly offered equipment costs are logarithmic and were being duplicated.

Due to this, WHO, supported by OCHA, established the Health Sector in February 2014, and since then has been providing leadership and coordination to support both national and local health authorities in Ukraine. Moreover, WHO has been coordinating the collection, analysis, dissemination and communication of essential information on health risks, health needs and health sector responses, gaps and performance.

Despite there being more than 50 registered partners in the Health Cluster, only a limited number are actually providing assistance. WHO provides technical assistance appropriate to the health needs of the emergency (including the provision of health policy and strategy advice; promotion of expert technical guidelines, standards and protocols; best practice advice and implementation; and strengthening of disease surveillance and disease early warning systems). In order to provide this, WHO/Health Cluster flagship interventions include the Mobile Emergency Primary Health Care Units (MEPUs), Emergency Primary Health Care Posts (EPPs) and the provision of medicines. Donor funds that are provided to $\mathrm{WHO}$ are divided among the partners (e.g. The Ukrainian Red Cross, IMC). Moreover, WHO provides the core services for the Health Cluster (e.g logistics; the establishment of offices; surge and human resources management; procurement and supply management; administration, finance and grant management; support service delivery; inform HCT decision-making; planning and strategy development; and monitoring and reporting).

There are reports of Intensive Care Unit (ICU) ventilators and technical equipment being sent to functioning ICUs in Luhansk, small clinics and hospitals receiving the same first aid kits and incompatible medical supplies from disparate sources and medical teams arriving from abroad to the ATO offering surgical expertise in areas with an abundance of foreign-trained Ukrainian master surgeons in need of advanced surgical and diagnostic equipment, not expertise.

For example, the many peripheral injuries that occur with blast and sniper fire trauma require in-theater c-arm radiology capability, which doesn't exist in the ATO or in many areas throughout Ukraine, leading to external fixation of open fractures, which produces poor medical outcomes. The duplication of these services and support is not only a waste of valuable resource, it also shows that the international medical and health security response for the crisis is fragmented, poorly organized throughout and not unified in approach or goals.

This was no different with training initiatives for medical capacity building. Throughout Mariupol, Luhansk and Donetsk multiple teams heading to clinics and regional medical centers found that other local and international organizations had already been there, offering different levels of equipment and conflicting best practices in training. Sometimes groups arrive or depart within days of each other. This duplication does not help with capacity and it disrupts local operations and drains valuable resources with no stop-loss mechanisms.

In an effort to eliminate this duplication of basic and advanced emergency medical training for civil and defense forces, wealthy oligarchs have stepped-in to fill some gaps. Ukrainian patriots and philanthropists Elena and Viktor Pinchuk funded a Combat Medic program Medsanbat (medsanbat.info). This training system raises the medical standards in pre-hospital medicine for the military, volunteer battalions, police, trauma surgeons and emergency doctors in civilian hospitals, clinics and ambulances, the border guards and police and local civic volunteers helping regional humanitarian actors carry out their mission. The medical standards are rooted in North American prehospital and military medicine and follow the Tactical Combat Casualty Care (TCCC) guidelines and trauma protocols from Advanced Trauma Life Support (ATLS) and International Trauma Life Support (ITLS) for the very specific injuries caused by war and civilian healthcare support activities; many of them not seen by Ukrainian surgeons and physicians since World War II or while deployed to Iraq in 2004 to 2005.

Duplication has also been seen among the many volunteer and professional groups appearing and trying and teach the above-mentioned clinical standards. However, not all groups have the clinical and operational experience to provide and offer training and instruction based on any battlefield experience, knowledge of best practices for trauma or in experience dealing with conflict zones. However, in the pre-hospital medical community, the overriding conclusion is that in times of war and acute conflict any training that can be offered, even if it is sub-standard, is certainly better than none. Despite this, sometimes the message is mixed; if clinical standards are not communicated, negative health outcomes can ensue. The need for a standardized approach is acute. 


\section{WHO Can Fix It}

The unified health leadership necessary to reign in outlier organizations and actors and collate goals and activities to promote health security for eastern Ukraine is lacking. However, Dr. Dorit, the WHO Director for Ukraine and a fast and efficient health operator, quickly identified some of this duplication and pushed $\mathrm{WHO}$, as the leading organization, to move all health and medical related actors under its umbrella organisation.

This was first done in late summer of 2014, while many uncertainties of the conflict and the true needs were still being described and defined through ad hoc and weekly health sector meetings. These meetings were held with members of the Ministry of Health's Headquarters for Health in Emergencies (e.g. Schtab). However, poor collaboration and only tacit support from the Ministry of Health remained a barrier; endemic corruption and a drowning bureaucracy were overwhelmingly stifling the health security for the strangled population in the East.

Despite these challenges, Dr. Dorit and her team were able to promote emergency legislation to deliver polio and tetanus vaccines to the East where at the time emergency supplies had been depleted. Furthermore, despite the ongoing humanitarian crisis, access to pharmaceuticals ran up against further obstacles in the form of bureaucratic processes. With help from UNICEF, WHO has supported the Coalition Agreement of Parliamentary Fractions enabling reform to the preexisting system of procurement of medicines according to European standards and principles (procurement of vaccines and medicines directly from the manufacturer).

2015 will be a transitional year in terms of reform procurement funded by the state budget and to purchasing medicines and vaccines through international agencies, such as WHO and UNICEF [12]. Additionally, the Ukrainian Cabinet of Ministers is preparing changes to the Decree on Pharmaceuticals to support recognition of medicines from countries with strong regulatory bodies including Australia, Canada, Israel, Japan, the United States and the European Union.

Dr. Dorit was also able to liaise with many regional and local healthcare facilities with exhausted supplies in Donetsk, Luhansk, and especially Mariupol before the onslaught of Russian tanks as the deadly offensive struck and the city fell under seige. However, escalation of the conflict and violence also meant that WHO had to escalate its response, organization and structure. Therefore, Dr. Dorit upgraded the Health Sector to the Health Cluster in order to strengthen response and support.

WHO has identified great gaps exist in terms of access to treatment for non-communicable diseases (NCDs), to pharmaceuticals and to ongoing care such as insulin, dialysis consumables, blood transfusions and primary and many emergency care medicines and supplies in hospitals, especially those with high concentrations of IDPs. To improve the capacity of the Ukrainian Ministry of Health to deal with the humanitarian crisis, WHO helped encourage the formation of the Department of Public Health which will be responsible for surveillance and action programs to address many of the aforementioned health security risks and shortcomings of the current system.

At a very practical level, $\mathrm{WHO}$ is providing the Dnipropetrovsk, Donetsk, Luhansk, Kharkiv, and Zaporizhzhia regions with Inter-agency Emergency Health Kits and is overseeing reproductive health kits issued for many regions. To be closer to the affected area, the WHO Field Coordinator established the main WHO Field Office in Kharkiv with the next to be set up in Mariupol and health assessments in the Izum and Kharkiv areas ongoing in order to identify their needs. Mobile Emergency Primary Health Care Unit (MEPU) teams are being recruited through the Ukrainian Red Cross and IMC in order to provide mobile primary healthcare services to IDPs and populations left without access.

Lastly, the WHO led Humanitarian Response website aims to streamline information sharing among the humanitarian community in Ukraine. It is easy to navigate and provides useful overviews of contacts, events/meetings, key documents, maps, infographics, statistics and other operational data that can help mitigate the duplication of services offered, focus activity in those areas with the greatest need, and help communication with governmental agencies and humanitarian actors.

For now, the most likely development for Russia is continued economic decline, with the main uncertainty centered on the effects the economic crisis will have on both Russian actions in Ukraine and on domestic stability [13].

\section{Disclaimer}

The author of this paper has conducted a Health Assessment for the Ukrainian World Congress in Summer of 2014 and is currently a Medical Consultant for Medsanbat. Much of the information gathered in this report is based on official and unofficial health data discussed and relayed by Dr. Dorit and her team at WHO, first-hand experience in the field, and other medical and health actor contacts throughout eastern Ukraine. The views expressed here are those of the author and do not necessarily reflect the views of any sources or governmental or non-governmental bodies or agencies, past, present or future.

\section{The Author}

John Quinn is a medical consultant specializing in conflict, disaster and emergency medicine. He holds Masters Degrees in Public Health and is both a paramedic and emergency medical doctor with over 15 years experience in Chicago, Peru, Iraq, Timor-Leste and Ukraine.

He designed, implemented and directed a telemedicine program for medical evacuation at an emergency operations center in Amman, Jordan; has performed emergency medical impact assessments in Ukraine, Israel and Pales- 
tine, Iraq, Kurdistan and Timor-Leste and has set up and operated remote medicine clinics in other conflict zones. $\mathrm{He}$ is currently completing his $\mathrm{PhD}$ in Hygiene and Epidemiology of fragile and failed states (2015). He worked as an emergency physician at a Level One Trauma Center in Ireland and as a locum physician in emergency depart-

\section{References}

[1] UN Human Rights Monitoring Mission in Ukraine and the World Health Organization's conservative estimates based on available official data. These totals include: Ukrainian armed forces casualties as reported by the Ukrainian authorities; 298 people from flight $\mathrm{MH}-17$; casualties reported by civil medical establishments and local administrations of Donetsk and Luhansk regions: and civilians and some members of armed groups (without distinguishing them). $\mathrm{OHCHR}$ and $\mathrm{WHO}$ believe that actual fatality numbers are considerably higher.

[2] Luck J, Peabody JW, DeMaria LM, Alvarado CS, Menon R. Patient and provider perspectives on quality and health system effectiveness in a transition economy: Evidence from Ukraine. Social Science \& Medicine. 2014;114:57-65.

[3] Quinn J, Mensah E, Hnillicova H, Bencko V. Iraqi Physician Brain Drain in Prolonged Conflict. The New Iraqi Journal of Medicine. 2011;7(1):88-98.

[4] Holt E. Health professionals targeted in Ukraine violence. The Lancet. 2014;383(9917):588.

[5] Hankivsky O, Vorobyova A. Health Care Delivery System: Ukraine. In: The Wiley Blackwell Encyclopedia of Health, Illness, Behavior, and Society. Wiley Blackwell; 2014. pp. 889-894.

[6] World Bank Provides Support for a Health- ments throughout the UK and Ireland. Dr. Quinn presently works between Eastern Ukraine and Iraq, providing emergency medical consulting and training in Tactical Combat Casualty Care and emergency medicine mentorship to local physicians. He is based in Prague with his family.

ier Ukraine. World Bank; 2015. Available from: http://www.worldbank.org/en/news/pressrelease/2015/03/04/world-bank-provides-supportfor-a-healthier-ukraine.

[7] Lagarde C. Statement by IMF Managing Director Christine Lagarde on Ukraine. Brussels, Belgium: International Monetary Fund; 2015. Available from: https:/www.imf.org/external/np/sec/pr/ 2015/pr1550.htm.

[8] Holt E. Health care collapsing amid fighting in east Ukraine. The Lancet. 2015;385(9967):494.

[9] Eurdolian A, Porter Z. Ukraine, Situation Report 28. United Nations Office for the Coordination of Humanitarian Affairs (OCHA); 2015.

[10] This is a conservative estimate from the UN Human Rights Mission in Ukraine (HRMU) and World Health Organization based on available official data.

[11] Center UMC. John Quinn: With the right training and equipment many lives of the soldiers could be saved;. Available from: http://uacrisis.org/9278-john-quinn.

[12] Porter Z. Ukraine, Situation Report 21. United Nations Office for the Coordination of Humanitarian Affairs (OCHA); 2014.

[13] Mankoff J, Kuchins A. Russia, Ukraine, and U.S. Policy Options: A Briefing Memo. Center for Strategic and International Studies; 2015. Available from: http://csis.org/files/publication/150129_Mankoff_ RussiaUkraineUSOptions_Web.pdf. 


\title{
Educational Pathways to Remote Employment in Isolated Communities
}

\author{
David Denkenberger ${ }^{1,2}$, Julia Way ${ }^{1,3}$ and Joshua M. Pearce ${ }^{1,4,5 *}$ \\ ${ }^{1}$ Michigan Tech Open Sustainability Technology (MOST) Lab, Michigan Technological University, MI, USA \\ ${ }^{2}$ Civil and Architectural Engineering, Tennessee State University, Nashville, TN, USA \\ ${ }^{3}$ Career Development Education, Michigan Tech Career Services, Michigan Technological University, MI, USA \\ ${ }^{4}$ Department of Materials Science \& Engineering, Michigan Technological University, MI, USA \\ ${ }^{5}$ Department of Electrical \& Computer Engineering, Michigan Technological University, MI, USA
}

* Corresponding author: E-Mail: pearce@mtu.edu; Tel.: +1 906-487-1466

Submitted: 4 May 2015 | In revised form: 4 August 2015 | Accepted: 25 August 2015 |

Published: 29 September 2015

\begin{abstract}
Those who live in isolated communities often lack reliable, skilled employment opportunities, which fundamentally undermines their human security. For individuals who wish to remain in their isolated communities for family, religious, philosophical or other reasons, their attachment to their communities creates a disincentive for higher education. This promotes low educational achievement, which in turn results in low socioeconomic status, lack of social mobility, and a generational cycle of poverty. The human misery that results from such a feedback loop is observed in isolated communities throughout North America, including aboriginal communities in Canada. Fortunately, maturation of information and communication technologies now offers individuals the potential to gain high-skilled employment while living in an isolated community, using both (i) virtual work/remote work and (ii) remote training and education. To examine that potential, this study: 1) categorizes high-skill careers that demand a higher education and are widely viable for remote work, 2) examines options for obtaining the required education remotely, and 3) performs an economic analysis of investing in remote education, quantifying the results in return on investment. The results show that the Internet has now opened up the possibility of both remote education and remote work. Though the investment in college education is significant, there are loans available and the return on investment is generally far higher than the interest rate on the loans. The results identified several particularly promising majors and dozens of high-income careers. The ability to both obtain an education and employment remotely offers the potential to lift many people living in isolated communities out of poverty, reduce inequality overall, and provide those living in isolated communities with viable means of employment security, which not only allows personal sustainability, but also the potential for personal growth.
\end{abstract}

Keywords: distance education; distributed work; employment; ICT; isolated communities; jobs; job security; remote work; telework 


\section{Introduction}

A reliable form of employment is currently one of the central tenets of human security [1-5]. Lack of employment opportunities leads to extreme poverty of indigenous people living in isolated communities throughout the world including the Pacific [6], former British colonies [7], and the Americas, Australasia, South East Asia, Europe, and Russia [8]. In addition, a poverty of opportunities exists in isolated communities even within well-developed nations for common citizens like those in the United States. For example, in the upper peninsula of Michigan, during the last recession, unemployment rates topped $25 \%$ [9], and the undercounting of unemployment in the U.S. is well established $[10,11]$. Education is important for ending a poverty of opportunity, as it is critical for self-empowerment and increasing the prospects of employment, higher wages, and social mobility [12-15]. For individuals who wish to remain in their isolated communities for family, religious, philosophical, or other reasons, often there are simply not enough jobs with living wages available. For example, in Canada, all Aboriginal identity groups have substantially lower incomes than the general population [16], and their attachment to their communities creates poor incentive for higher education, thus promoting low educational achievement, which, in turn, results in low socioeconomic status [17]. For the young people committed to staying in their isolated communities for personal reasons, if there are few (or no) jobs that require higher education, there is no incentive for them to obtain this education and the cycle of poverty continues generationally.

Fortunately, maturation of information and communication technologies now offers the potential to gain highskilled employment through remote work (also called telework, virtual work, or distributed work) [18-37]. This allows individuals to have rewarding and high compensation employment while living in an isolated community. In addition, online and distance education enable the ability to acquire a vast array of types of training and education remotely [38-50]. By coupling these two Internet-enabled opportunities, a complete solution of employment in an isolated region is possible. There have been many studies of online education (e.g. [38-51]) and remote work (e.g. [18$37,52]$ ), as well as studies about the general advantages of extending Internet into remote areas (e.g. [53]). However, this study is unique in that it explores the interaction of online education and remote work as a complete package for people in isolated communities who do not wish to relocate.

To examine the potential of distance learning and remote work to enable secure employment for individuals in isolated communities, this study: 1) categorizes high-skill careers that demand a higher education, which are widely viable for remote work and 2) examines options for ob- taining the required education remotely. The results are discussed and conclusions are drawn to help guide policy makers and educators in providing isolated communities with viable means of employment security.

\section{Methods}

A list of careers was generated and categorized that represented high-skill careers that require a higher education. Only permanent jobs were considered, as opposed to the typically temporary unskilled jobs that are frequently found on digital freelance websites (e.g. Freelancer, Fiverr, FlexJobs, Elance, Guru and oDesk). This list was then reduced by eliminating all career paths that could not be accomplished remotely because of physical/hands-on curriculum requirements. The list was further refined to jobs for which the education needed to complete them could be found remotely with existing universities requiring a fouryear degree. Finally, the list was further refined by eliminating all jobs with a sinking market due to technology (e.g. journalists, translators, legal assistants, and travel agents) and jobs that were highly competitive (e.g. authors and artists), as a career could not be reasonably guaranteed having completed a degree. Then the list was matched with the top affordable online universities in the U.S. by degree type [54]. Next, the total degree cost was calculated assuming 120 credit hours and 4 years (accreditation policies) [55-58], though not taking into account university associated fees. Each career was matched with tuition cost, wage, and accreditation, and is shown in Table 1. All monetary values are given in USD. The data from Tables 1 and 2 are used to determine the economic benefits of obtaining a university degree remotely that would enable one to work remotely. The estimates are conservative, as they assume that the student is only attending to their education full- time and avoiding all high-school diploma level work while earning their degree. The opportunity cost (foregone wages during college) is assumed to be at the mean wage for high school wages for ages 18 to 24 : about $\$ 23,000$ in the U.S. [59], which again is a conservative assumption, as most entry level workers do not receive this wage. Over the 4 years of college, this results in $\$ 92,000$ of opportunity cost. This is larger than any of the tuition costs considered as seen in Table 1. In most cases, the very simple analysis of return on investment equaling the reciprocal of the payback time yields a reasonable approximation. However, a rigorous, full cash flow analysis is more accurate. This is performed assuming a $2 \%$ per year raise due to experience, and a $2 \%$ per year raise due to economic growth (adjusted for inflation). This is applied to the high school wage as well, which currently has a median of $\$ 33,000$ per year for all working ages [60] and the mean is 1.2 times larger [59]. 
Table 1. Careers from Table 2 with tuition, wage, and accreditation (USD).

\begin{tabular}{|c|c|c|c|}
\hline Career & Total tuition cost & Wage $\left(\$ \mathrm{yr}^{-1}\right)$ & Accreditation \\
\hline Architect & $\$ 69,840[61]$ & $\$ 78,640[62]$ & $\begin{array}{l}\text { Commission on Colleges of the Southern Association of Colleges } \\
\text { and Schools }\end{array}$ \\
\hline Psychologist & $\$ 47,760[63]$ & $\$ 75,790[62]$ & Higher Learning Commission \\
\hline Radiologic Technologists & $\$ 51,600[64]$ & $\$ 57,510[62]$ & Higher Learning Commission \\
\hline Accountant & $\$ 11,560[65]$ & $\$ 69,790[62]$ & Northwest Commission on Colleges and Universities \\
\hline Financial Analysts & $\$ 54,480[66]$ & $\$ 92,250[62]$ & Higher Learning Commission \\
\hline Advertising Sales Agents & $\$ 54,480[66]$ & $\$ 60,910[62]$ & Higher Learning Commission \\
\hline PR representative & $\$ 54,480[66]$ & $\$ 64,050[62]$ & Higher Learning Commission \\
\hline Market researcher & $\$ 54,480[66]$ & $\$ 68,700[62]$ & Higher Learning Commission \\
\hline Brokerage Clerk & $\$ 54,480[66]$ & $\$ 50,780[67]$ & Higher Learning Commission \\
\hline Personal Financial Advisors & $\$ 54,480[66]$ & $\$ 108,090[62]$ & Higher Learning Commission \\
\hline Inventory controller & $\$ 54,480[66]$ & $\$ 93,180[68]$ & Higher Learning Commission \\
\hline $\begin{array}{l}\text { Business Operations Specialists, } \\
\text { Other }\end{array}$ & $\$ 54,480[66]$ & $\$ 73,000[62]$ & Higher Learning Commission \\
\hline Sales Managers & $\$ 54,480[66]$ & $\$ 126,040[62]$ & Higher Learning Commission \\
\hline Real Estate Sales Agents & $\$ 54,480[66]$ & $\$ 55,530[62]$ & Higher Learning Commission \\
\hline $\begin{array}{l}\text { Securities, Commodities, and } \\
\text { Financial Services Sales Agents }\end{array}$ & $\$ 54,480[66]$ & $\$ 103,260[62]$ & Higher Learning Commission \\
\hline Insurance Sales Agents & $\$ 54,480[66]$ & $\$ 63,730[62]$ & Higher Learning Commission \\
\hline Managers, All Other & $\$ 54,480[66]$ & $\$ 110,210[62]$ & Higher Learning Commission \\
\hline Event planner & $\$ 54,480[66]$ & $\$ 50,910[62]$ & Higher Learning Commission \\
\hline Tax preparer & $\$ 54,480[66]$ & $\$ 43,870[62]$ & Higher Learning Commission \\
\hline Meteorologist & $\$ 51,600[64]$ & $\$ 88,090[69]$ & Higher Learning Commission \\
\hline Drafters & $\$ 44,040[70]$ & $\$ 54,850[62]$ & $\begin{array}{l}\text { Commission on Colleges of the Southern Association of Colleges } \\
\text { and Schools }\end{array}$ \\
\hline $\begin{array}{l}\text { Software Developers and } \\
\text { Programmers }\end{array}$ & $\$ 44,040[70]$ & $\$ 95,280[62]$ & $\begin{array}{l}\text { Commission on Colleges of the Southern Association of Colleges } \\
\text { and Schools }\end{array}$ \\
\hline Civil Engineers & $\$ 44,040[70]$ & $\$ 87,130[62]$ & $\begin{array}{l}\text { Commission on Colleges of the Southern Association of Colleges } \\
\text { and Schools }\end{array}$ \\
\hline Designers, All Other & $\$ 44,040[70]$ & $\$ 55,360[62]$ & $\begin{array}{l}\text { Commission on Colleges of the Southern Association of Colleges } \\
\text { and Schools }\end{array}$ \\
\hline Fashion Designers & $\$ 40,560[71]$ & $\$ 73,690[62]$ & Middle States Commission on Higher Education \\
\hline Editor & $\$ 40,560[71]$ & $\$ 64,140[62]$ & Middle States Commission on Higher Education \\
\hline Technical writer & $\$ 40,560[71]$ & $\$ 71,950[62]$ & Middle States Commission on Higher Education \\
\hline Graphic designer & $\$ 40,560[71]$ & $\$ 50,670[62]$ & Middle States Commission on Higher Education \\
\hline Film and Video Editors & $\$ 40,560[71]$ & $\$ 75,090[62]$ & Middle States Commission on Higher Education \\
\hline Publicist & $\$ 40,560[71]$ & $\$ 68,700[62]$ & Middle States Commission on Higher Education \\
\hline Statistician & $\$ 44,040[70]$ & $\$ 84,010[62]$ & $\begin{array}{l}\text { Commission on Colleges of the Southern Association of Colleges } \\
\text { and Schools }\end{array}$ \\
\hline Budget Analysts & $\$ 44,040[70]$ & $\$ 73,940[62]$ & $\begin{array}{l}\text { Commission on Colleges of the Southern Association of Colleges } \\
\text { and Schools }\end{array}$ \\
\hline Actuary & $\$ 44,040[70]$ & $\$ 110,090[62]$ & $\begin{array}{l}\text { Commission on Colleges of the Southern Association of Colleges } \\
\text { and Schools }\end{array}$ \\
\hline Computer scientist & $\$ 22,380[72]$ & $\$ 113,190[73]$ & Higher Learning Commission \\
\hline Information Security Analysts & $\$ 22,380[72]$ & $\$ 91,600[62]$ & Higher Learning Commission \\
\hline Game developer & $\$ 22,380[72]$ & $\$ 69,410[74]$ & Higher Learning Commission \\
\hline Software Developers, Applications & $\$ 22,380[72]$ & $\$ 99,530[62]$ & Higher Learning Commission \\
\hline $\begin{array}{l}\text { Software Developers, Systems } \\
\text { Software }\end{array}$ & $\$ 22,380[72]$ & $\$ 106,050[62]$ & Higher Learning Commission \\
\hline
\end{tabular}


Table 2. Major, career, and example online college.

\begin{tabular}{|c|c|c|}
\hline Type & Career & Example Source of Remote Education \\
\hline Architecture Major & Architect & University of Virginia \\
\hline Biological Sciences Major & Psychologist & Ohio Christian University \\
\hline Biological Sciences Major & Radiologic Technologists & University of Phoenix \\
\hline Business Major & Accountant & Western Governors University \\
\hline Business Major & Financial Analysts & Eastern New Mexico University \\
\hline Business Major & Advertising Sales Agents & Eastern New Mexico University \\
\hline Business Major & $\mathrm{PR}$ representative & Eastern New Mexico University \\
\hline Business Major & Market researcher & Eastern New Mexico University \\
\hline Business Major & Brokerage Clerk & Eastern New Mexico University \\
\hline Business Major & Personal Financial Advisors & Eastern New Mexico University \\
\hline Business Major & Inventory controller, & Eastern New Mexico University \\
\hline Business Major & Business Operations Specialists, All Other & Eastern New Mexico University \\
\hline Business Major & Sales Managers & Eastern New Mexico University \\
\hline Business Major & Real Estate Sales Agents & Eastern New Mexico University \\
\hline Business Major & Securities, Commodities, and Financial Services Sales Agents & Eastern New Mexico University \\
\hline Business Major & Insurance Sales Agents & Eastern New Mexico University \\
\hline Business Major & Managers, All Other & Eastern New Mexico University \\
\hline Business Major & Event planner & Eastern New Mexico University \\
\hline Business Major & Tax preparer & Eastern New Mexico University \\
\hline Earth Sciences Major & Meteorologist & University of Phoenix \\
\hline Engineering Major & Drafters & University of Southern Mississippi \\
\hline Engineering Major & Software Developers and Programmers & University of Southern Mississippi \\
\hline Engineering Major & Civil Engineers & University of Southern Mississippi \\
\hline Engineering Major & Designers, All Other & University of Southern Mississippi \\
\hline Liberal Arts Major & Fashion Designers & Wilmington University \\
\hline Liberal Arts Major & Editor & Wilmington University \\
\hline Liberal Arts Major & Technical writer & Wilmington University \\
\hline Liberal Arts Major & Graphic designer & Wilmington University \\
\hline Liberal Arts Major & Film and Video Editors & Wilmington University \\
\hline Liberal Arts Major & Publicist & Wilmington University \\
\hline Mathematics Major & Statistician & University of Southern Mississippi \\
\hline Mathematics Major & Budget Analysts & University of Southern Mississippi \\
\hline Mathematics Major & Actuary & University of Southern Mississippi \\
\hline Technology Major & Computer scientist & Fort Hays State University \\
\hline Technology Major & Information Security Analysts & Fort Hays State University \\
\hline Technology Major & Game developer & Fort Hays State University \\
\hline Technology Major & Software Developers, Applications & Fort Hays State University \\
\hline Technology Major & Software Developers, Systems Software & Fort Hays State University \\
\hline
\end{tabular}

The payback time, in combination with how long the increased income stream lasts in time, $\mathrm{T}$ (years), can be converted to a return on investment with a return, $R$ [75]:

$$
\frac{P}{S}=\frac{\left(1-e^{-R T}\right)}{R}
$$

where $P$ is the principal investment, $S$ is the savings per year, and $\frac{P}{S}$ is the working time to payback the investment. For instance, with a career length of 40 years and a payback time of 15 years, the ROI would be about $6 \%$. Assuming that the increased income is actually adjusted for inflation, meaning that the income without the higher education rises with inflation, and the income with the higher education rises with inflation, this ROI is actually adjusted for inflation. If this investment is compared in nominal terms (e.g. not adjusted for inflation) it would be closer to an $8 \%$ return on investment, which is normally considered excellent.

\section{Results}

The payback analysis is summarized in Table 3 . For the short payback times, the rigorous method yields lower returns on investment because the fact that there is a delay between the invested money and getting a return becomes more important. However, for long payback times, the rigorous analysis gives a higher return. This is because economic growth becomes significant over these longer times. 
Table 3. Career, payback time, and simple and rigorous return on investment.

\begin{tabular}{|c|c|c|c|}
\hline Career & Payback time (yr) & Simple Return on Investment & Rigorous Return on Investment \\
\hline Architect & 4.2 & $24 \%$ & $19 \%$ \\
\hline Psychologist & 3.9 & $26 \%$ & $20 \%$ \\
\hline Radiologic Technologists & 8.1 & $12 \%$ & $13 \%$ \\
\hline Accountant & 3.5 & $29 \%$ & $22 \%$ \\
\hline Financial Analysts & 2.8 & $36 \%$ & $24 \%$ \\
\hline Advertising Sales Agents & 6.9 & $14 \%$ & $14 \%$ \\
\hline PR representative & 6 & $17 \%$ & $15 \%$ \\
\hline Market researcher & 5.1 & $20 \%$ & $17 \%$ \\
\hline Brokerage Clerk & 13.4 & $7 \%$ & $10 \%$ \\
\hline Personal Financial Advisors & 2.1 & $47 \%$ & $29 \%$ \\
\hline Inventory controller & 2.7 & $36 \%$ & $25 \%$ \\
\hline Business Operations Specialists, Other & 4.4 & $23 \%$ & $18 \%$ \\
\hline Sales Managers & 1.7 & $59 \%$ & $33 \%$ \\
\hline Real Estate Sales Agents & 9.3 & $11 \%$ & $12 \%$ \\
\hline Securities, Commodities, and Financial Services Sales Agents & 2.3 & $43 \%$ & $27 \%$ \\
\hline Insurance Sales Agents & 6.1 & $16 \%$ & $15 \%$ \\
\hline Managers, All Other & 2.1 & $48 \%$ & $29 \%$ \\
\hline Event planner & 13.2 & $8 \%$ & $10 \%$ \\
\hline Tax preparer & 36.1 & $0 \%$ & $6 \%$ \\
\hline Meteorologist & 3 & $34 \%$ & $23 \%$ \\
\hline Drafters & 9 & $11 \%$ & $12 \%$ \\
\hline Software Developers and Programmers & 2.5 & $41 \%$ & $26 \%$ \\
\hline Civil Engineers & 2.9 & $35 \%$ & $24 \%$ \\
\hline Designers, All Other & 8.7 & $11 \%$ & $12 \%$ \\
\hline Fashion Designers & 3.9 & $26 \%$ & $20 \%$ \\
\hline Editor & 5.4 & $18 \%$ & $16 \%$ \\
\hline Technical writer & 4.1 & $24 \%$ & $19 \%$ \\
\hline Graphic designer & 12.2 & $8 \%$ & $10 \%$ \\
\hline Film and Video Editors & 3.8 & $27 \%$ & $20 \%$ \\
\hline Publicist & 4.6 & $22 \%$ & $18 \%$ \\
\hline Statistician & 3.1 & $32 \%$ & $23 \%$ \\
\hline Budget Analysts & 4 & $25 \%$ & $20 \%$ \\
\hline Actuary & 1.9 & $52 \%$ & $31 \%$ \\
\hline Computer scientist & 1.6 & $64 \%$ & $35 \%$ \\
\hline Information Security Analysts & 2.2 & $45 \%$ & $28 \%$ \\
\hline Game developer & 3.9 & $26 \%$ & $20 \%$ \\
\hline Software Developers, Applications & 1.9 & $52 \%$ & $31 \%$ \\
\hline Software Developers, Systems Software & 1.7 & $58 \%$ & $33 \%$ \\
\hline
\end{tabular}

\section{Discussion}

\subsection{Economics of Remote Education and Employment}

The concept of the payback time is widely used to evaluate investments: this is the time required to pay back the initial investment. In this case, the initial investment is the tuition and the income foregone during the time of getting the degree (opportunity cost). Since it is assumed that the student stays at home, there would not be an additional room and board cost relative to having a job that does not require higher education. The payback framework generally assumes that there is initial investment at one point in time and then a money savings beginning immediately thereafter. In the case of a college education, it typically takes four years and that is the degree evaluated here. This makes the payback time longer than the time actually spent working to pay back the education costs. However, even adjusted for inflation, wages tend to increase (this is economic growth). This is especially true for jobs that require a college education. Since a payback frame- work assumes that education garners an increase in salary that is constant over time, the real case tends to shorten the equivalent payback time. These factors roughly cancel out. Therefore, the simple approximation of the payback time equaling the time required working to pay back the cost of education is used. $\mathrm{P}$ is the principal investment, $S$ is the savings per year, and P/S is the working time to payback the investment. When put in these terms, many people require a very short payback of only a few years [75]. However, there are some circumstances when education can take longer to pay back. Therefore, a more helpful metric to evaluate the investment is the return on investment (ROI). Most people are familiar with this metric because it is equivalent to an interest rate on a savings account or a loan. As can be seen by the results shown in Table 3, all but three jobs (tax preparer, event planner, and brokerage clerk), not only had positive ROls, but were deep into the double digits of return. For example, software developers can expect to earn over a $30 \% \mathrm{ROI}$ every year over their entire careers while working at home and having been trained remotely. This again is a conservative 
estimate and will be discussed in the risk section below as part of the unquestionable benefit for the graduate to have made the investment in education. To make this clearer, a case study will be presented that illustrates the pathway.

\subsection{Case Study: Nunavut Couple}

Consider a hypothetical case of a young Inuit couple living in Nunavut in a close knit, isolated community that they do not want to leave. Unfortunately, the community is depressed and has few local job prospects. The ongoing economic challenge of dependence on expensive diesel fuel for electricity and the slow uptake of renewable energy $[76,77]$ has limited the ability of the people in Nunavut to address other issues, including housing shortages, inadequate health services, and perhaps most importantly, under-funded education [78-82]. Fortunately, QINIQ, a Canadian company, has begun to use a combination of satellite and wireless communications technology to provide broadband Internet service to 25 remote communities in the Canadian territory of Nunavut [83]. Using this access, the couple began to dabble in coding, using free online resources that teach computer programming. They started at the grade school level with Scratch, a tool developed by Lifelong Kindergarten group at MIT Media Lab [84] and then moved on to progressively more complicated coding at code.org, which is a non-profit dedicated to expanding participation in computer science by making it available in more schools and expanding participation by women and underrepresented students of color [85]. The husband became interested in pure computer science and decided to pursue his degree from Fort Hays State University, while the wife was more interested in software programming and targeted an online degree from University of Southern Mississippi. They would need to invest about $\$ 22,000$ and $\$ 44,000$ for their respective degrees, but upon completion, he could expect to make over $\$ 113,000$ per year and she would make over $\$ 54,000$ per year, bringing their family income to over $\$ 168,000$, if they both chose to work fulltime. This is roughly three times the median income for families living in Nunuvut and much greater than those living in isolated communities, in general [86]. It should be noted that the cost of living in northern communities, such as in this example, is significantly higher than those living in more temperate regions. Assuming full time work, their ROls would be $26 \%$ for her and $35 \%$ for him on their investment in their education. He could gain employment at a company like IBM, because even employees who live nearby to an office rarely come to work physically, because they use the avatar interaction software, Second Life [87]. She might work for herself as a consultant providing freelance coding services. This arrangement gives them both the flexibility to continue living in their remote community, enough work-life balance to start and support a family, and a high enough income to live well and propagate higher education and higher wages for their children. In addition, as they can work from home, they can reduce their work-related expenses to computers and broadband access, completely eliminate commute time, as well as numerous and diverse other work related expenses, and garner time, monetary, and environmental benefits, as well. Furthermore, much of their money would be spent locally, providing additional local employment.

\subsection{Community Preparation for Distributed Education and Employment}

Based on the benefits to the individuals and the community as a whole (discussed in section 4.5), communities may want to proactively invest to assist individuals in obtaining a higher education and the remote employment that demands it; specifically, by providing high speed internet services. However, many jobs could possibly be done without high-speed Internet, because real-time conversations can be accomplished over the phone, while emails and videos can download over time. The exception would be if screen sharing or videoconferencing is required. In addition, many educational offerings still do not rely on video. In summation, although it may be possible that distance education be achieved without high-speed Internet, it would be a benefit, and for particular types of educational resources and jobs, a necessity. An example of a community already doing this is Manning, lowa. It has a population of 1500 , but it installed high-speed Internet and has attracted alumni to come back to telecommute [88].

Thus, several policies can be implemented in isolated communities to foster distributed education and employment. First, free public libraries providing both a physical location and an educational foundation to support a learning community should be supported. These libraries can act as hubs for individuals who do not have access to the computers or the Internet connections needed to gain an education (which will itself enable the individual to afford these in the future for employment). Second, offering personal, free high-speed Internet access for all citizens should be a goal for all communities, but is particularly important for isolated communities with a smaller fraction of their population with any personal Internet access. Many people do not have the financial means of computer access and this barrier can be addressed through one or more of the following: 1) community-supported information technology (IT) access, 2) donations and charity, 3) community and individual loans, and 4) reliance on free and open source hardware and software. This latter approach can radically reduce the IT infrastructure costs. For example, an open source, credit-card-sized computer such as the Raspberry $\mathrm{Pi}$ costs under $\$ 40$ and can be made into a fully functional computer with discarded components (e.g. keyboard, mouse, and display). Similarly, outdated, Windows based computers can be salvaged from scrap yards and revitalized with Linux-based operating systems for free, significantly improving their performance and making them useful for Internet-based education. 


\subsection{Risks and Benefits}

There are several risks when discussing this approach, due to the fundamental limitation of this paper, which is an implicit reliance on the ceteris paribus fallacy (i.e. the assumption that external variables will remain constant, while factors that include the global environment and the global economy are in flux). First, will the person be able to get the intended job? A 2014 study found that only $27 \%$ of college graduates are in a job that matches their major and that only $62 \%$ of college grads are in a job that requires a college degree [89]. As reported by the Washington Post [90], this implies that obtaining a college level education is of questionable merit. However, this implication has two major flaws. First, university degrees offer graduates a wide selection of jobs that may not focus directly on their major. For example, a physics major may get a job as a computer programmer or even a game designer, and a rudimentary analysis would infer s/he was not employed in her/his field. A deeper analysis would uncover that many modern video/computer games, for example, have complex physics engines to ensure realistic game play [91]. More importantly, it is clear from U.S. Bureau of Labor Statistics data that college graduates are far more likely to have jobs, make more money, and overall have better self efficacy in the economy [60]. So, for example, a job like a tax preparer does not absolutely demand a college degree, but having one makes the potential employee far more likely to acquire the job and be able to hold on to the job in a poor economy. The reality is that individuals are far better off with college degrees than without, even if they are not employed in positions directly related to their specific major.

The second major risk, from an individual's perspective, is the potential for competition, either domestically (what if everyone in America started to use this approach?) or internationally. Today, on websites like Freelancer, there are already incredibly talented artists, programmers, and writers, for example, that are willing to work for what would be considered exceptionally low wages in the U.S. Thomas Friedman notes in "The World is Flat" that native English speakers will still have an advantage in the near-term. However, in the medium term, there is likely to be a talented, polite, professional, English-speaking middle-class coming out of countries like India who will be incredibly competitive in the online job market [92]. Having a diploma will help U.S. citizens compete, and there will still be the opportunity to gain an even more valuable bachelor's or graduate degree as prestigious institutions offer more online training. It should be pointed out here that the opportunities provided by an online education are particularly helpful to people outside of well-developed North American economies. The model provided here is applicable to anyone living in an isolated community anywhere on Earth who has the drive to complete the academic requirements, the capital to invest in an appropriate online education (or ability to acquire a loan), and the technical means to ac- cess it. In many ways, the results presented here are the worst-case scenario, as the analysis is based on the U.S. educational system, which has exorbitant fees because of a combination of weak government support, administrative bloat, and excessive administrative compensation packages [93].

This last point leads to a third risk of unintended consequences. Corporate-based administrative thinking favors online education because of the scalability, cost savings, and the continued erosion of faculty autonomy [93]. Encouraging this trend, then, has the moral hazard of deevolving university education to simple job training (as is common with for-profit online only educational institutes). This would further weaken the educational foundation and critical thinking skills needed in the populace for effective citizenship in a democracy, and undermine the academic freedom of university professors to challenge authorities and the paradigms that propagate inequality and human insecurity.

Even with continued changes to both the global economy and the global environment, human security is enhanced with education. First, the global economy is shifting, as more low-skill jobs are automated. In the last few decades, automation and off-shoring in developed countries has focused mainly on middle skill jobs, i.e. the middle class. It is forecasted that future automation will continue to eliminate some middle skill jobs (and even some higher skill jobs), but the majority of the loss will be of low skilled jobs [94]. For example, Baxter, a $\$ 22,000$ robot that can be trained by grabbing its arms and showing it what to do, can easily replace much unskilled human labor [95]. In their seminal paper on the potential for the future automation of jobs, Frey and Osborne found that, although $47 \%$ of U.S. employment is at risk from near-term automation, educational attainment exhibits a strong relationship with the unlikeliness of computerization. This means that getting a college education in remote areas will become even more important in the future than it is now. It is true that higher degrees of automation and distributed manufacturing with 3-D printing has the potential to create jobs, but as Pistono has pointed out, often jobs created by technology employ a small fraction of the people previously employed [96]. Furthermore, these new jobs require a high level of education, flexibility, intelligence, and entrepreneurship [96]. In addition, many of the new tasks created by automation can only be handled with additional automation [95]. Of course, there are some jobs that currently require a college degree that are likely to be automated, like legal assistants and even journalists. Readers are advised to consult the Appendix of Frey and Osborne on near-term decisions. For example, the probability of automation for real estate sales agents is $86 \%$, which should be taken into account when considering the relatively high $\mathrm{ROI}$ calculated in Table 3. In addition, the probability of automation of medical and clinical laboratory technologists is $90 \%$, insurance sales agents is $92 \%$, tax examiners, collectors, and revenue agents is $93 \%$, and accountants and auditors is $94 \%$. 
Therefore, caution purely from a financial perspective, is recommended for people pursuing these careers. Lastly, as continued climate destabilization occurs because of fossil fuel-related pollution [97], the global economy will be significantly affected [98] and individuals will want to mitigate their personal career risk. For example, education for long-term careers associated with the coal industry are of highly questionable utility due to both the changes occurring in the industry now [99] and potential liabilities related to climate change [100-102].

Despite these risks, it is clear from this study that with careful selection and attainment of online training and education, specifically with a focus on a high ROI, it is possible to obtain remote employment in an isolated community. In addition to the economic benefits for the individual in any remote community in obtaining a higher education and the concomitant income, there are also benefits to the community. These benefits are less straight forward to quantify. For example, the presence of a highly educated individual (e.g. a civil engineer) in an isolated community is likely to contribute to the community's human security in complex and synergistic ways, quite independent of the engineer's own economic welfare or "payback time". Such an engineer might provide quantitative reasoning that would be useful in community decisions made by municipalities, help avoid scams, or improve a community's sustainability performance. Similarly, a critical mass of highly educated individuals in a remote community who value education for their children's community can change the educational atmosphere in schools to improve the outcomes in future generations. It has also been found that people with higher levels of education are more likely to become entrepreneurs [89], thus providing additional benefits and

\section{References}

[1] United Nations Development Programme Human Development Report. United Nations Organisation; 1994.

[2] Alkire S. A Conceptual Framework for Human Security. CRISE (Department of International Development, University of Oxford); 2003. Available from: http://economics.ouls.ox.ac.uk/13003/1/ workingpaper2.pdf.

[3] Bajpai KP. Human security: concept and measurement. Joan B. Kroc Institute for International Peace Studies, University of Notre Dame; 2000.

[4] Acharya A. Human security: East versus west. International Journal. 2001;p. 442-460.

[5] Tadjbakhsh S, Chenoy A. Human security: Concepts and implications. Routledge; 2007.

[6] Maiava S, King T. Pacific indigenous development and post-intentional realities. Exploring postdevelopment: Theory and practice, problems and perspectives. 2007; p. 83-98.

[7] Cornell SE. Indigenous peoples, poverty and self- jobs for people in the community who are not able to obtain higher education themselves. Educated people will also be able to help elevate others in their communities by forwarding/motivating a higher education philosophy, acting as mentors, roll models, and academic and career advisors, writing letters of recommendation to universities, etc. This is particularly important for those living in aboriginal communities where individuals do not generally have contacts external to the community. The availability, and certainly the free access to the Internet, can provide an almost unlimited amount of valuable information and education outside of specific degrees of study, such as health, economy, ecology, politics, etc. Future work is needed in this area to provide more quantitative values of these benefits.

\section{Conclusions}

People wishing to remain in remote communities have traditionally been disadvantaged economically, socially, and politically. However, the Internet has now opened up the possibility of both remote education and remote work. Though the investment in college education is significant, education loans are generally available, and the return on investment is generally far higher than the interest rate on the loans, or any other type of traditional and typical economic investment vehicle. This study has identified several particularly promising majors and dozens of high-income careers. The ability to obtain both an education and employment remotely offers the potential to bring many people living in isolated communities out of poverty, reduce inequality overall, and provide those communities with viable means of employment security, now, and in the future. determination in Australia, New Zealand, Canada and the United States. Native Nations Institute for Leadership, Management, and Policy; 2006.

[8] Eversole R, McNeish JA, Cimadamore AD, et al. Indigenous peoples and poverty: an international perspective. Zed Books; 2005.

[9] County Tops State Unemployment Rate. Available from: http://www.npr.org/2009/09/27/113251646/up-county-tops-state-unemployment-rate.

[10] Gogoi P. The Jobless Effect: Is the Real Unemployment Rate $16.5 \%, 22 \%$, or...? Daily Finance. Available from: http://www.dailyfinance.com/2010/07/16/ what-is-the-real-unemployment-rate/.

[11] Many Left Uncounted in Nation's Official Jobless Rate. PBS NewsHour. Available from: http://www.pbs.org/newshour/bb/business-julydec09-undercounted_07-02/.

[12] Lindley J, Machin S. The Postgraduate Premium: Revisiting trends in social mobility and educational inequalities in Britain and America. 2013;Available from: http://www.suttontrust.com/researcharchive/ the-postgraduate-premium/. 
[13] Barnett J, Adger WN. Climate change, human security and violent conflict. Political Geography. 2007;26(6):639-655.

[14] Brown P, Reay D, Vincent C. Education and social mobility. British Journal of Sociology of Education. 2013;34(5-6):637-643. Available from: http: //dx.doi.org/10.1080/01425692.2013.826414.

[15] Hout M. Social and economic returns to college education in the United States. Annual Review of Sociology. 2012;38:379-400.

[16] Wilson D, Macdonald D. The income gap between Aboriginal peoples and the rest of Canada. Canadian Centre for Policy Alternatives Ottawa; 2010.

[17] Mendelson M. Aboriginal peoples and postsecondary education in Canada. Caledon Institute of Social Policy Ottawa; 2006.

[18] Haddon L, Silverstone R. Telework and the changing relationship of home and work. In: Mansell R, editor. Management of Information and Communication Technologies: Emerging Patterns of Control; 1994. Available from: http://www. Ise.ac.uk/media@Ise/WhosWho/AcademicStaff/ LeslieHaddon/TeleworkHomeWork.pdf.

[19] Stanworth C. Telework and the Information Age. New Technology, Work and Employment. 1998;13(1):51-62. Available from: http://dx.doi.org/ 10.1111/1468-005X.00038.

[20] Collins FBRW. Distributed work arrangements: A research framework. The Information Society. 1998;14(2):137-152.

[21] Stanworth C. Women and work in the information age. Gender, Work \& Organization. 2000;7(1):2032.

[22] Vilhelmson B, Thulin E. Is regular work at fixed places fading away? The development of ICT-based and travel-based modes of work in Sweden. Environment and Planning A. 2001;33(6):1015-1030.

[23] Hoffman EC. Information and communications technology, virtual offices and telework. South African Journal of Information Management. 2002;4(2).

[24] Sullivan C. What's in a Name? Definitions and Conceptualisations of Teleworking and Homeworking. New Technology, Work and Employment. 2003;18(3):158-165.

[25] Haddon L, Brynin M. The character of telework and the characteristics of teleworkers. New Technology, Work and Employment. 2005;20(1):34-46.

[26] Dunn H. Teleworking the mobile Caribbean: Emerging patterns of broadband-assisted remote work among the marginalized in Jamaica and Trinidad and Tobago. Information Technologies \& International Development. 2009;5(2):52-66.

[27] Mulki J, Bardhi F, Lassk F, Nanavaty-Dahl J. Set up remote workers to thrive, MIT Sloan Management Review. 2009. Available from: http://sloanreview.mit. edu/article/set-up-remote-workers-to-thrive/.

[28] Swart G. Distributed Workforce: More Than a Trend.
Available from: http://smallbusiness.foxbusiness. com/entrepreneurs/2011/07/05/evolution-

employment-todays-free-agents-core-to-businessgrowth/.

[29] Survey: From Free Agent Nation to OnDemand Workforce. 2011. Available from: https://www.odesk.com/blog/2011/06/survey-fromfree-agent-nation-to-on-demand-workforce/.

[30] Busch E, Nash J, Bell BS. Remote work: An examination of current trends and emerging issues. Center for Advanced Human Resource Studies, Cornell University. 2011;2(3):6.

[31] Zook M, Samers M. 7 Tele-mediated servants and self-servants of the global economy: labour in the era of ICT-enabled e-commerce. Handbook of Employment and Society: Working Space. 2011;124.

[32] Bosch-Sijtsema PM, Fruchter R, Vartiainen M, Ruohomäki V. A framework to analyze knowledge work in distributed teams. Group \& Organization Management. 2011;p. 1059601111403625.

[33] Sullivan C. In: Remote working and work-life balance. Springer; 2012. p. 275-290.

[34] Breaugh JA, Farabee AM. In: Telecommuting and flexible work hours: Alternative work arrangements that can improve the quality of work life. Springer; 2012. p. 251-274.

[35] Messenger JC, Ghosheh N. Work sharing during the great recession: New developments and beyond. Edward Elgar Publishing; 2013.

[36] Chesley N, Siibak A, Wajcman J. Information and communication technology use and work-life integration1. Handbook of Work-Life Integration Among Professionals: Challenges and Opportunities. 2013;p. 245.

[37] Yamakami T. In: Nomadic Work Life Support Using ICT: Toward Multi-generational Techno-socio Innovation. Springer; 2014. p. 233-239.

[38] Keegan D. Foundations of distance education. Psychology Press; 1996.

[39] Beldarrain Y. Distance education trends: Integrating new technologies to foster student interaction and collaboration. Distance education. 2006;27(2):139153.

[40] Carr S. As distance education comes of age, the challenge is keeping the students. Chronicle of higher education. 2000;46(23).

[41] Bernard RM, Abrami PC, Lou Y, Borokhovski E, Wade A, Wozney L, et al. How does distance education compare with classroom instruction? A metaanalysis of the empirical literature. Review of educational research. 2004;74(3):379-439.

[42] Pearce JM. Appropedia as a tool for service learning in sustainable development. Journal of Education for Sustainable Development. 2009;3(1):45-53.

[43] Branker K, Corbett J, Webster J, Pearce JM. Hybrid virtual-and field work-based service learning with green information technology and systems projects. 
International Journal for Service Learning in Engineering, Humanitarian Engineering and Social Entrepreneurship. 2010;5(2):44-59.

[44] Ter Horst EE, Pearce JM. Foreign languages and sustainability: Addressing the connections, communities, and comparisons standards in higher education. Foreign Language Annals. 2010;43(3):365383.

[45] Moore MG, Kearsley G. Distance education: A systems view of online learning. Cengage Learning; 2011.

[46] Lei J, Zhao Y. Distance Education. In: Hattie J, Anderman EM, editors. International guide to student achievement. Routledge; 2013. p. 442.

[47] Moore MG, editor. Handbook of distance education. Routledge; 2013.

[48] Moore MG. Handbook of distance education. Routledge; 2013.

[49] Van Dusen GC. Digital Dilemma: Issues of Access, Cost, and Quality in Media-Enhanced and Distance Education. ASHE-ERIC Higher Education Report. 2014;25.

[50] Evans T, Nation D. 12 Educational Technologies: reforming open and distance education. Reforming open and distance education: Critical reflections from practice. 2013;p. 196.

[51] Muirhead B. The Benefits of an Online Education Consortium for Alberta, 3 (4). IEJLL: International Electronic Journal for Leadership in Learning. 1999;3. Available from: http://iejll.synergiesprairies. ca/iejll/index.php/ijll/article/view/472.

[52] Crellin IR. The Australian Telecentre Program: A New Approach to Technology Transfer and Rural Community Development. 1994.

[53] Smart WJ, Coles G. Bring on the broadband: a case for regional centres in Australasia. IBS Journal of Business. 2011;3(June):13.

[54] Top Affordable Universities by Degree Type. Available from: http://www.onlineu.org/most-affordablecolleges.

[55] North Central Association of Colleges and Schools, the Higher Learning Commission. Available from: http://policy.hlcommission.org/Policies/assumedpractices.html.

[56] Commission on Colleges of the Southern Association of Colleges and Schools. Available from: http://www.sacscoc.org/pdf/ 2012PrinciplesOfAcreditation.pdf.

[57] 57. Northwest Commission on Colleges and Universities. Available from: http://www.nwccu.org/ Pubs\%20Forms\%20and\%20Updates/Publications/ Standards\%20for\%20Accreditation.pdf.

[58] Middle States Commission on Higher Education. Available from: www.msche.org.

[59] Spizman LM. Mean vs. Median Statistical Earnings. In: ACS vs. CPS. Allied Social Science Association Annual Meetings. Philadelphia, PA, USA; 2014.
[60] Bureau of Labor Statistics. Current Population Survey, 2014

[61] Tuition, Fees \& Estimated Cost of Attendance. University of Virginia. Available from: http://www. admission.virginia.edu/admission/tuition.

[62] United States Department of Labor. Occupational Employment Statistics. May 2014 National Occupational Employment and Wage Estimates United States. Available from: http://www.bls.gov/oes/ current/oes_nat.htm.

[63] Tuition \& Fees: Adult and Graduate Degree Programs. Ohio Christian University. Available from: https://www.ohiochristian.edu/adult-degreeprograms/tuition.

[64] Finantial Plan. University of Phoenyx. Available from: http://www.phoenix.edu/tuition_and_financial_ options/financial-plan-services/review-tuition-andexpenses.

[65] Western Governors University. Degree overview. Bachelor of Science Accounting. How long will it tke? It dependw on you. Available from: http://www.wgu.edu/business/ accounting_bachelor_degree\#program.

[66] Tuition and Fees. University of New Mexico. Available from: http://www.enmu.edu/future-students/ tuition/.

[67] United States Department of Labor. Occupational Employment Statistics. Occupational Employment and Wages, May 2014. 4043-4011 Brokerage Clerks. Available from: http://www.bls.gov/oes/ current/oes434011.htm.

[68] United States Department of Labor. Occupational Employment Statistics. Occupational Employment and Wages, May 2014. 3011-3071 Transportation, Storage, and Distribution Managers. Available from: http://www.bls.gov/oes/current/oes113071.htm.

[69] United States Department of Labor. Occupational Employment Statistics. Occupational Employment and Wages, May 2014. 2019-2021 Atmospheric and Space Scientists. Available from: http://www.bls.gov/ oes/current/oes192021.htm.

[70] General Tuition \& Fees. The University of Southern Mississippi. Available from: http://www.usm.edu/ business-services/general-tuition-fees.

[71] Tuition \& Fees for 2015-2016. Wilmington University. Available from: http://www.wilmu.edu/ studentfinancialservices/tuition.aspx.

[72] Tuition and Fees. Fort Hays State University. Available from: https://www.fhsu.edu/sfs/students_ parents/tuition/.

[73] United States Department of Labor. Occupational Employment Statistics. Occupational Employment and Wages, May 2014. 1115-1111 Computer and Information Research Scientists. Available from: http://www.bls.gov/oes/current/oes151111.htm.

[74] United States Department of Labor. Occupational Employment Statistics. Occupational Employment 
and Wages, May 2014. 1027-1014 Multimedia Artists and Animators. Available from: http://www. bls.gov/oes/current/oes271014.htm.

[75] Pearce J, Denkenberger D, Zielonka H. Accelerating applied sustainability by utilizing return on investment for energy conservation measures. International Journal of Energy, Environment and Economics. 2009;17(1):61.

[76] McDonald NC, Pearce JM. Renewable energy policies and programs in Nunavut: Perspectives from the federal and territorial governments. Arctic. 2012;p. 465-475.

[77] McDonald NC, Pearce JM. Community Voices: Perspectives on Renewable Energy in Nunavut. Arctic. 2013;p. 94-104.

[78] Nunavut Adult Learning Strategy. Iqaluit: Department of Health and Social Services. 2008.;.

[79] Recruitment and retention of Inuit nurses in Nunavut. Report prepared by Aarluk Consulting Inc., March 2009, on behalf of NTI. Iqaluit: Department of Health and Social Services. 2010.

[80] Nunavut maternal and newborn health care strategy 2009-2014. Iqaluit: Department of Health and Social Services. 2009.

[81] Fiscal and economic outlook. Iqaluit: Department of Finance Nunavut.

[82] Egeland GM, Pacey A, Cao Z, Sobol I. Food insecurity among Inuit preschoolers: Nunavut Inuit child health survey, 2007-2008. Canadian Medical Association Journal. 2010;182(3):243-248.

[83] QINIQ. Available from: https://www.qiniq.com/ technology.

[84] Scratch-Imagine, Program, Share. Available from: http://scratch.mit.edu/.

[85] Code.org. Available from:http://code.org/about.

[86] Statistics Canada. Median total income, by family type, by province and territory (All census families). Available from: http://www.statcan.gc.ca/tablestableaux/sum-som/l01/cst01/famil108a-eng.htm.

[87] Second Life Community. Available from: https: //community.secondlife.com/t5/Working-InworldGeneral/As-Seen-on-CNBC-New-IBM-CaseStudy-Showcases-Value-of-Meeting/ba-p/640377.

[88] Riley R. Manning Touts High Speed Broadband, Seeks Telecommuters. WHOTV.com, January 18, 2015.

[89] Abel JR, Deitz R. Agglomeration and Job Match- ing among College Graduates. Federal Reserve Bank of New York Staff Reports 587. 2014. Available from: http://www.newyorkfed.org/research/ staff_reports/sr587.pdf.

[90] Plumer B. Only 27 percent of college grads have a job related to their major. Washington Post. May 20, 2013. Available from: http://www.washingtonpost.com/blogs/wonkblog/ wp/2013/05/20/only-27-percent-of-college-gradshave-a-job-related-to-their-major/.

[91] Lewis M, Jacobson J. Game engines. Communications of the ACM. 2002;45(1):27.

[92] Vanderbok W. The World is Flat: A Brief History of the Twenty-First Century. Macmillan; 2005.

[93] Ginsberg B. The fall of the faculty. Oxford University Press; 2011.

[94] Frey CB, Osborne MA. The future of employment: how susceptible are jobs to computerisation? 17 September 2013. Available from: http://www.oxfordmartin.ox.ac.uk/downloads/ academic/The_Future_of_Employment.pdf.

[95] Kelly K. Better Than Human: Why Robots WillAnd Must-Take Our Job. Wired. 24 December 2012. Available from: http://www.wired.com/2012/ 12/ff-robots-will-take-our-jobs/all/.

[96] Pistono F. Robots will steal your job, but that's OK: How to survive the economic collapse and be happy. 10 February 2012. Institute of Ethics and Emerging Technologies. Available from: http://ieet.org/index. php/lEET/more/pistono20120211.

[97] Oreskes N. The scientific consensus on climate change. Science. 2004;306(5702):1686-1686.

[98] Stern NH, Treasury HM, et al. Stern Review: The economics of climate change. vol. 30. HM Treasury London; 2006.

[99] 85. Randall, T. The latest sign that coal is getting killed. Bloomberg. 13 July 2015. Available from: http://www.bloomberg.com/news/articles/2015-0713/the-latest-sign-that-coal-is-getting-killed.

[100] Allen M. Liability for climate change. Nature. 2003;421(6926):891-892.

[101] Grossman DA. Warming up to a not-so-radical idea: Tort-based climate change litigation. Columbia Journal of Environmental Law. 2003;28:1.

[102] Faure M, Peeters M. Climate change liability. Edward Elgar Publishing; 2011. 


\title{
Redefining Human Security for Vulnerable Migrants in East Asia
}

\author{
Jiyoung Song
}

School of Social Sciences, Singapore Management University, 90 Stamford Road, Singapore 178903.

E-Mail: jysong@smu.edu.sg

Submitted: 5 August 2015 | In revised form: 23 November 2015 | Accepted: 24 November 2015 |

Published: 14 December 2015

\begin{abstract}
This article proposes human security as an analytical framework to understand the current trends of irregular migration (both forced and unauthorised) in East Asia and revisits the seven pillars of human security defined in the 1994 Human Development Report by the United Nations Development Programme (UNDP). It explains how the concepts of human security are parallel to those prescribed in international human rights conventions but different in terms of the attitude towards states. Human security does not directly challenge state authority and adds a sense of urgency and moral authority that requires extra-legal measures by the states. The author argues that human security is the securitisation of human rights and is a better framework and policy discourse than human rights to engage with state and non-state actors, especially in East Asia where political leaders are more receptive to the former idea. The study draws examples from stateless Rohingyas, undocumented sex workers in Thailand and Singapore, trafficked brides from Vietnam and Cambodia, and smuggled North Korean refugees in China to demonstrate the nexus between human security and irregular migration.
\end{abstract}

Keywords: asylum; East Asia; human security; smuggling; trafficking; undocumented migrants

\section{Introduction}

In spite of the increasing roles played by individuals and non-state actors, states still hold the primary responsibilities to protect and guarantee human security of citizens and residents within their territorial borders. The State is not just an actor that enacts and amends legislation on transnational migration between states and implements policy measures, but is also a structure under which domestic and international, private and public actors, interact with one another. Transnational migration is one such area where states are the gate-keepers of their own territorial boundaries and provide rules and regulations about immigration. Cross-border migration can be approached from different perspectives. While state sovereignty, territorial integrity, national security or criminal justice perspectives represent a conservative voice [1-7], liberal and crit- ical scholars focus more on individual freedom of movement, the global economic structure and migrants' socioeconomic conditions [8-10].

This article offers a critical review of different schools of thoughts on migration and security from conservative, liberal and critical perspectives, which is followed by a critical assessment of the Copenhagen School's securitisation theory. The main purpose of the review is to examine how academic discourses of international security have evolved over the years, especially after the end of the Cold War, from state- and defence-centric to more people-centred perspectives, merged with other discourses of human rights and sustainable development. After an overview of key debates on human security, it examines the 1994 UNDP definition of the seven pillars of human security as the most comprehensive and encompassing framework. It conceptually dismantles the seven 
pillars - namely personal, community, political, economic, food health and environmental securities-and shows how similar the contents of human rights and human security are. It concludes that human security is the securitisation of human rights that attaches a sense of urgency and paramount importance to affected people, regardless of their legal status, and that requires extra-legal and extrapolitical measures by the concerned states.

The study draws on a number of recent examples from East Asia (both South and North) where migrants risk their lives to cross the borders through unauthorised land or sea routes in order to relocate themselves and their families to more secure places. They include North Korean 'smuggled refugees' [11], undocumented Cambodian workers and trafficked fishermen in Thailand [12], overstayed Bangladeshi workers in Japan [13], stateless Rohingyas [14], trafficked Vietnamese brides in Korea [15] and Karen refugees in Thailand [16], to name a few. Migrant' decisions to move across their national boundaries are driven by their natural instinct for survival to go to a more secure place even when the movement is unauthorised by relevant state authorities. Irregular migration is a highly complex area of studies as most cases present mixed migration with multiple causes in a vicious circle. In other words, a migrant who wanted to escape from poverty and discrimination, pays for a smuggler to cross the border and ends up being a victim of human trafficking. Where $\mathrm{s} /$ he is rescued, s/he realises s/he could have claimed refugee status, so s/he does. Still, s/he has no right to work. Within the broad category of unauthorised movement, the boundaries and key definitions of irregular migration (which includes undocumented labour migration, human trafficking, people smuggling and asylum seeking) are all blurred and the process of irregular migration is highly unpredictable.

While migrants are in such dire conditions, the current human rights framework is insufficient to solve the problem. According to Article 13(2) of the 1948 Universal Declaration of Human Rights, individuals have the right to leave a country of origin. However, international human rights law does not provide an express right for the individual to reside elsewhere nor place a duty upon other states to receive them. Mobility is therefore incompletely defined and protected under the existing human rights regime. It is the states that decide whom they want to receive as residents, temporary and permanent alike, and accept as citizens. State obligations to protect and respect basic human rights of those who are not their citizens have not been properly observed under international law. In this regard, human security may offer a powerful language and discourse for international and regional cooperation to tackle irregular migration. The term promotes the urgency and paramount importance attached to affected people regardless of their legal status, as well as to hosting societies. Human security highlights the on-going challenge posed by irregular migration that requires immediate measures by the concerned states that go beyond traditionally defined domestic rules and regulations on immigration or charitable humanitarian consideration. By redefining the seven pillars of human security in the context of irregular migration in East Asia, the study contributes to the clarity of mixed terminologies and multiple causes of irregular migration as well as to the growing body of knowledge and theoretical development for the existing literature on the nexus between human insecurity and irregular migration.

\section{The Securitisation of Migration}

This section critically reviews three main theories of migration in relation to security. The real world of scholars and practitioners present a mixture of some of these basic ideas and the lines among the three schools are highly blurred (see Table 1 below). Nevertheless, the purpose here is to provide the most distinctive lines of argument on this area. Philippe Bourdeau [1] aptly introduces three models of securitisation of migration. The first and mainstream model is from the realist tradition of International Relations (IR). Robert Kaplan [17] warned that Western states should fear the 'coming anarchy' associated with mass migration while Samuel Huntington [18] declared that the persistent flow of Hispanic immigrants would constitute a major potential threat to America's cultural and political identity. One of the most well-known conservative migration scholars is Myron Weiner [19] who stated that 'advanced industrial countries can protect their borders from invading armies but not from hordes of individuals who slip into harbours, crawl under barbed-wire fences and wade across rivers'. Weiner's migration-security nexus [20] draws what he calls the Security Stability Framework on how international migration creates conflict within and between countries from a realist perspective, which sees migration as a potential threat to national security. For realists, therefore, the expansion of international migration is dangerous for state sovereignty and the balance of power among states in the international system and would create violent conflicts among states [21].

For liberals, on the other hand, national borders should be open for free trade, labour mobility and individual liberty, although there are several different sub-groups within the liberal camp. For example, neoliberals would advocate for free trade, fewer regulations and unrestricted labour mobility while classical liberals focus on individual liberty, human rights and justice. Liberal scholars envisage the "client politics model' [22-24] or the 'embedded liberalism model' $[25,26]$, both of which support freedom of movements. In this liberal perspective, international institutions and international laws are supposed to set rules and regulations that respect individual freedom and democracy, and that contribute to shaping more cooperative and open-minded state behaviour towards globalisation and international migration. Free(r) movements, however, on the contrary, have made many migrant workers' conditions worse instead of helping them alleviate poverty, underdevelopment and corruption, an issue which the next group of scholars 
Table 1. Three models of securitisation of migration.

\begin{tabular}{|c|c|c|c|}
\hline & Realism & Liberalism & Critical Theory \\
\hline \multirow[t]{2}{*}{ Basic premisses } & $\begin{array}{l}\text { Migration creates conflict within and } \\
\text { between countries. Migration is a po- } \\
\text { tential threat to national security. }\end{array}$ & $\begin{array}{l}\text { National borders should be open for } \\
\text { free markets, labour mobility and indi- } \\
\text { vidual liberty. }\end{array}$ & $\begin{array}{l}\text { Insecurity and fear are mostly imag- } \\
\text { ined and constructed by mundane, bu- } \\
\text { reaucratic practices and decisions of } \\
\text { everyday politics. }\end{array}$ \\
\hline & $\begin{array}{l}\text { International migration affects state } \\
\text { sovereignty, the balance of power } \\
\text { among states, and the nature of vio- } \\
\text { lent conflicts in the international sys- } \\
\text { tem. }\end{array}$ & $\begin{array}{l}\text { The threats realists argue are posed } \\
\text { by migrants can be negated by the } \\
\text { rules and regulations set up by inter- } \\
\text { national institutions and international } \\
\text { law. }\end{array}$ & $\begin{array}{l}\text { Security professionals, conservative } \\
\text { media, nationalist politicians and } \\
\text { xenophobic individuals foster the } \\
\text { creation of fear mongering around } \\
\text { migration. }\end{array}$ \\
\hline \multirow[t]{3}{*}{ Scholars } & Robert Kaplan & Gary P. Freeman & Didier Bigo \\
\hline & Samuel Huntington & Virginie Guiraudon & Ole Wæver \\
\hline & Myron Weiner & Christian Joppke & \\
\hline
\end{tabular}

address.

Critical theorists oppose both realist and liberal views, arguing that security is neither about survival nor about urgency and exceptional practices. Rather, security is the 'result of mundane bureaucratic decisions of everyday politics that create a sense of insecurity, fear, danger and unease' $[27,28]$. Didier Bigo identifies this as the 'governmentality of unease'. According to him, the securitisation process is above all 'routinised practices of professionals of security, essentially police and bureaucrats'. This relates to Ole Wæver's securitisation theory to identify existential threats from imagined enemies and to highlight 'speech act'. The speech acts are not only done by bureaucrats or security professionals but also by the conservative media, nationalist politicians or xenophobic individuals who post their opinions on the Internet and they spread over a few minutes across space. The state (or Bigo's security professionals), in this sense, waits until normative equilibrium is reached in the society and belatedly reacts to social demands in democratic society. Threats may not exist, but fear does endogenously within individuals living in the system of mass migration. It is not just created by external sources of bureaucrats.

The Copenhagen School, which is part of the critical theory and is led by Wæver, gives specific methodological insights into the securitisation of irregular migration. Barry Buzan's Securitisation Theory (ST) $[29,30]$ provides a framework to theorise how East Asian states are securitising irregular migration and to identify which security norms the states are constituting and utilising over the years. As Bourdeau [1] says, ST is 'the most widely applied and fully developed model of relationships between migration and security' and a 'most creative and productive analytical framework'. Securitisation is, by definition, the 'process of integrating migration discursively and institutionally into security frameworks that emphasise policing and defence' [1]. Like social constructivism [31], one of the greatest strengths of ST is that it shifts the focus of analysis away from merely material factors to socio-cultural and normative ones.

Wæver [32] himself identifies his own ST as an analysis of 'actual linguistic practices to see what regulates discourse'. The Copenhagen School examines what practitioners 'do in talking security'. Wæver's notion of security is that it is the 'result of a move that takes politics beyond the established rules of the game and frames the issue as above normal politics', which also applies to human security. However, his interpretation of the designation of existential threat is negative in a sense that it is only to justify the use of extraordinary measures or special powers such as enforcement and secrecy. His view of security is a 'failure to deal with issues as normal politics'. For Wæver, therefore, de-securitisation is the optimal long-range solution, which limits the scope for interpretations of security to human dimensions.

I would add a new human dimension to Waever's ST. There have been changing conceptions of security from state-centric to people-centred. I would still place this new dimension under the post-structural critical school as my version of human security framework is going beyond both realist/liberal rational theory and instead focusing on nonlinear circular processes of human insecurity and irregular migration. Previous work on the securitisation of migration focus on the negative notion of security as urgency, control and power [23,33]. Maggie Ibrahim [34] for example, calls the securitisation of migration the 'latest and most modern form of racism'. In fact, fear-mongering, criminal imagery of migrants, witch-hunting or 'othering' particular ethnic groups are old tactics of securitisation of migrants. However, this limited and negative state-centric perspective of securitisation does not capture the changed concepts of security in a more humane way and that includes considerations of the agency of migrants. The Rohingya boat people crisis in May 2015 also presents multi-faceted human security issues of irregular migration concerning the poverty, conflict and discrimination that drive migrants into the illegal sea routes that are operated by traffickers. 
There is another problem with ST that is the disconnection between theory and empirical evidence. As Bigo $[28,35]$, the founding father of the Paris School, points out, actual policy practices often reveal patterns different from those found in official discourses. Many have tried to fill this gap. Bourdeau [1] brings his own cases from Canada and France whereas Melissa G. Curley and Wong Siu-lun [36] provide Northeast Asian case studies. Feminist security studies offer valuable observations and analyses on how different forms of migration are securitised or undersecuritised [37-41], which provided inspiration for the current study. Migrants' self-organising behaviour and interactions among themselves and with the state migration regimes are key to understanding the evolutionary correlation between migration and security.

\section{Human Security: Securitisation of Human Rights}

As explained above, the conventional notion of security focuses on national defence, military security or territorial integrity of sovereign states, virtually synonymous with 'defence' $[42,43]$. Notions of personal, cultural or environmental security emerged and the reconceptualisation of security has been carried out by IR theorists [30,42,44,44-51]. The major breakthrough was the 1994 UNDP report. In the report, the UNDP laid out two broad categories of human security: 'freedom from fear' and 'freedom from want' [52-54]. It argued that 'human security is not a concern with weapons - it is a concern with human life and dignity', best insured through prevention and people-centeredness. It detailed seven components of human security: personal, community, political, economic, food, energy and environment securities that are interdependent with one another.

Since then, human security has been revisited for further investigation for its utility and its relation to other global political concerns $[43,55-57]$. Some have a narrow definition of human security as 'vulnerability to physical violence during conflict' [58] while others share a broader concept, linking it with other areas such as development or globalisation $[59,60]$, which is often represented as the Canadian vs. Japanese conceptions of human security [61]. Ernst Haas [62] long argued that the security literature needs to learn from the 'evolutionary epistemology' of global life. Similarly, Mark Duffield [63] agrees that human security provides a means of distinguishing geopolitics, the security of states, from biopolitics, the security of population. For many in East Asia, economic, food, energy and environmental issues are real and immediate threats to their peoples' survival and resilience. Developing countries like Myanmar, Vietnam, Cambodia, the Philippines and Indonesia send many economic and marriage migrants overseas and migrants send remittance back to their countries of origin. North Korea has chronic food shortage [64-66]. China, Japan and South Korea started planning to secure long-term food security, especially rice, and energy secu- rity, which both involve seasonal labour forces. Japan, Indonesia and the Philippines are vulnerable to natural disasters such as typhoons, whereas the Greater Mekong region faces man-made environmental degradation through mining and dam construction, activities that result in forced eviction at times.

Each state's historical (post-colonial), political and cultural backgrounds constitute its attitude to human rights vs. human security. Many in East Asia were under Western colonial rule (except for Korea which was under the Japanese rule) and have authoritarian political structures, which have been deeply embedded in hierarchical maledominant role-based cultures or religions. Governments are under pressure for their lack of transparency and accountability, rising middle-classes or ethnic rivalry. In this environment, the political elites are more receptive toward the idea of collective (human) security while being resistant to individual human rights. A state as an actor also wants to survive as individual migrants do. The former prime ministers of Singapore and Malaysia, Lee Kuan Yew and Mahathir bin Mohamad, for example, defined human rights as Western concepts that were not suitable for many Asian countries. The former Singaporean foreign minister Kishore Mahbubani also argues that human rights are an 'aggressive alien Western concept' [67]. The default assumption in human rights is that the state is the potential perpetrator either by committing human rights violations or by omitting its obligations to protect human rights. Statesociety relations are confrontational under the doctrine of human rights. In the language of human security, however, states remain the primary guarantors of human security or providers of goods and services for people's well-being while being able to establish normal authority in international society by looking after its own people as well as vulnerable migrants. Having a closer examination of the contents of the seven pillars of human security endorsed by the UNDP in 1994 [52], however, I would argue that they are all within the realm of international human rights as seen below Table 2 .

Whereas human rights challenge state authority and sovereignty and often accuse states of being potential perpetrators, human security expects state moral authority, expands state responsibilities to non-citizens, i.e. vulnerable migrants regardless of their legal status, and urges trans-political supra-national measures that go beyond existing national mechanisms. It is the urgency and the magnitude of impact on vulnerable irregular migrants that transcends state sovereignty and territorial integrity and that can affect hosting societies on a greater scale if no proper measures are taken in time. This requires immediate transnational cooperation. In this regard, a good state may want to seize the opportunity to take ownership of human security and play a responsible role for the regional security. 
Table 2. Human Security and Human Rights.

\begin{tabular}{|c|c|c|}
\hline $\begin{array}{l}\text { Seven Pillars of } \\
\text { Human Security }\end{array}$ & International Human Rights & $\begin{array}{l}\text { Provisions of Human Rights } \\
\text { Treaties }\end{array}$ \\
\hline Personal Security & $\begin{array}{l}\text { The right to life, liberty and security; not to be discriminated, based on race, ethnicity, } \\
\text { language, religion, sex, political opinion or social origin, birth, disability, gender, sexual } \\
\text { orientation; to freedom from violence, torture, slavery, exploitation, arbitrary arrest, or } \\
\text { summary execution; to recognition before the law, fair trial, privacy, family, property, } \\
\text { identity/nationality, movement and residence, gender equality, freedom of thought and } \\
\text { education. }\end{array}$ & $\begin{array}{l}\text { UDHR Articles 1-19, 26; IC- } \\
\text { CPR Articles 2-3, 6-20, 23- } \\
\text { 4, 26; ICESCR Articles 2-3, } \\
\text { 10, 13-4; CEDAW; CRC; CAT; } \\
\text { and other ILO conventions no } \\
\text { forced labour or child labour }\end{array}$ \\
\hline $\begin{array}{l}\text { Community Secu- } \\
\text { rity }\end{array}$ & $\begin{array}{l}\text { The right to cultural life; to preserve cultural practices, values or heritage from sec- } \\
\text { tarian violence or not to be discriminated against, based on certain race, ethnicity, } \\
\text { nationality or religion. }\end{array}$ & $\begin{array}{l}\text { UDHR Article 27; ICCPR Ar- } \\
\text { ticle 27; ICESCR Article 15; } \\
\text { CERD; and MWC }\end{array}$ \\
\hline Political Security & $\begin{array}{l}\text { The rights to freedom of assembly, political participation; not to be discriminated } \\
\text { based on political opinion, to vote and to stand for election, to free and fair elec- } \\
\text { tion, to freedom of speech, to form and maintain political organisations, or to organise } \\
\text { social movements. }\end{array}$ & $\begin{array}{l}\text { UDHR Articles 2, 20-21; IC- } \\
\text { CPR Articles 21-22, } 25\end{array}$ \\
\hline Economic Security & The rights to basic income, social security, work and rest, trade union. & $\begin{array}{l}\text { UDHR Article 22-4; ICE- } \\
\text { SCR Articles } 6-9 ; \text { and other } \\
\text { ILO conventions on minimum } \\
\text { wage, etc.) }\end{array}$ \\
\hline Food Security & The rights to adaquate standard of living, freedom from hunger, access to basic food. & ICESCR Articles 11 \\
\hline Heath Security & $\begin{array}{l}\text { The rights to standard of living, health, to be protected from infectious or chronic } \\
\text { diseases and to access health services. }\end{array}$ & $\begin{array}{l}\text { UDHR Article 25; ICESCR Ar- } \\
\text { ticles } 12\end{array}$ \\
\hline $\begin{array}{l}\text { Environmental Se- } \\
\text { curity }\end{array}$ & $\begin{array}{l}\text { The rights to adaquate standard of living, clothing, housing, and clean environment, } \\
\text { especially water and air, or the right to be protected from man-made environmental } \\
\text { disasters. }\end{array}$ & ICESCR Articles 11 \\
\hline
\end{tabular}

Unlike the misconceived idea of human rights as an imperial Western concept among many authoritarian leaders in East Asia, human security has the potential to grow more as a foreign policy concept. There are signs many East Asian elites are already receptive to the idea of human security. Amitav Acharya [68] went even further, arguing that human security is originally an 'Asian' concept as Mahbub ul Haq, who is the main author of detailing the concepts of human security in the 1994 UNDP report, is an 'Asian' scholar. Japan has initiated the Asian approach to human security by embracing socio-economic aspects such as food and energy security in contrast to the Canadian emphasis on the 'freedom from fear' in armed conflict. The Japanese government saw human security comprehensively covering 'all the menaces that threaten human survival, daily life and dignity-for example, environment degradation, violations of human rights, transnational organised crime, illicit drugs, refugees, poverty, anti-personal landmines and other infectious diseases such as AIDS' $[43,69]$. Japan's comprehensive security, therefore, bears both a traditional statist notion of closer military cooperation with the US and non-traditional economic, energy and food security [70]. Although Acharya [68] remains pessimistic in arguing that ASEAN countries' main concern is regime survival and legitimation as in the case of Singapore's 'Total Defence' [71] rather than genuine concern for people's well-being and security, the two are inseparable.

Furthermore, some East Asian leaders embrace and mobilise human security in their public speeches [72-74] (on the Asian conception of human security, see: $[75,76]$ ). In 2002, Chinese Premier Zhu Rongji and ASEAN lead- ers jointly declared on cooperation in the field of nontraditional security at the sixth China-ASEAN Summit in Phnom Penh, Cambodia. At the Symposium on 'Realizing Human Security in Asia' in Tokyo in 2010, the SecretaryGeneral of the Association of Southeast Asian Nations and former Thai Foreign Minister, Surin Pitsuwan, endorsed the concept of human security as 'a rather comprehensive concept... [that]... will not be in competition with the issue of state sovereignty. In fact, it is making the state's sovereignty more meaningful because state security and state sovereignty, also would involve responsibility' [77]. Pitsuwan also connected the concept to social safety nets in the wake of the 1997 Asian Financial Crisis. In the recent publication of the Armed Forces of the Philippines [78] Internal Peace and Security Plan: Bayanihan, the wholeof-nation 'human security' approaches were identified as the strategic planning for peace and security, natural disasters and other illicit activities such as human trafficking, piracy and people smuggling.

\section{4. 'Human' Securitisation of Irregular Migration}

The final section of the article examines the nexus between human (in)security and irregular migration. Many have tried to bring in broader concepts of human security in migration studies, rather than traditional national and border security perspectives. Elspeth Guild and Joanne van Selm [79] reconceptualise security as 'political and legal security', 'cultural and identity security' and 'personal and economic security' in their study on the impact of immigrants on hosting countries. Literature 
on the migration-development nexus $[80,81]$, migrationdevelopment-security [82], and migration-globalisationhuman security [83] employs people-centred security concepts. The nexus between human insecurity and irregular migration has been observed in the East Asian context. Dewi F. Anwar [84] has tried to weave together the ideas of human rights, security and irregular migration. In particular, she identified new threats to human security as the exploitation of irregular workers, the growing incidence of people smuggling and human trafficking. However, Anwar did not concretise the contents of human security and used the term with 'non-traditional' security interchangeably, which made the concept very vague. With further embodiment and comparison with established international human rights norms, the UNDP's human security lens can provide an alternative agent-based analysis for the motivations of migrants, the vulnerability they face as well as the potential or imagined threats they pose to hosting societies.

Human (in)security has been the main driver for irregular migration. Because of their irregular status, migrants' human security comes under greater threat (no matter where they end up), which feeds into the vicious cycle of insecurity-triggered migratory patterns. Unless this vicious circle is broken by urgent extra-legal measures by the concerned states, both vulnerable migrants and hosting societies can end up in highly insecure situations. In spite of the greater risk that irregular migration poses for all societies, the term 'irregular migration' has been associated with the illegality of people's movements. It is labelled clandestine, illegal, sans papier (undocumented), uncontrolled, unlawful, unauthorised, alien without residence status, or non-compliant. In 1974, the United Nations made the first reference to irregular migration in connection with the treatment of 'illegal aliens' [85]. In the following year, the UN General Assembly adopted Resolution 3449 (30) where it called on the UN system to use the term 'nondocumented' or 'irregular' in official documents rather than 'illegal' migrants. The International Organization for Migration defines irregular migration as the 'movement that takes place outside the regulatory norms of the sending, transit and receiving countries'. I would define irregular migration as emerging patterns of people's mobility that does not conform to established rules, norms, customs or morality, which include unauthorised illegal migration as well as forced migration. Following Martin Ruhs and Bridget Anderson's compliance approach [86], 'unauthorised' here has two meanings: one is movement that has not abided by existing migration regulations in a given state and the other is that states do not have laws (yet) to regulate illicit migration. For this article, people 'affected' [87] by irregular migration fall into four categories: 1) unregistered, overstayed or misusing-visa labour migrants; 2) asylum seekers, stateless people, or IDPs; 3) trafficked persons or 4) smuggled people. In reality, however, these four categories are blurred and cross-boundary: undocumented Cambodian fishermen become easy targets for traffickers [88] and
North Korean asylum seekers in China get 'help' from missionary smugglers to use the underground railway to cross the border to Southeast Asia [89].

East Asia produces a large number of irregular migrants inter-regionally but also intra-regionally. Border controls are not rigidly enforced in certain places due to geographical challenges or the lack of government capacity. East Asia's diverse and vibrant environments create intraregional migration for labour, sex, marriage or freedom. East Asia has high degrees of demographic, political, economic, socio-cultural and ethnic diversity, which makes the cross-border movements more frequent and fluid as in diffusion and osmosis in physics. In China, it has the world's biggest population of 1.38 billion and one of the smallest, Brunei with only 412,000 in 2012 [90]. In terms of income, East Asia has the lowest GDP per capita of Lao PDR (US\$ 751 ) and the highest of Japan (US\$ 37,433) in 2013 [91]. In the Golden Triangle, the Balkans of Asia, there are numerous ethnic minorities sharing the national borders between Thailand, Myanmar and Lao for trade or employment. The International Organisation for Migration (IOM) [92] recognises that irregular migration remains one of the biggest challenges across the region 'with the most common forms being unauthorised labour migration movement and trafficking for labour and sexual exploitation, sometimes through international marriages'. The following subsections will introduce a few exemplary cases of irregular migration in relation to human (in)security, based on the author's own reading, observation and fieldwork in the region for the past decade. The list is not exhaustive.

\section{Asylum Seeking}

In forced migration, personal, community, political and environmental insecurities (physical safety, ethnic and political violence as well as natural disasters and man-made environmental damages) push migrants to neighbouring countries. Many ethnic minorities such as the Karen, Mon or Rohingya peoples escape from state-induced discrimination and armed conflict in Burma to neighbouring countries such as Thailand and Malaysia through whatever possible land and sea routes, despite the fact they are unauthorised channels (fieldwork in Ban Dong Yang and Mae La camps in Thailand and focus group interviews with 58 refugees in total between 2013 and 2015). Some pay for smugglers to get them out of situations of violence and poverty. Others are deceived by human traffickers and kept in confinement until ransom is paid or until they are sold for sex or labour exploitation. North Koreans also escape from state-induced political violence, food and economic insecurity, and severe floods and draught in the 1990s. They head to China and then down to Thailand, Vietnam or Cambodia, knowing that the border crossing is illegal both in sending and receiving countries (fieldwork in Yanbien, China in 1999, Seoul, South Korea in 2000-2005 and Bangkok, Thailand in 2012).

International human rights or refugee laws have been 
ineffective in responding to imminent threats to asylum seekers and hosting populations as the states concerned do not fully respect human rights norms and instead prioritise sovereignty and national security. Burma, North Korea, China, Vietnam and Cambodia have the worst records of state compliance with international human rights and they are not bound by humanitarian or refugee conventions either. Under international law, none of the concerned countries show commitment to the respect for, or protection of, human rights for those vulnerable asylum seekers. These states merely treat these vulnerable individuals as illegal migrants who violate domestic immigration regulations. This does not deter asylum seekers from leaving their countries of origin (because it does not address the original issue of insecurity that pushes irregular migration), but it does encourage underground smuggling networks to grow, which places the migrants in greater danger.

Because of the precarious and illegal status of asylum seekers and the lack of sufficient government measures, migrants' food, health, environment and community securities are at stake in hosting countries (lack of access to basic food, exposure to unhygienic environments and communicable diseases, discrimination against certain ethnic groups or threats from locals to report to the authorities). For Karen refugees, Thailand offered temporary shelter for more than a decade where refugees received food, health services, basic education and vocational training. In the case of North Korean asylum seekers, China has turned a blind eye and they remain in the hands of underground Christian missionaries or smugglers. The existence of asylum seekers and refugees often creates diplomatic tension between sending and receiving countries. Burma and Thailand have regular dialogues how to handle the Karen refugees. Vietnam once sent 486 North Koreans in a chartered Korean Air flight to South Korea and North Korea publicly condemned the decision. While Thailand allows some Karen refugees to remain as residents, China repatriates North Koreans and tightens border control, based on the bilateral agreement with North Korea. The latter case opens underground smuggling and trafficking networks that can penetrate borders, which only make both migrants and citizens more vulnerable and place regional security in greater danger. As China closes the borders with North Korea, the region's economy slows down and community cohesion is disturbed [93]. Trafficking in persons and people smuggling occur in commercial land and sea routes [94]. Turbulent and poorly managed borders can also attract other related criminal activities such as goods smuggling and fraud [95] that have impact on not just asylum seekers but the hosting populations.

\section{Undocumented Labour Migration}

The next group is undocumented labour migrants who seek better economic security and knowingly violate immigration rules and work permit requirements. These are mostly unskilled workers and they make up the largest number of migrant workers in Asia [96]. There are no fixed sending or receiving countries. A decision to move to another country to find work is relative and non-linear. Decisions are made through interactions with migrants' neighbours, families and friends. Employment agencies play a significant role and some have exploitative practices that are not regulated by states. While existing flows from countries like Bangladesh, Indonesia and the Philippines are constant, migrant workers from Vietnam, Cambodia, Laos and Burma have also entered the global labour market. Among economic migrants who come with proper visas, many become irregular as they overstay or misuse visas. Up to one in four migrant workers in Asia may have illegal status [97]. According to the International Labour Organisation [97], labour flows from Indonesia and Thailand to Malaysia are largely illegal and Thailand hosts up to 1.7 million illegal workers. Undocumented migrants have no access to justice and are not entitled to legal protection from abuse, the non-payment of salaries. Bangladeshi or Nepalese factory workers in Japan overstay and become illegal migrants [98]. Cambodian seasonal workers cross the border to Thailand without proper travel documents or work permits [99]. Philippine sex workers enter Singapore with social visit passes and solicit in streets or bars (fieldwork in Singapore in 2012 and in-depth interviews with eight sex workers). They are targets of police raids and arrested for the breach of immigration rules.

States treat them as illegal migrants who breach the national laws on immigration and work permits. Furthermore, the growth of irregular migration in East Asia is linked to both governments' unwillingness to effectively manage migration and to employers' desire for cheap labour [100]. Most Asian countries have tended to turn a blind eye to undocumented workers at times of economic growth and to campaigns of mass expulsion in economic downturns. These workers have no recourse or access to justice when their rights are violated. Hosting countries do not recognise their legal rights as the latter has no legal standing in the country of their residence. International human rights laws do little to protect irregular migrant workers. Most countries that host undocumented migrant workers have not signed or ratified the International Convention on the Protection of the Rights of All Migrant Workers and Members of Their Families [101].

In the meantime, the very presence of undocumented labour migrants in a country, when not properly managed, poses potential threats to personal, community, economic, food, health and environmental securities for hosting societies. The public is exposed to health hazards from unmanaged epidemic or transmittable diseases through human contact because irregular migrants share the same space as host societies. Undocumented migrants are not covered by national healthcare systems. Accumulated grievances may trigger communal violence against the local population. Leaving undocumented migrant workers unprotected can create long-term socio-economic problems for hosting societies. Many governments, however, 
tend to focus on their illegal status and the deportation of these workers once caught no matter how long they have contributed to the hosting country's economy. Repatriation may provide the concerned government a short-term cost-effective solution. However, in the long run, exploitation and unfair treatment can bring about unintended diplomatic and political conflict between the sending and receiving countries.

\section{Trafficking in Persons and People Smuggling}

The third and fourth categories of irregular migrants are people who are affected by human trafficking and people smuggling. They include victims, survivors, their families, brokers, aid workers and anyone who migrate or have migrated to transport other people for the purposes of exploitation or for pure financial gain. These two terms are often confused. The former involves a form of exploitation in the final destination and can happen within a national boundary whereas the latter refers to the movement of people from one country to another through an unauthorised channel. In the case of trafficking, individual traffickers can be charged for their criminal activity. States can also be held responsible for failing to protect the human rights of trafficked persons. Smuggling, however, is defined as a transnational organised crime and no state is legally responsible for the protection of smuggled people unless they prove themselves exploited by smugglers or seek political refuge. Vulnerable populations who live in zones of conflict and poverty become targets of traffickers for exploitation. Young people are particularly vulnerable. North Korean women and women from refugee camps in Thailand are sold and resold to Chinese men as wives for sexual exploitation and domestic servitude [94]. Young Vietnamese and Cambodian women are arranged to marry South Korean, Japanese and Taiwanese men through international match-making agencies who work for profit [15]. Many of them are confined at home with their passports confiscated by their husbands. Uneducated and poor women and children from Burma and Indonesia work as domestic workers in Singapore, often not paid for several months or years because of the money they owe the employment agencies. They are also verbally and physically abused by their employers and denied their day-off from work [102]. Their movements are managed by profitoriented employment or marriage agencies.

While not denying irregular migration has to be solved in part through the prosecution of organised criminals and protection of victims, it is also a serious human problem that needs to be seen from the agent's perspective rather than treating them merely as criminals/victims and putting them in prisons/shelters. Poverty, lack of education and social stigma are identified as causes of trafficking in persons $[103,104]$. There are also other facilitating factors such as a symbiotic relationship between established (legalised) and underground (criminalised) sectors [105]. Without assistance from local security guards, police and other law enforcement officials, irregular migration would be impossible. Trafficked or smuggled migrants, because of their precarious legal status, are exposed to the great risk of exploitation, fear of deportation, physical and mental abuses and other human rights violations and discrimination.

Human rights are not likely to be a dominant foreign policy norm in the region. While only the Philippines and Indonesia are signatories to the International Convention of the Protection of Migrant Workers and Their Families, many East Asian countries have ratified the Convention against Transnational Organised Crime and its protocols on human trafficking and people smuggling [106]. A rare occasion states act together is the recent migrant smuggling incidents at sea [107]. It was security not human rights that made states respond to the crisis. International news cover the stories of stranded migrants at sea from Burma, Bangladesh and Sri Lanka which include all four irregular migrant groups I have described earlier in this paper. For example, they include Rohingya asylum seekers, many of whom are victims of human trafficking, and smuggled Bangladeshi migrants, who were to be undocumented migrant workers. The only two Muslim-majority countries, Malaysia and Indonesia, offered temporary shelters while the Thai, Singaporean and Australian governments turned them away [108]. International humanitarian or human rights laws do little to change state behaviour when they collide with notions of state sovereignty and territorial integrity. The urgency human security attaches to stress the magnitude of impact on human lives has a better chance to induce state action.

\section{Conclusion}

Irregular migration is a transnational human security problem that requires urgent extra-legal measures and goes beyond normal politics. International human rights norms have not been so effective as to induce state action to protect vulnerable migrants as well as hosting societies. For this reason, this article went in search for a more appropriate discourse that could capture the nature and impact of irregular migration on people. It found the 1994 UNDP's seven pillars of human security most comprehensive and also parallel to the norms of international human rights with changing state responsibilities. The multifaceted 1994 UNDP framework moves away from the narrow vs. broad concepts of human security and helps better understand the causes and consequences as well as the constitutive processes of irregular migration. Human security does not challenge state sovereignty as much as the language of human rights appears to, but gives states greater ownership over the causes and consequences of human insecurity and the opportunity to exercise moral authority in international relations. It therefore has a better chance to induce state action than the existing human rights regime, especially in the East Asian context. This comprehensive human security approach to irregular migration stands a better chance than the narrow criminal justice or individu- 
alistic human rights perspectives.

This article identifies the lack of personal, economic, food and environmental securities as the main drivers for irregular migration. Migrants move across their national borders to find a safer place for their survival, very often knowing that the way to do so is not authorised by the relevant migration regimes. They may reside in foreign countries without proper permits or with misused documents. The act of irregular migration, which is often forced by states or prompted by other profit-minded individuals or corrupt government officials, puts migrants under a new set of human insecurities not just for migrants themselves but also for hosting populations. Human insecurity caused by irregular migration is not a matter of migrants vs. citizens but a matter for all migrants and citizens. Human security provides a better normative framework to understand the motivations and human costs of irregular migration. Each trajectory of irregular migration has its own path dependency, learning curves, interactions with other stakeholders such as families, brokers, smugglers, employers or immigration officers, and feedback loops. Irregular migration is a complex system where a large number of heterogeneous agents are interacting with one another in a highly unpredictable manner.

The current study introduces a number of case studies from East Asia. However, the implications described above can be universal. While being careful about providing concrete policy recommendations, I would argue restrictive immigration rules and political measures do not solve the problem. In fact, they drive migration underground and deepen human insecurity for vulnerable migrants and their hosts. Open borders do not automatically solve the problem, either. Open borders are highly unlikely, especially in Northeast Asia where North Korea is testing its nuclear and missile programmes. Even in Southeast Asia, the idea of open borders for a common market can only be realised in the distant future because of the income gap between the most and least developed countries in the region. Open borders without access to justice and

\section{References and Notes}

[1] Bourdeau P. The Securitisation of Migration: A Study of Movement and Order. London, UK: Routledge; 2011.

[2] Newman E, Selm Jv. Refugees and Forced Displacement: International Security, Human Vulnerability and the State. New York, NY, USA: United Nations University Press; 2003.

[3] Ong A, Nonini D. In Ungrounded Empires: The Cultural Politics of Modern Chinese Transnationalism. London, UK: Routledge; 1997.

[4] Shain Y, Barth A. International Migration and Sending Countries. Basingstoke, UK: Palgrave; 2003.

[5] Castles S, Miller MJ. The Age of Migration: International Population Movements in the Modern World. information, socially responsible businesses and competent civil society will only drive already vulnerable migrants into increasingly exploitative environments. Providing basic food, healthcare and clean living conditions, regardless of a person's legal status, is not just moral and humanitarian for all irregular migrants but would also be beneficial for better human security of the hosting society, too.

With growing human insecurity not just caused by political violence but more and more by non-political factors such as poverty, underdevelopment, extremism, inequality, social exclusion, and environmental damage, scholars and practitioners in the field need to be able to understand the dynamic and complex nature of irregular migration. The process is not linear but highly unpredictable and constitutive. One such case is the growing number of environmental refugees who are not recognised by the 1951 Refugee Convention or by any international protection regimes. More people are displaced by natural disasters, which immediately place those affected under highly vulnerable food, shelter, health and environmental conditions. These conditions subsequently lead to more serious and detrimental long-term economic deprivation and lack of education. IDPs and refugees then become targets for traffickers. Otherwise, those with resources flee using migrant smugglers and become undocumented labour migrants elsewhere. As I reiterated in this article, the criteria of irregular migration is extremely blurred in real life. The media and policy-makers are better informed by clear terminologies and types of irregular migrants laid out in this article so that when we have a refugee crisis, we do not call it a migrant crisis, or we do not call what is human trafficking migrant smuggling any more.

\section{Acknowledgements}

The current study was funded by the Singapore Ministry of Education (Fund No.: C242/MSS14S004). The author would like to thank the anonymous reviewers for their helpful comments to improve the earlier version of the paper.
6] Castles S, Davidson A. Citizenship and Migration: Globalization and the Politics of Belonging. London, UK: Routledge; 2000.

[7] Geddes A. The Politics of Migration and Immigration in Europe. London, UK: Sage; 2003.

[8] Brettell CB, Hollifield JF. Migration Theory: Talking Across Disciplines. London, UK: Routledge; 2000.

[9] Joppke C. Selecting by Origin: Ethnic Migration in the Liberal State. Cambridge, MA, USA: Harvard University Press; 2005.

[10] Statham P, Geddes A. Elites and Organized Publics: Who Drives British Immigration Politics and in Which Direction? Western European Politics. 2006;29(2):245-266.

[11] Song J. 'Smuggled Refugees': The Social Construc- 
tion of North Korean Migration. International Migration. 2013;51(4):158-173.

[12] Derks A. Migrant Labour and the Politics of Immobilisation: Cambodian Fishermen in Thailand. Asian Journal of Social Science. 2010;38(6):915-932.

[13] Rahman M, Lian K. The Development of Migrant Entrepreneurship in Japan: Case of Bangladeshis. Journal of International Migration \& Integration. 2011;12(3):253.

[14] Balazo P. Truth \& Rights: Statelessness, Human Rights, and the Rohingya. Undercurrent. 2015;11(1):6-15.

[15] Lee H. Trafficking in women? Or multicultural family? The contextual difference of commodification of intimacy. Gender, Place \& Culture: A Journal Of Feminist Geography. 2014;21(10):1249.

[16] Fuertes A. Birds Inside a Cage: Metaphor For Karen Refugees. Social Alternatives. 2010;29(1):20-24.

[17] Kaplan R. The Coming Anarchy. The Atlantic. 1994;.

[18] Huntington S. The Hispanic Challenge. Foreign Policy. 28 October 2009; Available from: http://foreignpolicy.com/2009/10/28/the-hispanicchallenge/.

[19] Weiner M. The Global Migration Crisis: Challenge to States and to Human Rights. New York, NY, USA: Harper Collins College Publishers; 1995.

[20] Weiner M. Security, Stability and International Migration. International Security. 1992-1993;17(3):91126.

[21] Adamson F. International Migration in a Globalizing World: Assessing Impacts on National Security. In: Kirshner J, editor. Globalization and National Security. New York, NY, USA: Routledge; 2006. p. 35-73.

[22] Freeman GP. Winners and Losers: Politics and the Costs and Benefits of Migration. In: Messina AM, editor. Western European Immigration and Immigration Policy in the New Century. Westport, CT, USA: Praeger; 2002. p. 77-96.

[23] Freeman GP. Immigrant Incorporation in Western Democracies. International Migration Review. 2004;38(3):945-969.

[24] Freeman GP. National Models, Policy Types and the Politics of Immigration in Liberal Democracies. West European Politics. 2006;29(2):227-247.

[25] Guiraudon V, Joppke C. Controlling in New Migration World. London, UK: Routledge; 2001.

[26] Joppke C. Challenge to the Nation-State: Immigration in Western Europe and the United States. New York, NY, USA: Oxford University Press; 1998.

[27] Bigo D. The Emergence of a Consensus: Global Terrorism, Global Insecurity, and Global Security. In: d'Appollonia C, Reich S, editors. Immigration, Integration, and Security. America and Europe in Comparative Perspective. Pittsburgh, PA, USA: University of Pittsburgh Press; 2008. p. 67-94.

[28] Bigo D. Border Regimes, Police Cooperation and Security in an Enlarged European Union. In:
Zielonka J, editor. Europe unbound. Enlarging and Reshaping the Boundaries of the European Union. London, UK: Routledge; 2002. p. 213-239.

[29] Buzan B, Wæver O, Wilde Jd. Security: A New Framework for Analysis. Boulder, CO, USA: Lynne Rienner Publishers; 1998.

[30] Buzan B. Societal Security. In: Wæver O, Buzan $B$, Kelstrup M, Lemaitre P, editors. Identity, Migration and the New Security Agenda in Europe. London, UK: Pinter; 1993. p. 41-58.

[31] Wendt A. Social Theory of International Politics. Cambridge, UK: Cambridge University Press; 1999.

[32] Wæver O. Aberystwyth, Paris, Copenhagen: The Europeanness of New 'Schools' of Security Theory in an American Field. In: Tickner A, Blaney DL, editors. Thinking International Relations Differently. London, UK: Routledge; 2012. p. 48-71.

[33] Beare ME. Illegal Migration: Personal Tragedies, Social Problems, or National Security Threats? Transnational Organized Crime. 1997;3(4):11-41.

[34] Ibrahim M. The Securitization of Migration: A Racial Discourse. International Migration. 2005;43(5):163187.

[35] Bigo D, Tsoukala A. Terror, Insecurity and Liberty: IIliberal Practices of Liberal Regimes After 9/11. London, UK: Routledge; 2008.

[36] Curley MG, Siu-lun W. Security and Migration in Asia: The Dynamics of Securitisation. London. UK: Routledge; 2008.

[37] Hansen L. Gender, Nation, Rape: Bosnia and the Construction of Security. International Feminist Journal of Politics. 2000;3(1):55-75.

[38] Hansen L. The Little Mermaid's Silent Security Dilemma and the Absence of Gender in the Copenhagen School. Millennium. 2000;29(2):285-306.

[39] Enloe C. Bananas, Beaches and Bases. Berkeley, CA, USA: California University Press; 2001.

[40] Ticker A. Gender in International Relations. New York, NY, USA: Colombia University Press; 1992.

[41] Sjoberg L. Gender and International Relations: Feminist Perspectives. London, UK: Routledge; 2010.

[42] Poku N, Graham DT. Redefining Security: Population Movements and National Security. London, UK: Praeger; 1998.

[43] King G, Murray CTJ. Rethinking Human Security. Political Science Quarterly. 2001-2002;116(4):586610.

[44] Baldwin DA. The Concept of Security. Review of International Studies. 1997;(1):5-26.

[45] Matthews JT. Redefining Security. Foreign Affairs. 1989;68(2):162-177.

[46] Thomas C. In Search of Security: The Third World in International Relations. Boulder, CO: Lynne Rienner; 1987.

[47] Wiberg H. (Re-)conceptualizing security. Arms Control. 1992;13(3):487-492. 
[48] Krause K, Williams MC. From Strategy to Security: Foundations of Critical Security Studies. In: Krause K, Williams MC, editors. Critical Security Studies: Concepts and Cases. London, UK: UCL Press; 1997. p. 33-61.

[49] Booth K. Strategy and Emancipation. Review of International Studies. 1991;17(4):313-326.

[50] Jones RW. 'Message in a Bottle'? Theory and Praxis in Critical Security Studies. Contemporary Security Policy. 1995;16(3):299-319.

[51] Wæver O. Securitisation and Desecuritisation. In: Lipschutz RD, editor. On Security. New York: Columbia University Press; 1995. p. 46-86.

[52] Programme UND. New Dimensions of Human Security. New York, NY, USA: Oxford University Press; 1994.

[53] Chen LC. Human Security: Concepts and Approaches. In: Matsumae T, Chen LC, editors. Common Security in Asia: New Concepts of Human Security. Tokyo, Japan: Tokai University Press; 1995. p. 137-146.

[54] Florini AM, Simmons PJ. The New Security Thinking: A Review of the North American Literature. Carnegie Endowment for International Peace; 1998.

[55] Bellamy A, McDonald M. 'The Utility of Human Security': Which Humans? What Security? A Reply to Thomas and Tow. Security Dialogue. 2002;33(3):373-377.

[56] Kerr P, Tow WT, Hanson M. The Utility of Human Security Agenda for Policy Makers. Asia Journal of Political Science. 2003;11(2):89-114.

[57] Evans PM. Cooperative Security and its Discontents in Asia PAcific; The ASEAN Connection. American Asian Review. 2001;19(2):99.

[58] Lodgaard S. Human security: concept and operationalization. In: Expert Seminar on Human Rights and Peace, Palais Wilson, Geneva. vol. 8; 2000. p. $1-21$.

[59] Sen A. Development as Freedom. Oxford, UK: Oxford University Press; 1999.

[60] Sen A. Inequality Reexamined. Cambridge, MA, USA: Harvard University Press; 1992.

[61] Bernard Jr P. Canada and Human Security: From the Axworthy Doctrine to Middle Power Internationalism. American Review Of Canadian Studies. 2006;36(2):233-261.

[62] Haas E. Words Can Hurt You; or Who Said What to Whom about Regimes. In: Krasner S, editor. International Regimes. Ithaca, NY, USA: Cornell University Press; 1983. p. 23-59.

[63] Duffield M. Human Security: Development, Containment and Re-territorialisation. The Globalization of Security. 2005;(2):3-5.

[64] Park KA. Non-traditional security issues in North Korea. Honolulu: University of Hawaii Press, Center for Korean Studies; 2013.

[65] Kim M. Securitization of Human Rights: North Ko- rean Refugees in East Asia. New York, NY, USA: Praeger; 2012.

[66] Lee Sw. Human Security and North Korean 'Food Refugees'. South Asian Refugee Watch. 20012002;3-4:23-40.

[67] Mahbubani K. Can Asians Think? Times Editions; 3rd edition; 2004.

[68] Acharya A. Human Security: East versus West. International Journal. 2001;56(3):442-460.

[69] Ministry of Foreign Affairs of Japan. Diplomatic Bluebook 1999: Japan's Diplomacy with Leadership Toward a New Century. Urban Connections Inc.; 1999.

[70] Satoh Y. The evolution of Japanese security policy: Introduction. The Adelphi Papers. 1982;22(178):1.

[71] According to the Singaporean Ministry of Defence, 'Total Defence' is composed of five pillars: military, civil, economic, social and psychology defence, the last four of which can be translated into political, economic, community and personal securities among the seven human security criteria. Total Defence, however, stresses individual citizen" responsibility to take part in the defence and to play a role for any type of crises rather than the state's responsibility to protect. http://www.mindef.gov.sg/imindef/mindef_websites/ topics/totaldefence/about_us/what_is_td.html\# .VXzVRuuG_Zdlastaccessedon14June2015.

[72] Matsumae T, Chen L. Common Security in Asia: The New Concept of Human Security. Tokyo, Japan: Tokai University Press; 1995.

[73] Tow WT, Thakur R, Hyun IT. Asia's Emerging Regional Order: Reconciling Traditional and Human Security. Tokyo, Japan: United Nations University Press; 2000.

[74] Thiparat P. The Quest for Human Security: The Next Phase of ASEAN? Bangkok: Institute of Security and International Studies; 2001.

[75] Alagappa M. Comprehensive security: interpretations in ASEAN countries. In: et al RAS, editor. Asian Security Issues: Regional and Global. Berkeley, CA, USA: University of California, Institute of East Asian Studies; 1988.

[76] Bajpai K. The Idea of Human Security. International Studies. 2003;40:195-228.

[77] Pitsuwan S. Realizing Human Security in Asia; 2010.

[78] Internal Peace and Security Plan: "Bayanihan". Armed Forces of the Philippines; 2010.

[79] Guild E, van Selm J. International Migration and Security: Opportunities and Challenges. London, UK: Routledge; 2005.

[80] Newland K. Migration as a Factor in Development and Poverty Reduction. Migration Information Source. 1 June 2003; Available from: http://www.migrationpolicy.org/article/migrationfactor-development-and-poverty-reduction.

[81] A special issue at International Migration 2002;40(5) 
librello 4 s

\begin{abstract}
About Librello
Librello is a publishing house established in Basel, Switzerland. All content published by Librello is open access, available upon publication for any reader. We strongly believe that open access improves the exchange of scientific knowledge, and consists in a more ethic way of publishing the results of research supported by public funds.

Librello is an innovative publishing enterprise. Our novel model works on a membership basis to decouple the payment from the publication. On one side, we can afford a stringent peer-review with no economic pressure, and the authors also profit from our business model by being able to submit multiple manuscripts by a single annual fee.
\end{abstract}

Librello Publishing House

4000 Basel

Switzerland

http://librelloph.com 